Katia Ghosn
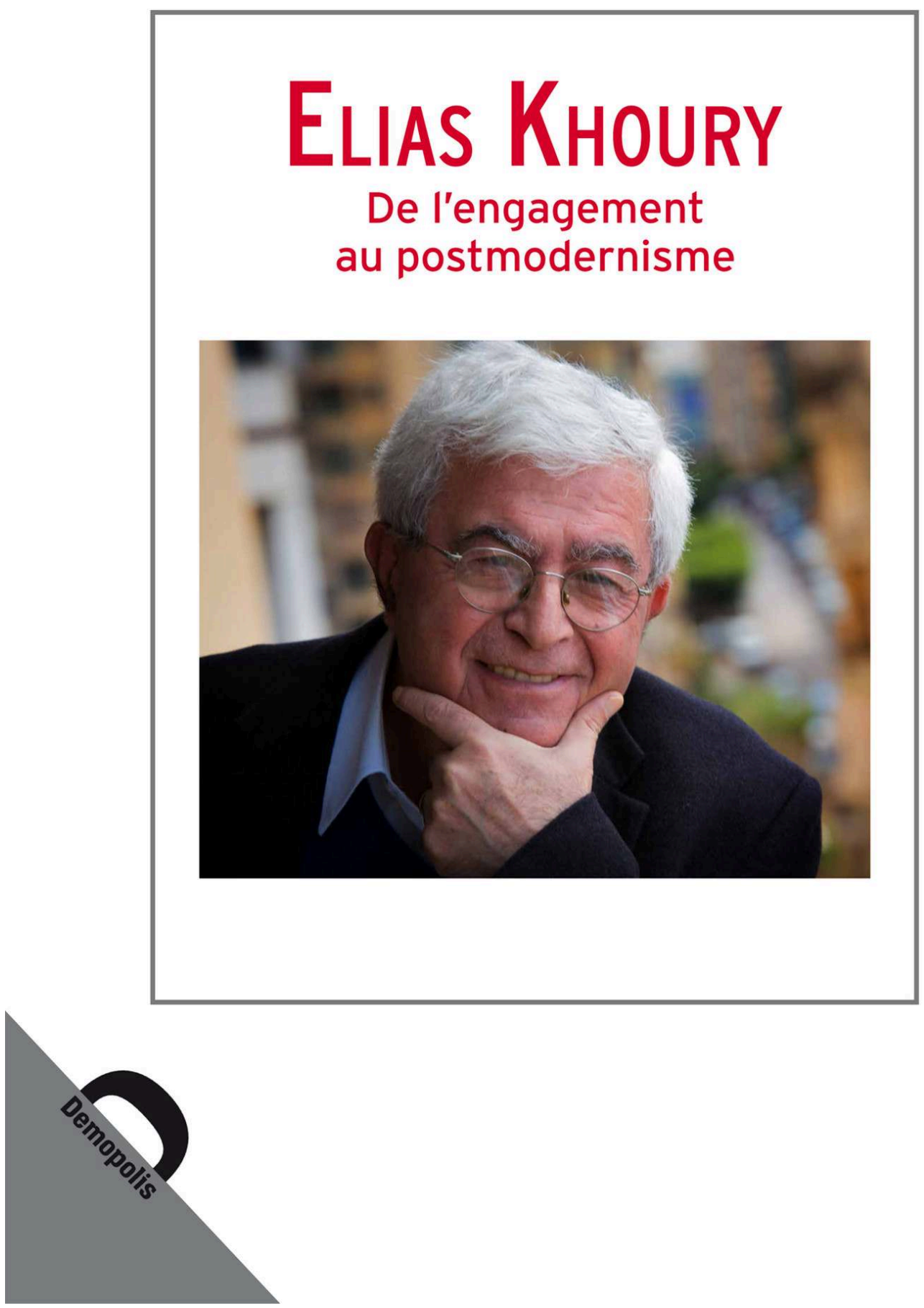


\section{Elias Khoury}

De l'engagement au postmodernisme

\section{Katia Ghosn}

DOI : 10.4000/books. demopolis. 1437

Éditeur : Demopolis

Année d'édition : 2018

Date de mise en ligne : 18 janvier 2019

Collection : Quaero

ISBN électronique : 9782354571573

\section{Doentitition}

http://books.openedition.org

\section{Édition imprimée}

ISBN : 9782354571351

Nombre de pages : 208

\section{Référence électronique}

GHOSN, Katia. Elias Khoury: De l'engagement au postmodernisme. Nouvelle édition [en ligne]. Paris : Demopolis, 2018 (généré le 02 octobre 2020). Disponible sur Internet : <http://books.openedition.org/ demopolis/1437>. ISBN : 9782354571573. DOI : https://doi.org/10.4000/books.demopolis. 1437.

\section{(c) Demopolis, 2018}

Conditions d'utilisation :

http://www.openedition.org/6540 




\section{ELIAS KHOURY}

De l'engagement au postmodernisme 


\section{«QUAERO »}

Collection dirigée par Jean-Christophe Tamisier

Voir aussi, sous la direction du même auteur:

Rachid El-Daïf. Le roman arabe dans la tourmente de la modernisation

Illustration de couverture:

Portrait d'Elias Khoury @ Talal Khoury

(C) Éditions Demopolis, 2018

67 , rue Saint-Jacques

75005 Paris

www.demopolis.fr

ISBN : 978-2-35457-135-1 


\section{KATIA GHOSN}

\section{ELIAS KHOURY}

De l'engagement au postmodernisme

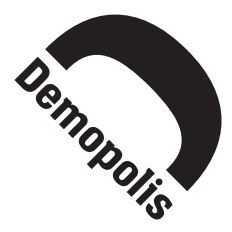



Mes remerciements pour cet ouvrage vont d'abord aux éditeurs, et plus particulièrement à Jean-Christophe Tamisier, directeur de la collection de recherche "Quaero", à qui je suis redevable non seulement pour le travail d'édition, mais aussi pour sa lecture attentive et ses commentaires judicieux.

Mes remerciements vont également à Elias Khoury pour sa disponibilité, et pour le temps accordé à nos entretiens dont le présent ouvrage a largement bénéficié.

Cet ouvrage a été publié avec le soutien de l'université Paris 8 et du CERMOM (INALCO); je les remercie pour leur contribution.

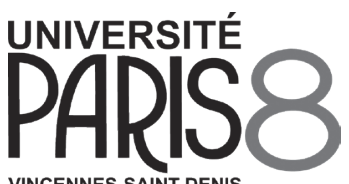

VINCENNES-SAINT-DENIS i na l c o

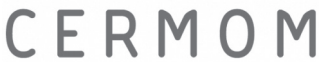

Centre de Recherches Moyen-orient Méditerranée 



\section{Translittération}

\begin{tabular}{|c|c|c|c|c|c|}
\hline$s$ & , & ب & $\mathrm{b}$ & ت & $\mathrm{t}$ \\
\hline ث & th & ج & $\mathrm{j}$ & $\tau$ & ḥ \\
\hline$\dot{\tau}$ & $\mathrm{kh}$ & د & $\mathrm{d}$ & $\dot{j}$ & $\mathrm{dh}$ \\
\hline ر & $\mathrm{r}$ & j & $\mathrm{z}$ & س & $\mathrm{s}$ \\
\hline ش & $\operatorname{sh}$ & ص & ș & ض & d \\
\hline$b$ & $\mathrm{t}$ & ظ & $\mathrm{Z}$ & $\varepsilon$ & ، \\
\hline$\dot{\varepsilon}$ & gh & ف & $\mathrm{f}$ & ق & q \\
\hline 5) & $\mathrm{k}$ & $J$ & $l$ & r & $\mathrm{m}$ \\
\hline ن ن & $\mathrm{n}$ & 。 & $\mathrm{h}$ & 9 & $\mathrm{w}$ \\
\hline ي & $\mathrm{y}$ & & & & \\
\hline
\end{tabular}

Voyelles longues

$\begin{array}{lll}\bar{a} & \bar{u} & \overline{1}\end{array}$

Diphtongues

و $a w$

أي ay

ال al- (même devant les antéro-palatales)

shadda pour la double consonne 
Sur la couverture du présent ouvrage, le nom de l'auteur, « Elias Khoury ", figure tel qu'il apparaît en tête de ses romans traduits en français. Mais au sein du texte, il est translittéré (comme l'ensemble des noms cités) par souci d'exactitude selon le système ci-dessus; on trouvera donc "Ilyās Khūrī ". À une réserve près : lorsqu'il s'agit de citations le mentionnant, nous avons gardé la transcription retenue par les auteurs concernés.

S'agissant des citations de romans de Khūrī, nous nous sommes référée aux traductions en français de ces derniers. Pour les romans non traduits en français, la traduction est nôtre; la page mentionnée fait référence à l'édition en langue arabe.

\section{Traduction des titres d'œuvres}

Nous avons pris le parti de présenter, tout au long de cet ouvrage, en italiques les titres des traductions françaises publiées, et en romain entre guillemets les traductions purement indicatives de ces titres. 


\section{Introduction \\ Ilyās Khūrì: une vie, une ouvre}

Figure majeure de la littérature arabe contemporaine, le Libanais Ilyās Khūrī est également critique littéraire, dramaturge et chroniqueur. Il est un intellectuel engagé qui n'a eu de cesse de remettre en question les problèmes de sa société et de témoigner sur des épisodes catastrophiques de l'histoire de son pays. Il n'en reste pas moins qu'il se situe résolument du côté de la littérature, car « seuls l'amour et la littérature donnent un sens au non-sens de la vie » (Awlād al-ghetto, p. 29).

Auteur d'une douzaine de romans, de nouvelles, d'essais critiques et d'une pièce de théâtre (voir la bibliographie en fin de volume), son œuvre est entièrement rédigée en arabe. Ses romans sont traduits dans une quinzaine de langues.

La vie et l'œuvre d'Ilyās Khūrī sont dans un rapport relationnel de détermination réciproque. Elles condensent toute une période particulièrement tourmentée de l'histoire du Liban contemporain, tout en inscrivant leur présence dans le monde qu'elles cherchent à représenter. Non seulement Khūrī participe activement à la vie sociale et politique de son pays, mais il engage, dans son œuvre, la totalité de sa personne. Entre la personne de l'écrivain et son œuvre s’instaure un va-et-vient à peine camouflé. Dès lors, l'histoire-mémoire déployée dans l'œuvre pourrait se lire comme une histoire de soi. 
L'accord d'une œuvre et d'une vie est une des formes qui caractérise l'engagement. D'ailleurs, Khūrī lui-même se plaît à lier sa naissance, en 1948, à la date de la guerre israélo-arabe qui se conclut la même année par la proclamation de l'État d'Israël et l'expulsion de centaines de milliers de Palestiniens de leurs terres, voyant dans cette coïncidence le signe d'un destin et le point de départ naturel de son futur engagement. Au delà de ce clin d'œil anecdotique - toutes les personnes nées en 1948 ne se sont tout de même pas engagées pour la cause palestinienne ! essayons de cerner de plus près les principaux enjeux politiques, religieux, sociétaux, auxquels Khūrī a tenté de répondre par l'action et par sa création littéraire.

Ilyās Khūrī est né à Achrafieh, un quartier chrétien de l'est de Beyrouth, dans une famille petite-bourgeoise. Il y réside jusqu'en 1975, date à laquelle la guerre civile divise la capitale libanaise en deux secteurs antagonistes séparés par une ligne de démarcation. Ses positions de gauche le contraignent à quitter BeyrouthEst, marqué politiquement à droite, et à se réfugier à l'ouest de la ville, comme ce fut le cas pour bien d'autres intellectuels libanais.

Le titre de son roman al-Jabal al-șaghīr ${ }^{1}$ (La Petite Montagne) fait référence au nom par lequel la population locale désignait le quartier d'Achrafieh. Les premières lignes du roman, nostalgiques, invoquent le souvenir de ce quartier dont les traits ont été altérés par le passage du temps :

Une seule colline, ou plusieurs, je ne me souviens plus. Plus personne ne s'en souvient. Une colline sur le côté Est de Beyrouth que nous appelions une montagne car les montagnes étaient loin. Nous avions peur pour la montagne avec sa flore, qui avançait vers le bord de Beyrouth et s'y affalait. Les

1. Ilyās Khūrī, al-Jabal al-șaghīr, Beyrouth, Dār al-ādāb, 1977. Traduction par Saadia Zaim, La Petite Montagne, Paris, Arléa, 1987. 
figuiers de Barbarie qui égratignaient nos pieds meurent, le palmier fléchit et la montagne s'approche de ses limites.

D'ailleurs, soucieux de sauvegarder l'histoire physique de Beyrouth, Khūrī s'oppose, avec son ami l'architecte Jad Tabet, au projet, dit "Solidere ", de réaménagement et de construction du Grand-Beyrouth, décidé par le chef du gouvernement Rafĩq Ḥarīīī, assassiné en 2005.

Nous pouvons lire dans l'Histoire de Beyrouth ${ }^{2}$ de l'écrivain et journaliste libanais Samīr Qașīr une description saisissante de la situation urbaine anarchique qui a détruit la mémoire visuelle de la ville.

Qașīr a été assassiné en 2005 en raison de son engagement politique contre la mainmise syrienne sur le Liban. Il était d'ailleurs un ami très proche de Khūrī. Ils ont collaboré dans les colonnes du quotidien al-Nahār ; ensemble, avec le politologue Ziād Mājid, ils participent au Mouvement de la gauche démocratique, qui fit partie de l'alliance du " 14 mars », une coalition anti-syrienne. L'aventure prit fin avec le déclenchement de la guerre israélo-libanaise de 2006, en raison de divergences apparues alors au sein du mouvement. La guerre menée par le Hezbollah contre l'armée israélienne était, à ce moment de l'histoire, défendable aux yeux de Khūrī, une position loin d'être partagée.

C'est à Achrafieh que la conscience politique de Khūrī se

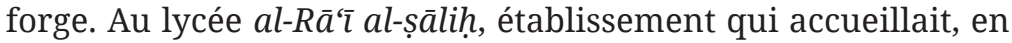
plus des lycéens du quartier, de jeunes musulmans et des Palestiniens boursiers de l'UNRWA (Office de secours et de travaux des Nations unies pour les réfugiés de Palestine dans le Moyen-Orient), il découvre, vers l'âge de 17 ans, la cause palestinienne et ses soutiens.

2. Samir Kassir, Histoire de Beyrouth, Paris, Perrin, 2012. 
C'est aussi à Achrafieh, devant l'église Notre-Dame, à la sortie de la messe, qu'il lit son premier tract, distribué par un groupe de jeunes militants du parti communiste ; c'était en 1957 ou 1958, se souvient-il ${ }^{3}$. Il pourrait paraître surprenant de voir les communistes d'alors diffuser leur idéologie aux fidèles sur le parvis d'une église orthodoxe. Le caractère curieux ou antinomique de leur action s'atténue lorsqu'on connaît les attachements de la communauté orthodoxe (dont Khūrī est issu). Rā'ihat al-Ṣābūn ${ }^{4}$ ( L'odeur du savon") raconte ainsi l'histoire rocambolesque de la messe de requiem célébrée pour le repos de l'âme de Staline. À l'annonce de sa mort, les Achrafiotes se rendent à l'église Notre-Dame en brandissant des portraits du dirigeant soviétique, appellent le prêtre et lui commandent cette cérémonie. Pour eux, Staline c'était la Russie, et la Russie c'était l'orthodoxie ; ils oubliaient que la Russie soviétique était officiellement athée et avait persécuté l'Église orthodoxe. Les orthodoxes du Liban étaient restés attachés à la Russie par un lien serré, imposé au XIX ${ }^{\mathrm{e}}$ siècle par les tsars à un Empire ottoman affaibli et largement contraint de céder aux exigences des puissances. La Russie protégea ainsi les orthodoxes comme la France défendait les maronites (catholiques orientaux reconnus par le Saint-Siège) - élément de rivalité qui fut l'une des causes de la guerre de Crimée. Durant toute cette période, les écoles russes se multiplièrent au Liban, à Damas et en Palestine. À Achrafieh, les établissements de Zahrat al-Iḥsān et Kulliyat al-Bichāra (le collège orthodoxe de l'Annonciation) se développèrent, de même que l'école Mar Ilyās Bțīna (Saint Élie Btina) à Beyrouth. La Russie fonda, également dans la localité d’Achrafieh, un grand hôpital,

3. Les informations concernant Ilyās Khūrī sont issues d'entretiens personnels avec l'auteur.

4. Ilyās Khūrī, Rā'iḥat al-Ṣābūn, Beyrouth, Dār al-ādāb, 2002. 
Mustashfā al-rūm ("l'hôpital des Roum ${ }^{5}$ »), pour concurrencer la faculté française dirigée par les Jésuites. Khūrī raconte, amusé, que sur la table de la salle à manger d'une parente à lui, se dressaient, l'un à côté de l'autre, le portrait de Nicolas II et celui de Staline.

Ces liens expliquent l'adhésion de la plupart des villages orthodoxes du Liban, dans les années 1950 à 1970, soit au parti communiste, soit au parti social-nationaliste syrien fondé par Antūn S‘āda, un chrétien orthodoxe. Une minorité adhéra au Baath et au nationalisme arabe. Il n'est pas anodin que l'un des fondateurs du mouvement politique Baath, qui a tenté de combiner le socialisme et le nationalisme arabe, Mishāl 'Aflaq, ait lui aussi été un chrétien orthodoxe. Ajoutons que les orthodoxes ne se sont pas sentis concernés par la guerre confessionnelle au Liban, État héritier du Grand Liban créé par la France au lendemain de la Première Guerre mondiale au sein de la Syrie sous mandat, au seul bénéfice selon eux des chrétiens maronites; les orthodoxes libanais sont bien plus en solidarité avec leurs coreligionnaires de Syrie, de Jordanie et de Palestine.

Khūrī a été influencé par cette histoire collective, et partage avec la communauté orthodoxe l'ouverture à la culture arabomusulmane et à l'idéologie panarabe. Dans le même ordre d'idées, il voue une profonde admiration à Georges Khudr, fondateur autrefois du mouvement de la Jeunesse orthodoxe (Harakat al-shabība al-urthudhuksiyya) à laquelle le jeune Khūrī avait adhéré, devenu par la suite métropolite (évêque grec-orthodoxe) du Mont-Liban. Khudr se situe lui aussi dans la mouvance

5. Rūm, désigne, au Liban, les deux communautés religieuses chrétiennes: les " rūm orthodoxes », les grecs-orthodoxes et les « rūm catholiques », les grecscatholiques. Les Arabes appelaient ainsi les peuples héritiers de l'empire romain, d'Occident ou d'Orient (Byzance). Au Liban, Les catholiques (tout court) sont les maronites. 
Elias Khoury - De l'engagement au postmodernisme

nationale arabe, comme en témoigne son ouvrage Filasțin al-musta'āda («La Palestine reconquise »). Khūrī lui a consacré une étude, publiée dans al-Dhākira al-mafqūda ( "La mémoire perdue »), recueil qui rassemble plusieurs analyses critiques rédigées entre 1972 et 1981 . Ces études mettent en lumière les problématiques auxquelles est confrontée la littérature arabe et les raisons de l'échec du projet moderniste de la renaissance arabe.

Aujourd'hui Khūrī se dit athée (la lecture de Camus l'y a amené), mais cet athéisme ne l'a pas conduit à rompre avec les rituels liturgiques. Le Vendredi saint et Pâques sont des fêtes qu'il continue à célébrer en famille. Quant à la Bible, elle aura été pour lui non seulement un texte religieux, mais sa porte d'entrée dans la littérature, comme il aime à le dire. Malgré son instrumentalisation politique, la religion reste à ses yeux un besoin fondamental de l'être humain. La révolution française et la révolution bolchévique, les deux tentatives majeures pour en finir avec la religion, ont échoué du fait que, selon lui, on ne peut étouffer le besoin humain d'une autorité spirituelle. Cette tension entre un existentialisme athée, d'une part, et la rémanence d'une vision biblique du monde, d'autre part, se répercute sur ses romans, comme nous le verrons.

Le religieux comporte, chez lui, une connotation politique et vice versa. Prenons cet exemple tiré d'al-Jabal al-șaghīr (La Petite Montagne) :

L'église est un navire; Jaber est dans son navire et nous, nous sommes dans le vaste navire. À l'extérieur, les tirs devenaient plus forts et le mouvement avançait.

[...] Nous nous sommes arrêtés devant la grande fosse et avons déposé le navire dans le sable et la terre.

- Le navire s'est noyé.

6. Ilyās Khūrī, al-Dhākira al-mafqūda, Beyrouth, Dār al-ādāb, 1982. 
- Non, il ne s’est pas noyé. (p. 59)

$[\ldots]$

Pourquoi le cercueil d'un combattant est-il ici comparé à un navire ? Le navire est un symbole religieux : il renvoie à l'Église, en référence à l'histoire de Noé, et préfigure le salut des croyants. La lutte politique est propre à revêtir une dimension sacrée. Ici intervient le Christ, figure à la fois religieuse, politique et résolument humaine. Nous reviendrons sur cette thématique porteuse de sens.

Khūrī avait vécu les années 1965-1967, période de grandes tensions politiques, dans la peau d'un étudiant en histoire à l'Université libanaise (Beyrouth) ; celle-ci avait connu de fortes mobilisations étudiantes ; manifestations et grèves s'étaient succédées, menées par différents mouvements et organisations de gauche. Cette période coïncide également avec les débuts de l'action des fedayins (fidā’iyyūn, combattants de la guérilla palestinienne), membres du Fatah. En 1966, l'armée libanaise assassine le premier fedayin, Jalāl Ka'wash, au camp de 'Ayn al-Ḥilwa à Saïda ; cette histoire est racontée dans al-Wujūh al-bayḍa $\bar{a}^{77}$ (Un Parfum de paradis). La manifestation contre l'armée, à laquelle Khūrī prend part, dégénère et se termine par un bain de sang. Les Palestiniens entrent au Liban en 1968.

Khūrī a également été, comme tant d'autres, influencé par le grand projet politique et social porté par le nassérisme ; un projet qui suscita, à l'époque, de l'espoir bien au-delà de l’Égypte. Élu en 1954, Nasser jouissait d'une grande aura ; il faisait rempart face à l'État d'Israël qui venait de naître et incarnait la lutte contre le colonialisme britannique et l'impérialisme occidental; sa résistance à la guerre menée conjointement par Israël, la

7. Ilyās Khūrī, al-Wujūh al-bayḍā', Beyrouth, Dār Ibn Rushd, 1981. Dār al-ādāb, 1983. Trad. par Luc Barbulesco, Un Parfum de paradis, Paris, Arléa, 2007. 
France et la Grande-Bretagne suite à la nationalisation du canal de Suez en 1956, l'instauration de la République arabe unie fusion de l'Égypte et de la Syrie qui dura de 1958 à 1961 -, une expérience considérée comme le premier embryon de l'union arabe, et enfin son soutien à la guerre d'Algérie firent de lui, dans une optique laïque, moderniste et transformatrice, le Raïs incontesté du monde arabe, au moins jusqu’à 1967, année de la cuisante défaite des Arabes face à Israël.

Mais le combat politique à proprement parler de Khūrī commence après cette défaite, quand il décide de soutenir la résistance palestinienne et intègre le Fatah, ou Mouvement de libération de la Palestine, organisation politique et militaire fondée par Yasser Arafat en 1959.

Parallèlement à son engagement politique, Khūrī effectue à Paris, de 1971 à 1973, des études de sociologie à l'École des hautes études en sciences sociales (EHESS) et soutient, sous la direction d'Alain Touraine, un mémoire sur la guerre confessionnelle libanaise de 1840-1860.

En 1971, à Beyrouth, il rencontre le poète palestinien Maḥmūd Darwīsh. En 1973, il intègre le Centre des études palestiniennes et, en 1975, accède à la fonction de secrétaire de rédaction du mensuel Shu'ūn Filasținiyya ("Affaires palestiniennes ») dirigé par Darwīsh.

Un affaiblissement de la dimension nationaliste de sa pensée marque le début de sa période marxiste. Parmi ses lectures figurent pêle-mêle le Manifeste du parti communiste, des essais de Lénine dont Que faire ? et L'État et la Révolution, des souvenirs de campagne de Che Guevara, des textes de critique trotskyste de l'Union soviétique ainsi que les écrits de Mao Zedong sur la révolution culturelle. Sans oublier l'œuvre d'Althusser.

Quelle que soit son attirance alors pour le marxisme-léninisme, il n'adhère pas au Parti communiste libanais et reste 
affilié au Fatah. Outre un rejet profond de la dimension totalitaire de l'Union soviétique, notamment sous Staline, il ne peut faire sien l'alignement servile du PCL sur la politique de Moscou ; celui-ci ne laisse aucune marge d'exercice à une politique nationale indépendante. Or Khūrī vise toujours, pour sa part, l'unité arabe et la libération de la Palestine.

Ce n'est qu'en 1975, avec l'éclatement de la guerre civile libanaise, que l'Organisation de libération de la Palestine (OLP) décide de faire front commun avec le Mouvement national libanais (MNL), une coalition dirigée par le leader druze Kamāl Jumblāt qui regroupait principalement le Parti communiste libanais (PCL), le Parti socialiste progressiste de Jumblāt (PSP), le Parti social nationaliste syrien (PSNS) et l'Organisation d'action communiste au Liban (OACL), située à la jonction du nationalisme arabe et du marxisme. Le but du MNL était de défendre la résistance palestinienne, menacée par les phalanges chrétiennes, les Katā'ib, et d'éviter la répétition du massacre du "Septembre noir » (1970) en Jordanie. Jumblāt voulait mener un projet révolutionnaire au Liban, marqué pour commencer par l'abolition du confessionnalisme politique, le changement de la loi électorale et la fin de l'hégémonie maronite sur l'État. D’où sa décision, en 1976, de faire tomber le gouvernement et d'occuper les territoires chrétiens.

Le MNL, tout comme le reste des partis politiques libanais, fut pris dans les filets du confessionnalisme. Jumblāṭ perdit son pari et fut assassiné en 1977.

Le 6 juin 1982, l'opération Paix pour la Galilée est menée par Ariel Sharon, alors ministre israélien de la défense, dans le but de neutraliser l'OLP, installée à Beyrouth-Ouest. Les 15000 combattants palestiniens et leurs dirigeants se replient à Tunis. Bashīr Jmayyil, élu président de la république le 23 août 1982, collabore avec l'occupation israélienne. Il est assassiné trois 
semaines après son élection, le 14 septembre. Du 16 au 17 septembre 1982, les phalangistes chrétiens, avec l'aval de Tsahal, massacrent, aux camps de Șabrā et de Shātīlā, des centaines de réfugiés palestiniens. La commission d'enquête Kahana établira la responsabilité indirecte de Sharon, temporairement écarté de la vie politique.

Ces événements sanglants ainsi que les décennies noires qui les ont engendrés seront relatés dans Bāb al-shams ${ }^{8}$ (La Porte du soleil), un ouvrage considéré comme le récit littéraire par excellence de l'histoire contemporaine de la Palestine. La mission confiée à la littérature s’y révèle dans toute son acuité : la littérature formule certes des problèmes et apporte des outils d'intelligibilité, mais elle est essentiellement " un refuge contre la mort » et un rempart contre la tyrannie de l'histoire à sens unique. En rusant avec le temps, elle fait de telle sorte qu'il ne nous tue pas. Elle agence les souvenirs afin de mieux les oublier. Elle demeure indéniablement une fascinante leçon de liberté : «Tu mourras, mais tu seras libre, même de ta propre histoire ", comme le dit bien Khalīl à Yūnus (Bāb, p. 390).

Les opérations de la résistance forcent l'armée israélienne à se retirer provisoirement de Beyrouth le 27 septembre 1983, puis définitivement en 1985. À cette époque, Khūrī - tout en restant au Fatah - se rapproche du PCL et participe au comité de rédaction de la revue al-Ṭarì ( "La voie »), sans pour autant intégrer le parti.

Ce rapprochement avec le PCL fut de coute durée. Il prend fin à l'issue de «la guerre de la montagne " qui opposa, de 1982 à 1984, le chef druze du Parti socialiste progressiste Walīd Jumblāṭ aux miliciens chrétiens des Forces libanaises. Le PCL

8. Ilyās Khūrī, Bāb al-shams, Beyrouth, Dār al-ādāb, 1998. Traduit par Rania Samara, La Porte du soleil, Arles, Actes Sud, 2003. 
s’allie avec Jumblāț. S’ensuit une série de massacres qui aboutit à la destruction d'une trentaine de villages chrétiens et à l'exode de milliers d'habitants. Des centaines de militants communistes, quand bien même alliés à Jumblāț, périssent sous les coup des miliciens du parti du chef druze, parce qu'ils étaient chrétiens d'origine.

Rien de concluant ni d'authentique donc dans l'expérience de gauche telle qu'on pouvait la vivre au sein du PCL ou en lien avec lui. Mais ce n'était pas mieux, voire plutôt pire, au sein du Fatah. La gauche de ce dernier était divisée en deux : un mouvement maoïste en concurrençait un autre, proche de l'Union soviétique. Khūrī se retrouva dans le camp maoïste. Cependant, depuis 1979, l'influence de la révolution iranienne de Khomeiny était montée en puissance. Les mouvements islamistes s’infiltrèrent au sein de la gauche du Fatah. Le camp maoïste traversa une crise idéologique profonde. Des sections entières se rallièrent à la révolution islamique, provoquant la désintégration de l'emprise gauchiste et, entre autres, l'éloignement de Khūrī.

Ce dernier continua toutefois à collaborer à la revue mensuelle Shu'ūn Filasțīniyya ("Affaires palestiniennes », 1974-1979) et à soutenir la cause palestinienne.

De 1979 à 1981, il dirige la page culturelle du quotidien al-Safir. Ses articles paraissent dans un ouvrage intitulé Zaman al-'iḥtilä $l^{9}$ ("L'époque de l'occupation »), aujourd'hui épuisé. De 1991 à 2008, il prend la direction de la page culturelle du quotidien al-Nahār. Le rédacteur en chef, Jibrān Twaynī, est assassiné en 2005.

Khūrī reconnaît les erreurs de son camp. Nous nous sommes comportés comme les autres, nous avons kidnappé et assassiné, assène-t-il. Al-wujūh al-bayḍ̂à' témoigne du cycle infernal des

9. Ilyās Khūrī, Zaman al-'iḥtilāl, Beyrouth, Mu'assasat al-'ādāb al-‘arabiyya, 1985. 
Elias Khoury - De l'engagement au postmodernisme

assassinats. L’armée du Fatah capture un combattant du camp adverse et le crible de balles:

Pourquoi l'ont-ils abattu? Je l'ai supplié de ne pas faire. J'étais sérieux cette fois, mais ils l'ont tué. Je ne leur ai pas dit son nom et ne le dirai à personne. Moi seul lui ai parlé et n’ai pas trouvé de raison pour le tuer.

- Pourquoi, pourquoi, lui ai-je demandé. Je lui ai promis qu'on ne le tuerait pas.

- T’as promis! Non, il faut le tuer.

- Mais pourquoi? C'est un jeune, il n'a rien à voir... il est prisonnier.

- Tu crois que si on t’avait capturé, tu serais resté vivant?

- Mais nous...

- Tais-toi. Tout le monde est impliqué [...] c'est une guerre; nous ne jouons pas, eux non plus. Ils nous tuent. Nous les tuons. (p. 234)

Bāb al-shams (La Porte du soleil) porte un jugement sévère sur les institutions étatiques palestiniennes coupables de corruption, de bureaucratisation et de dégradation de l'image du fedayin :

Les fedayins ne ressemblaient plus aux fedayins et, là, il ne s'agit pas de corruption, de pots-de-vin ou des discordes d'avant l'invasion de 1982. Je savais que ça existait et que nous en avions honte. Pourtant il y avait alors quelque chose qui nous permettait de tolérer la situation, disons qu'il y avait d'abord notre cause primordiale qui prévalait sur les pourris et les salauds. (p. 671)

" J'aurais dû partir. Mais je suis resté et j’ai témoigné ", ajoute Khūrī. Témoigner est une caractéristique importante de son œuvre, sur laquelle nous aurons à revenir.

En 2005, Khūrī prend fait et cause pour l'« intifada de l'Indépendance ", un vaste soulèvement antisyrien qui prit corps suite à l'assassinat du Premier ministre Rafīq Harīrī. Rapidement, ce 
mouvement qui se voulait démocratique se retrouve piégé par le système politique confessionnel, et instrumentalisé par les puissances régionales et internationales.

Depuis le début des soulèvements en Syrie en mars 2011, Khūrī se mobilise contre le régime dictatorial de Bashār alAssad. Il continue, également, à militer auprès de mouvements de la société civile qui peinent à créer des poches de résistance face à une classe politique corrompue et vendue aux puissances étrangères. En plus de sa participation aux mobilisations contre le scandale des déchets et le disfonctionnement de l’État impuissant à trouver des solutions pour le ramassage des ordures, il a soutenu, en 2016, lors de la campagne pour les élections municipales libanaises, la liste dissidente "Bayrūt Madīnatī » ("Beyrouth ma ville») qui brigue, contre celle des caciques du régime, les 24 sièges du conseil municipal de la capitale, mobilisation vouée d'avance à l'échec dans un système politique sclérosé. Sur sa page Facebook, il dénonce aussi bien le racisme et la violence dont sont victimes les employées de maison étrangères que les réseaux mafieux et esclavagistes de prostitution.

Mais sa grande blessure reste l'effondrement de l'Organisation de libération de la Palestine. Avec le délitement de celle-ci, l'espoir, selon lui, de changer radicalement la situation s'est effondré. «Une des raisons pour laquelle je n’ai pas intégré un parti politique libanais serait probablement mes études en histoire et ma thèse de licence consacrée à la guerre civile libanaise de 1860. J'avais compris que rien n'échappe à la structure confessionnelle. Le Liban est condamné à la guerre perpétuelle ", dit-il.

Le portrait que lui consacre Christophe Boltanski ${ }^{10}$ dans les colonnes de Libération est très juste: "Elias Khoury n'a cessé d'ausculter les blessures à peine enfouies de son pays, de lutter

10. Christophe Boltanski, Libération, 9 septembre 2006. 
contre l'amnésie imposée par une classe politique qui espère ainsi faire oublier ses propres crimes, de procéder à un travail de mémoire jamais effectué, d'examiner le basculement de ses semblables dans la violence. Il est celui qui écrit la page que les autres veulent tourner, un empêcheur d'enterrer en rond, de pacifier en silence."

« Notre objectif n'était pas seulement de libérer la terre, nous voulions libérer l'homme aussi " (Bāb al-shams, p. 72). Or, les engagements politiques de Khūrī se sont illustrés par des défaites. Ces défaites sont moins des revers personnels que la conséquence des tares que la culture et les systèmes politiques arabes ne parviennent pas à dépasser.

Est-ce une raison pour renoncer à tout engagement? Le roman de Khūrī n'invite-il pas à poursuivre la lutte sur de nouvelles bases, à commencer par une autocritique radicale, condition première et sine qua non d'un changement possible ? La narration ne s'attribue-t-elle pas une fonction d'éveil et de catharsis? Qui est, justement, le narrateur de ses romans, si proche de l'écrivain? Que nous raconte-il, et comment ? Quels moyens narratifs met-il en œuvre pour déconstruire une modernité dont les prémisses se sont soldées par l'échec?

Pour notre analyse, nous nous sommes limitée au corpus romanesque de l'auteur, et plus particulièrement aux romans suivants : al-Wujūh al-bayḍā' (Un parfum de paradis), Mamlakat al-ghurabā' ("Le royaume des étrangers »), Majma‘ al-asrār (Le Coffre des secrets), Bāb al-shams (La Porte du soleil), Yālū (Yalo), Ka'annahā nā'ima (Comme si elle dormait).

Le présent ouvrage plonge dans l'une des œuvres littéraires les plus marquantes du monde arabe, tente d'en dégager les 
dynamiques internes au vu des transformations du monde contemporain. Il s'efforce de répondre à plusieurs interrogations: quel est l'impact de la violence engendrée par les guerres et les conflits politiques sur l'écriture romanesque au Liban? Qu'en est-il de l'engagement et de la fiction historique après la fin des grandes idéologies? L'œuvre ouverte de Khūrī parvientelle à se libérer de l'autorité narrative ? Sa démarche déconstructionniste peut-elle être considérée comme postmoderne ? Cette dernière notion a-t-elle droit de cité au sein de la critique littéraire arabe?

Ces interrogations permettent, plus largement, de jeter quelque lumière sur des questions que le roman arabe contemporain se pose à lui-même, à travers des tentatives variées de renouvellement et de repositionnement, aussi bien par rapport à sa propre histoire que par rapport à la littérature occidentale. 



\section{1 \\ Le roman de la guerre civile?}

Selon l'historiographie officielle, la guerre civile libanaise commence le 13 avril 1975 et prend fin en 1990. Un incident sanglant, dans une banlieue de Beyrouth, entre les phalanges chrétiennes et des Palestiniens met le feu à la poudrière libanaise : le pays restera enflammé quinze années durant. En 1990, avec la bénédiction de Damas et de l'Arabie saoudite, les députés libanais signent l'accord de Taëf - du nom de la province saoudienne où furent menées les négociations - qui instaure une réconciliation nationale. Mais la déconfessionnalisation ${ }^{1}$ politique prévue dans la charte demeure un vœu hypothétique. Pis encore, la confessionnalisation en ressort renforcée. Les conflits refoulés, sans être apaisés, alimentent sans cesse les scénarios noirs d'une reprise des violences. Le feu n'est pas éteint qui couve sous les cendres, et pourrait à tout moment être ravivé par les intentions bienveillantes. La période de l'après-guerre témoigne de la fragilité de la paix retrouvée.

Le roman libanais contemporain peut être considéré comme l'enfant de cette guerre, écrit Khūrī². Brisant les tabous

1. Le Liban est doté d'un système politique pluriconfessionnel fondé sur une répartition du pouvoir déterminée par l'influence de chaque communauté religieuse. Ainsi le chef de l'État est chrétien maronite, le président du conseil des ministres est sunnite et le président du parlement est chiite.

2. Cf. Ilyās Khūrī, al-Riwāya, al-riwā 'ī wa-l-ḥarb (« Le roman, le romancier et la guerre »), Majallat al-abhāth, Beyrouth, éditions de l’Université américaine, nº 52-53, 2004. 
et ébranlant les assises idéologiques qui prévalaient jusque là, la guerre a libéré l'esprit, et par conséquent l'écriture, du carcan du consensualisme (tawfiqiyya) dominant. Dans al-Dhākira al-mafqūda (" La mémoire perdue »), Khūrī analyse longuement l'échec du projet de modernité arabe, fondé depuis la renaissance (nahda) sur ce consensualisme. Vouloir satisfaire les exigences de modernité occidentale tout en sauvegardant conjointement l'héritage culturel, linguistique et religieux arabe a mené à une impasse, que ce soit au niveau de la construction d'un État moderne ou au niveau de la culture, et notamment de la littérature. Les défaites à répétition ont montré les contradictions inhérentes à ce projet. Jusque là, la littérature avait adopté une approche qui tentait de satisfaire les exigences formelles nouvelles sans se détacher d'une certaine pensée traditionaliste, bien que les deux fassent mauvais ménage :

La guerre civile au Liban est une expérience historique qui a restructuré les forces sociales en place tout en dévoilant leurs contradictions. La guerre ne s'est pas déroulée seulement sur le terrain politique, elle a ravagé la mémoire, notre mémoire collective de la nahḍa. Cette mémoire qui se voulait moderne s'est effondrée avec la guerre, un effondrement caractéristique de la condition générale de la culture arabe. Les pensées toutes faites, les discours, les institutions et les valeurs héritées de la prétendue modernité de la nahda sont devenus vains. (al-Dhākira al-mafqūda, p. 26)

Une nouvelle littérature a pu ainsi se développer sur un terrain où tout était à reconstruire. Cette thèse n'est pas isolée; elle fait écho à d'autres études critiques, parues à la même période, qui ont contribué à forger ce qui sera communément appelé « la littérature de la guerre » (adab al-ḥarb). 
Yumnā al-Īd lie les transformations de l'écriture romanesque dans le roman libanais de la guerre à la guerre elle-même, voyant dans cette littérature une forme de résistance ${ }^{3}$.

Rafîf Șīdāwī $\bar{i}^{4}$ considère que les romans antérieurs à l'explosion de la guerre civile comme ceux de Tawfīq Yūsuf 'Awwād, Yūsuf Ḥabshī al-Ashqar, Suhayl Idrīs et d'autres, par delà la disparité de leurs visions et malgré leur dénonciation pessimiste des injustices engendrées par les structures sociales familiales et politiques sclérosées, avaient pour dénominateur commun un projet de refondation sociale et politique du Liban : ce projet est, selon elle, mis à mal dans les romans écrits pendant la guerre par des romanciers comme Rashīd al-Ḍa‘īf, Ilyās Khūrī, Ḥasan Dāwūd, 'Alawiyya Șubḥ ou Hudā Barakāt.

Sāmī Swaydān ${ }^{5}$ se situe dans cette même mouvance. Ces approches font ressortir les rapports entre société et littérature, et montrent l'impact, sur le roman libanais, d’un événement aussi déstructurant que la guerre civile.

Edward Saïd, quant à lui, a pertinemment souligné l'impossibilité pour le roman arabe en général, non seulement libanais mais aussi bien égyptien, palestinien, syrien, etc., de se désengager du politique : « Le roman arabe, ainsi entouré par le politique et, dans une large mesure, prisonnier des conflits locaux et du climat international, est, véritablement, un genre assiégé ${ }^{6}$.»

3. Cf. Yumnā al-T̃d, al-Kitāba, tahawwul fi al-tahawwul (« L'écriture, une mutation au sein d'une mutation ») Beyrouth, Dār al-ādāb, 2003.

4. Cf. Rafîf Șīāwī, al-Naẓra al-riwā 'iyya ilā-l- ḥarb al-lubnāniyya:1975-1995 (« Le regard romanesque sur la guerre libanaise »), Beyrouth, Dār al-Fārābī, 2003.

5. Sāmī Swaydān, Faḍā 'āt al-sard wa-madārāt al-takhayyul (al-ḥarb wa-l-huwiyya al-arabiyya), Beyrouth, Dār al-ābāb, 2006.

6. Edward Saïd, Ta'ammulāt ḥawla-l-manfa, Beyrouth, dār al-ādāb, 2004, p. 178. La traduction est de nous. Titre original: Reflections on Exile and other Essays, Harvard University Press, 2002. London, Granta books, 2001. 


\section{Littérature de guerre, mais de quelle guerre?}

L'œuvre d'Ilyās Khūrī pourrait donc être à bon droit considérée comme le produit de la guerre civile. À double titre : non seulement il a écrit durant cette période, mais ses romans, même ceux parus après 1990, ont la guerre pour sujet.

Dans Bāb al-shams (La Porte du soleil), Khalīl, un combattant palestinien réfugié au Liban, se souvient:

C'était la guerre civile au Liban.

Lorsque la guerre a commencé, je me suis rappelé 'Ammān et comment nous en avons été expulsés sans avoir été vaincus. En septembre 1970, nous avons été défaits sans avoir fait la guerre. Nous sommes partis dans les forêts de Jarash et de 'Ajlūn où ce fut la fin. [...]

À Beyrouth, la guerre a été différente. Elle a duré longtemps. $\mathrm{Au}$ début, je croyais qu'elle serait comme à 'Ammān, que le combat ne durerait pas plus que quelques semaines, et que nous nous retirerions ailleurs par la suite. J'avais tort, car le Liban a explosé entre nos mains. Un pays entier volait en éclats, et nous, nous courions parmi les débris des villes, des villages et des diverses communautés religieuses.

Je ne te ferai pas maintenant l'analyse de cette guerre du Liban, mais elle m’a terrorisé. J'étais terrorisé de voir le ventre de la ville exploser, ses entrailles sortir et les rues se transformer en vestiges des morceaux de la société décomposée. Tout s'est désintégré pendant la guerre civile: même moi, je me suis divisé en un grand nombre de personnages. Chaque jour, nous changions de discours politique et d'alliance, allant de la gauche au soutien des musulmans, des musulmans aux chrétiens, du massacre de Shātīlā en 1982, perpétré par les Israéliens et les phalangistes, au siège/massacre de 1985, mené par le mouvement Amal avec le soutien de la Syrie.

Comment croire que cette guerre était réelle? Je la revois encore, comme un rêve mystérieux, comme un nuage qui 
m'enveloppe de la tête aux pieds. C'est fascinant comme j'ai pu gober une telle quantité de slogans contradictoires. Les mots étaient alors aisés, le sang aussi. C'est pourquoi nous ne nous sommes pas aperçus du gouffre dans lequel nous étions en train de glisser. (Bāb, p. 143-144)

Un autre roman de l'auteur, Sīnālkū ${ }^{7}$, montre que la guerre, une vingtaine d'années après sa fin officielle, n'est manifestement pas un sujet clos. Le titre, "Sin alcohol" (sans alcool en espagnol), est le surnom d'un milicien qui semait la terreur à Tripoli pendant les premières années de la guerre. Quant à Karīm, un dermatologue de confession chrétienne, militant de la gauche laïque libanaise, il quitte son pays pour fuir la guerre et s'installe à Montpellier, en France, dans l'espoir que l'exil pansera ses blessures et finira par lui apporter l'oubli. N'y trouvant pas la paix souhaitée, il retourne au Liban, déterminé à reprendre les projets qu'il avait abandonnés à son départ. Or, les bombes, les désillusions et un sentiment de perte irrémédiable auront raison de ses espoirs. Même, le manifeste qu'il avait écrit avec son ami Dānī est récupéré par les islamistes; ces derniers ont juste effacé les termes « Marx " et « la classe ouvrière " et mis à la place le mot « islam ». Karīm prend un billet de retour pour la France. Le chemin qui le mène à l'aéroport est atteint par des coups de feu et d'obus. La fumée bouche l'horizon. Parviendrat-il à prendre l'avion? Incertitude, angoisse, échec sont le fin mot de l'histoire.

Le fait que, de l'aveu et de la pratique de Khūrī, se soit ainsi autonomisé un roman de la guerre civile, en rupture avec le roman de la génération précédente ne signifie nullement l'enfermement de ce roman dans un temps spécifique sans avant ni après : Khūrī s'attache, en effet, à faire la généalogie de cette

7. Ilyās Khūrī, Sīnālkūl, Beyrouth, Dār al-ādāb, 2012. Traduction par Rania Samara, Sinalcol: Le miroir brisé, Arles, Actes Sud, 2013. 
Elias Khoury - De l'engagement au postmodernisme

guerre, faisant remonter ses prémisses aux massacres qui eurent lieu dans la montagne libanaise en 1858-1860 entre les chrétiens et les druzes.

Tentant d'expliquer à ses bourreaux et geôliers les causes de son état de perturbation et de déchéance, Yālū, dans le roman éponyme, leur dit: "l'histoire de Yālū, c'est la guerre ${ }^{8}$ " (Yâlū, p. 290). Ce faisant, le roman lie le sort individuel du personnage à l'histoire collective du pays. Il revient notamment sur les massacres de 1858-1860, les décrivant comme le premier maillon de la longue chaîne de déterminismes à laquelle se réduit l'histoire moderne du Liban.

De même, le roman Majma al-asrār ${ }^{9}$ (Le Coffre des secrets) s'ouvre sur ces massacres de 1858-1860 ; ces derniers ont provoqué de grandes vagues d'émigration, poussant une partie de la famille Nașșār à émigrer et à s’installer en Colombie :

On dit, et Dieu seul le sait, que les hommes de la famille Nașșār ont été égorgés dans le village alors qu'ils fuyaient dans les rues étroites en terre battue. C'était un massacre. En ce temps-là, entre 1858 et 1860, le sud du Mont-Liban, depuis Rāshayya, Ḥāșbayya, Dayr al-Qamar et Shaḥhāar, baignait dans le sang. (Majma, p. 150)

Le retour à ces événements sanglants de l'histoire du Liban montre que l'hypothèse d'un roman lié à la guerre civile doit, sous peine de rester quelque peu empirique et confuse, être sérieusement travaillée en extension et en compréhension. Ainsi, 'Abdū Wāzin, écrivain et poète libanais, responsable de la page culturelle du quotidien panarabe al-Hayāt, observe que ce qui

8. Ilyās Khūrī, Yālū, Beyrouth, Dār al-ādāb, 2002. Traduit par Rania Samara, Yalo, Arles, Actes Sud, 2004.

9. Ilyās Khūrī, Majma al-asrār, Beyrouth, Dār al-ādāb, 1994. Traduction en français par Rania Samara, Le Coffre des secrets, Arles, Actes Sud, 2009. 
est communément appelé la " littérature de guerre ${ }^{10}$ " (adab al-ḥarb), renvoie, dans le contexte libanais, aussi bien aux romans qui ont la guerre pour sujet qu'à ceux qui ont été écrits pendant la guerre civile elle-même : celle-ci demeure un sujet une fois même qu'elle est éteinte et que le contexte a changé. À supposer d'ailleurs qu'il ait véritablement changé et que le moment actif de la guerre civile n’ait pas avant tout révélé une matière spécifiquement libanaise définie par la profondeur et la fatalité de la discorde. 'Abdū Wāzin souligne en tout cas que la trêve instaurée en 1990 n'est en rien parvenue à chasser le spectre de la guerre. Les conflits idéologiques et confessionnels qui ont atteint leur point culminant pendant la guerre civile de 1975 ont continué à gangréner le système sociopolitique libanais. "Les Libanais, écrit-il, ont l'intime conviction que l'arrêt des combats armés n’a pas été suffisant pour mettre un terme à la guerre qui est essentiellement la résultante d'un long conflit intellectuel et communautaire sans fin. Ainsi, la paix semble faire partie de la guerre elle-même, mais sans combats ni massacres. La guerre libanaise se distingue des autres guerres par sa permanence aussi bien dans le présent que dans la mémoire, que cela soit en temps de paix ou de conflit. »

Khūrī partage ce constat. Il explique, à ce sujet, comment les enjeux géopolitiques et stratégiques font du Liban un projet de guerres civiles à répétition ${ }^{11}$. D'ailleurs, son discours ne se démarque pas de celui qui est communément accepté par les Libanais. Il dit que le Liban, depuis sa création jusqu'à aujourd'hui, a toujours été un État faible, exposé aux tiraillements d'intérêt des puissances étrangères et à leur ingérence et

10. 'Abdū Wāzin, Riwāyat al-ḥarb al-lubnāniyya, madkhal wa namādhij (« Le roman de la guerre libanaise, introduction et exemples »), Dubai, Dār al-ṣadā, 2009, p. 19 11. Le point de vue de Khūrī ici reproduit est tel qu'il l'a exprimé lors d'un entretien personnel avec nous, réalisé à Beyrouth en août 2016. 
que, de ce fait, il n’a jamais réussi à se construire ni une histoire unifiée ni un avenir commun. L'histoire du Liban moderne ne commence pas, contrairement à ce qu'on peut lire, au XvI siècle avec le règne de la dynastie Maan qui a gouverné la montagne libanaise de 1544 à 1697. Car, continue-t-il, au temps des Maan, le Liban n'était qu'une province ottomane, sans délimitation territoriale. C'est la décomposition de l'Empire ottoman qui donne l'occasion aux Druzes de tenter d'acquérir l'hégémonie sur la montagne libanaise. La résistance des maronites à cette offensive débouche sur leur massacre par les Druzes, de 1840 à 1860 . Suite à ces tueries, la pression des puissances occidentales sur l'Empire ottoman mène à la création de la moutasarrifiyya, qui jouissait d'une relative autonomie. Le gouverneur, nommé par l'Empire ottoman, était chrétien, non Libanais et de nationalité ottomane. Un conseil consultatif central est formé sur base confessionnelle. Après la Première Guerre mondiale et l'effondrement de l'Empire ottoman, les vainqueurs, France et Royaume-Uni, se partagent la région. La création du Grand Liban, en 1920, entité coloniale française placée sous l'autorité du général Gouraud, consacre la répartition confessionnelle définie sous la moutasarrifiyya. Cette répartition confessionnelle, au fondement du régime politique libanais, gangrénera le pays jusqu'à aujourd'hui.

De ce fait, l'histoire du Liban, depuis son indépendance (1943), se résume, poursuit Khūrī, à des conflits interconfessionnels entrecoupés par des moments d'accalmie fragiles. Ces conflits sont la caisse de résonance de crises régionales, les différentes communautés faisant appel, selon les moments, à un soutien étranger ou à un autre. L'évolution des forces politiques dans la région entraîne, chaque fois, une remise en cause de l'équilibre interne du pays entre les différents partis qui se partagent le pouvoir. 
Le pacte national de 1943 consiste en un accord de partage du pouvoir entre sunnites et maronites: les dirigeants sunnites acceptent de renoncer à leur revendication d'union avec la Syrie. En contrepartie, les dirigeants maronites renoncent au protectorat de la France. Cependant, ce pacte ne sera pas respecté. Les maronites restent alliés à la France tandis que les musulmans cherchent un soutien parmi les pays arabes voisins. Ces alliances provoquent, entre autres, des tensions en 1956, lors de la crise de Suez, lorsque le président Sham'ūn refuse de rompre son alliance avec la Grande-Bretagne et la France.

La montée du nassérisme, en 1958, remanie la scène politique et ravive les tensions entre musulmans et chrétiens. En 1967, la défaite des pays arabes face à Israël incite la coalition des diverses milices chrétiennes (Kataêb, Parti national libéral, Bloc national) à inverser la situation à l'avantage des maronites. La montée de la résistance palestinienne et son implantation au Liban radicalise les positions entre, d'une part, l'OLP et ses alliés dont le Parti socialiste progressiste créé par Kamāl Jumblāț dans le fief druze, qui n’a de progressiste que le nom et, d'autre part, le Front chrétien, faisant éclater la guerre civile en 1975. Durant la guerre, les conflits de pouvoir n'ont pas opposé les maronites aux sunnites, comme en 1958, mais le Mouvement national (al-ḥaraka al-wațaniyya: coalition des partis nationalistes, laïques et de gauche) au Front chrétien. En 1976, le mouvement national était sur le point de remporter la victoire. Les dirigeants chrétiens demandent alors l'intervention de la Syrie qui en profite pour étendre sa domination sur le Liban.

La révolution iranienne, en 1979, et la victoire de Khomeiny débouchent sur la création du Hezbollah, qui consolide la montée en puissance du chiisme au Liban; en résulte l'accentuation des divergences d'intérêts et des tensions entre les deux 
principales confessions musulmanes, les sunnites faisant allégeance à l'Arabie saoudite et les chiites à la Syrie et à l'Iran.

L'invasion israélienne de 1982 conduit au départ des combattants palestiniens et à l'arrivée au pouvoir des alliés chrétiens de l'État hébreu. Bashīr Jmayyil est élu président — et assassiné quelques mois plus tard. Les massacres de Șabrā et Shātīlā, commis par les phalanges chrétiennes sous couvert israélien, sont la conséquence directe de cet assassinat. Puis le départ d'Israël, le retour en force de Damas et son alliance avec le Hezbollah signent le début de l'effondrement de l'éphémère pouvoir chrétien. Cet effondrement culmine avec l'accord de Taëf qui met fin, en 1990, à la guerre civile libanaise. En conséquence de cet accord, le Liban se retrouve sous tutelle syrienne et la répartition des forces sur l'échiquier politique est remaniée. Le gouvernement, dont le Premier ministre est sunnite, et l'Assemblée nationale, dont le chef est chiite, concentrent le pouvoir tandis que le président de la République, maronite, en sort affaibli. Pour récompenser la Syrie du soutien qu'elle leur a apporté, les États-Unis donnent leur feu vert à la tutelle syrienne pendant la première guerre du Golfe, consécutive à l'invasion du Koweït par Ṣaddām Ḥusayn en août 1990. Les tensions entre sunnites et chiites continuent de s'exacerber, bloquant le fonctionnement des administrations. Nous sommes toujours, pour le moment, pris dans cette configuration. L'échec de la création d'un État libanais fort et centralisé ainsi que l'instabilité de la région font que le Liban, conclut Khūrī, reste en proie à une guerre civile latente menaçant son intégrité en permanence.

La paix, considérée comme un bref moment d'accalmie, ne crevant en rien l'abcès confessionnel et idéologique fait que le malheur libanais demeure, jusqu'à nouvel ordre, sans fin. 


\section{Une littérature d'“ après 60 "}

Ces considérations sur l'histoire du Liban et sur la représentation littéraire de la guerre civile - passée, présente et à venir incitent à prendre avec précaution une périodisation de la littérature libanaise qui se focaliserait trop exclusivement sur le début des années 1970. Certes, l’idée d'un roman de la guerre civile fait sens. Cependant, ce point de vue, libanocentré, n'est pas inclusif d'autres niveaux d'approche. Car, comment envisager dès lors le tsunami survenu avec l'expulsion des Palestiniens, en mai 1948, de leurs villes et villages, suite à la création d'Israël sur les trois quarts de la Palestine historique, ou encore le problème national arabe en général - des événements qui impactent tout aussi bien la littérature libanaise?

Khūrī, d'ailleurs, considère que la question de la Palestine est le cœur des problèmes du monde arabe ; aucune solution de paix durable n'est envisageable sans le dénouement de cette question. Après Bāb al-shams, la parution de Awlād al-ghetto : Ismī Ādam ${ }^{12}$ témoigne du caractère imbriqué aussi bien des histoires des pays arabes que de leurs littératures.

Quelle place accorder aussi, sur le plan de l'histoire littéraire, à la guerre de 1967 ? Pour Fabio Caiani ${ }^{13}$, la critique littéraire a lieu de retenir cette date, par " convention ", pour marquer l'émergence d'un nouveau roman arabe. Une telle périodisation simplifierait une approche littéraire et historique complexe sans pour autant occulter l'impact d'autres événements déstabilisateurs comme la guerre libanaise. Une approche que nous partageons :

12. Ilyās Khūrī, Awlād al-ghetto: Ismī Ādam, Beyrouth, dār al-ādāb, 2016. Traduction en français par Rania Samara, Les Enfants du ghetto: je m'appelle Adam, Arles, Actes Sud, 2018.

13. Cf. Fabio Caiani, Contemporary Arab Fiction: Innovation from Rama to Yalo, London and New York, Routledge, 2007, p. 9. 
Elias Khoury - De l'engagement au postmodernisme

"Parler d'une littérature d'" après 60 » - au sein de laquelle le roman libanais est largement représenté - a le mérite de proposer une dénomination plus large et de mettre l'accent sur l'interconnexion de la littérature libanaise contemporaine avec le contexte environnant, comme avec le monde globalisé ${ }^{14}$. "

En effet, pendant deux décennies, de 1950 à 1967, les Arabes avaient gardé l'espoir de se relever de la nakba. Al-nakba, terme employé la première fois par Qusțanțin Zrayq dans son livre Ma'nā al-nakba ${ }^{15}$ ("Le sens de la nakba », 1948) signifie littéralement " désastre » ou " catastrophe ». La naksa, en référence à la guerre des Six-Jours, en déstabilisant les valeurs, plonge les Arabes dans une " rechute ". Cette débâcle politique constitue un tournant; la génération à laquelle appartient Khūrī, après avoir cru que l'unité arabe et le socialisme feraient advenir un monde meilleur, est désormais consciente que «les beaux jours où les sociétés ont un avenir collectif [sont] terminés ${ }^{16}$ ".

Sur la scène mondiale, la foi dans l'histoire fait place au scepticisme. Après la Seconde Guerre mondiale, jusqu'aux débuts des années 1970, le monde connaît une phase d'expansion économique dans un contexte de guerre froide puis de décolonisation. À partir du début des années 1970, l'économie mondiale passe par une période de récession marquée par une forte montée du chômage, de l'inflation et des crises régionales. L'économie mondiale sort de la récession au début des années 1980 par la libéralisation du commerce, la déréglementation financière et l'augmentation massive de l'endettement des particuliers, des

\footnotetext{
14. Katia Ghosn, «Le roman de Rachid el-Daïf à l'ère de la globalisation », in Rachid el-Daif: Le roman arabe dans la tourmente de la modernisation, Katia Ghosn (éd.), Paris, Demopolis, 2016, p. 16.

15. Qusțanțīn Zrayq, Ma'nā al-nakba, Beyrouth, Dār al-'ilm lil-malāyīn, 1948.

16. Basma Kodmani, « Une génération arabe traumatisée par la défaite », Le Monde diplomatique, juin 2007.
} 
entreprises et des États. L'effondrement des communismes dans les années 1980 et l'absence d'alternative à un libéralisme économique à la crédibilité libératrice vacillante marquent l'esprit du temps, et donc aussi la création romanesque. Ce contexte pèse de tout son poids sur le roman de Khūrī et participe de l'émergence de nouvelles formes d'écriture.

L'appellation "roman de la guerre civile ", tout en gardant une certaine pertinence, ne rend pas compte du fait que les guerres sont désormais mondiales comme l'est également la littérature.

\section{Impact du contexte sociopolitique sur l'écriture et émergence d'une interrogation métafictionnelle}

Raconter suppose la capacité de saisir ensemble, d'agencer les éléments épars de l'histoire, d'instaurer un ordre là où règnent confusion et désordre. Or, chez Khūrī, le narrateur réalise que ce pouvoir de présenter une histoire cohérente, achevée et obéissant à un ordre préétabli, n’est plus possible : « Nous trouvons les histoires jetées sur les chemins de la mémoire et les ruelles de l'imagination. Comment les structurer dans un pays où toutes les structures se brisent ${ }^{17}$ ? » (Mamlakat, p. 103). L'absence de structure, évoquée par le narrateur, est liée à un contexte politique instable et angoissant. Les valeurs se sont effondrées, entraînant dans leur chute toute possibilité de construire un monde cohérent et stable. En semant la confusion et le chaos, cette absence de structure contribue à l'égarement du narrateur dans sa tentative de reconstituer une histoire crédible et achevée. Bāb al-shams insiste sur l'idée selon laquelle la guerre n'a pas de commencement assignable : c'est comme si elle avait toujours été là. Elle

17. Ilyās Khūrī, Mamlakat al-ghurabā ', Beyrouth, Dār al-ādāb, 1993. 
brise tout et rend impossible la reconstitution d'une version unanimement reconnue des faits : " La question, c'est la guerre, et la guerre n’a pas de début » (Bāb, p. 282). La guerre comme effacement des traces constitutives des lieux et des personnes mène dans al-Wujūh al-bayḍă' (Un Parfum de paradis) à la folie. Suite à la mort de son fils Aḥmad, enrôlé par les milices lors de la guerre civile libanaise, Khalīl développe une maladie étrange. Il prend des gommes et efface les articles de journaux, puis commence à sortir dans les rues et peindre les murs de la ville en blanc, avant d'être tué, à son tour, dans des circonstances inconnues. La couleur de la guerre, chez Khūrī, est le blanc. Ce n'est ni le rouge, ni le noir. Le blanc est la couleur des linceuls, des précipices, du néant. «La mort est blanche, mon ami, comme les draps qui enveloppent ton corps sur ce lit métallique ", lit-on d'ailleurs dans Bāb al-shams (p. 196). Le blanc évoque également la page où rien n'est écrit. La guerre comme éclatement de l'histoire individuelle et collective met le narrateur devant une nouvelle page où tout serait à réécrire et où le travail de la mémoire est fortement sollicité : "Ces guerres n'étaient-elles pas des exercices de la mémoire ? On dit que la guerre est un exercice d'oubli car, si nous n’avions pas oublié les massacres que nous avions perpétrés, nous aurions été ravagés par le remords. " (Mamlakat, p. 95).

L'incertitude place le narrateur en face d'un matériau qu'il ne parvient plus à assembler. Cela va déclencher une interrogation métafictionnelle qui engagera le roman dans la réflexivité sur sa nature et son rôle. La fiction devient, elle-même, " une matière à réflexion à l'intérieur du discours romanesque, un mode d'écriture et de déchiffrement ${ }^{18}$ ". Nous nous référons ici à Mamlakat al-ghuraba $\vec{a}$ ( Le royaume des étrangers »), car ce roman ${ }^{19}$ est un

18. Jean-Paul Sermain, Métafictions, Paris, Honoré Champion, 2002, p. 12.

19. Non traduit en français. 
condensé du discours métafictionnel sur lequel se fonde l'écriture de Khūrī. Le narrateur y est un écrivain chevronné. Il a travaillé au Centre d'études palestiniennes et a enseigné à la Columbia University aux États-Unis. Il connaît aussi bien la littérature libanaise que la littérature mondiale. Il cite les poètes Fu'ād Gabriyāl Naffā' et Maḥmūd Darwīsh et des écrivains comme Marūn 'Abbūd et Jibrān Khalīl Jibrān. Il se réfère à Umberto Eco, à Vladimir Propp et n'hésite pas à se lancer dans une étude comparative entre l'une des histoires qu'il raconte dans ce roman, celle du médecin Luțî̉ Barakāt et celle du docteur Adam, racontée par Salman Rushdie dans Midnight's Children $^{20}$ (1981).

Le narrateur n'a pas de nom. Mais parlant à la première personne, il écrit que la guerre civile libanaise s'est transformée en "visages blancs" (wujūh bayḍa $\bar{a}$, p. 28). En mettant cette expression entre guillemets, le narrateur renvoie à l'un des romans de Khūrī, al-Wujūh al-bayḍă’ (" Les visages blancs»). Le roman fait également implicitement allusion à un autre roman de Khūrī : al-Jabal al-șaghīr (La Petite Montagne, p. 115). En y introduisant certains éléments autobiographiques, le narrateur nous autorise à poser une certaine identité entre lui et l'auteur Ilyās Khūrī.

Le narrateur-auteur se trouve confronté à la question théorique des apories de l'écriture romanesque vers la fin d'un $\mathrm{xx}^{\mathrm{e}-}$ siècle ravagé par la violence, une violence dénuée de sens et qui marque un certain épuisement de l'humain. Il s'interroge sur les problèmes qui l'empêchent de raconter une histoire crédible pour le lecteur et sur les moyens de les contourner. Les obstacles tiennent à des raisons externes et n'ont rien à voir avec un quelconque tarissement de l'inspiration du narrateur. La crise n'est pas due à un manque de savoir-faire; elle est la 
manifestation d'une volonté assaillie par les doutes, qui se remet en question et tente de reconstituer son rapport à un monde ayant perdu son évidence.

Mamlakat al-ghuraba $\bar{a}^{\prime}$ commence par un questionnement, sans cesse répété : «À propos de quoi j’écris ? (Mamlakat, p. 12). Ce questionnement revient comme un leitmotiv au commencement des quatre chapitres suivants et il n'est pas rare de le voir resurgir au milieu de la narration.

Le deuxième chapitre commence ainsi : "À propos de quoi j'écris? où est l'histoire? me demanda Maryam. » (p. 21) Et un peu plus loin : "Qu'est-ce que j'écris ? où est le problème ? lui demandai-je. » (p. 26). Le troisième chapitre commence par: "Qu'est-ce que j’écris ? Je ne sais pas. Je sens la parole se désintégrer et se disloquer. Nous sommes devant la mer Morte. » (p. 37) Et le chapitre 4: «Qu'est-ce que j'écris ? où est le problème dans cette histoire ? " (p. 63) De même pour le début du dernier chapitre : "Qu'est-ce que j’écris? » (p. 109). «Je ne sais pas », écrit-il à plusieurs reprises. " Je ne dirai plus je ne sais pas, je l'ai déjà dit des dizaines de fois dans ce roman. »(p.102) Les histoires tournent et demeurent inaccessibles :

Toutes les histoires que je connais et que je ne connais pas s'étaient assemblées là-bas, sur le bord brisé de cette mer salée de couleur grise. [...] Et derrière nous des villes qui glissaient vers les profondeurs du Jourdain comme si elles s'effondraient sous terre, glissant vers un lieu inaccessible, vers des histoires qui tournent et tournent apparemment sans fin. (Mamlakat, p. 11)

Cette interrogation métafictionnelle sur le roman était déjà à l'œuvre dans al-Wujūh al-bayḍă', paru en 1981, douze ans avant Mamlakat al-ghurabā'. Sāmī Swaydān y relève le primat du discours métafictionnel sur l'histoire elle-même : 
Al-Wujūh al-bayḍā' s'applique à attirer l'attention sur son style narratif particulier. Tout comme le roman ne cesse d'égrener les informations, de raconter les histoires, de rappeler les événements, il n’a de cesse de faire prévaloir son style singulier comme étant le vrai domaine de création. La façon de narrer l'événement a une plus grande importance que le sujet de la narration. L'intérêt porté au style n'écarte pas le sujet pour autant mais lui confère par cela même son plus beau rayonnement ${ }^{21}$.

Faite de blancs et d'incertitudes, prisonnière d'un contexte politique chaotique qui la force à se recomposer en permanence, l'histoire perd sa crédibilité. L'hésitation pourrait se répercuter sur le lecteur qui risque de se détacher de la lecture, n'y trouvant plus l'intérêt et le divertissement attendus. Ce souci taraude l'auteur-narrateur : "Et s'il se trouve quelqu'un qui voudrait la lire [l’histoire] » (Mamlakat, p. 71). Dans Riḥlat Ghandī al-șaghīr ${ }^{22}$ ("Le voyage du petit Ghandi »), Alice fait remarquer au narrateur que la télévision est devenue un meilleur moyen de divertissement que les histoires :

— À quoi bon écrire, nom de Dieu?

- Pour faire des livres et inventer des héros; les gens les lisent et se divertissent.

- Ils se divertissent en regardant la télévision, n’est-ce-pas mieux?

— Peut-être, qu'est-ce que j'en sais? (Riḥlat, p. 138)

La guerre se présente comme un élément déterminant de la perte d'évidence qui installe un malaise dans l'approche que

\footnotetext{
21. Sāmī Swaydān, Abhāth fĩ al-naș al-riwā' ì al-'arabì ("Études sur le texte fictionnel arabe"), 2000, p. 173

22. Ilyās Khūrī, Rị̣lat Ghandī al-ṣaghīr, Beyrouth, Dār al-ādāb, 1989. Traduit par Luc Barbulesco Le Petit Homme et la guerre: Le voyage du petit Gandhi, Paris, Arléa, 1994; Actes Sud, 2004.
} 
tente le narrateur de son art. Ce malaise constitue un trait distinctif de son écriture, car il est confronté à une situation déstabilisante marquée par l'effondrement des valeurs qui constituaient les assises de la refondation littéraire de la renaissance arabe. C'est pourquoi l'auteur-narrateur de Mamlakat al-ghurabä' insiste sur sa rupture avec les romanciers de la génération précédente. Il reconnaît en Marūn 'Abbūd (1886-1962) un maître incontesté de l'art de conter, et fait état de l'admiration de son père pour Jibrān Khalīl Jibrān (1883-1931), un écrivain reconnu pour son rôle déterminant dans l'évolution et la modernisation de la littérature arabe et pour son influence sur toute une génération d'écrivains arabes. Selon le père du narrateur, son fils ne fait que voler les histoires des gens et prétendre par la suite que ce sont les siennes. Le père dénie ainsi à son fils-écrivain toute créativité littéraire. Cependant, le narrateur fait remarquer que ni Marūn 'Abbūd ni Jibrān, réputés faire partie des avant-gardes de la renaissance moderne, n'auraient pu écrire comme il le fait lui-même car, eux, savaient, alors que lui ne sait pas. Eux connaissaient et maitrisaient leur sujet, pas lui. En prenant ses distances vis-à-vis d'auteurs ayant fortement marqué leur génération et participé à la refondation littéraire survenue dans le monde arabe, le narrateur instaure un après 'Abbūd et un après Jibrān, se plaçant lui-même dans l'après. Ilyās Khūrī entend de la sorte affirmer sa différence avec les modèles hérités, jouer un rôle de renouveau et transformer le champ littéraire arabe.

\section{Narration éclatée}

L'œuvre de Khūrī a l'ambition de fonder une esthétique dont le but serait une déconstruction des œuvres canoniques ayant auparavant marqué le genre. Or, ce souci de déconstruction, 
combiné à une incertitude quant à la survie du genre romanesque, caractérise la littérature postmoderne. Dans une étude consacrée au récit de la quête dans le roman américain postmoderne, Salwa Karoui-Elounelli ${ }^{23}$, maître-assistante de littérature anglo-américaine à l'université de Sousse en Tunisie, montre que le roman postmoderne puise sa thématique dans cette attitude incertaine et subversive. Le jeu métafictionnel qui permet au narrateur de se jouer des théories littéraires est également qualifié par Pierre-Luc Landry de "postmoderne ». Il se réfère au concept de "suspension volontaire de l'incrédulité ", développé par Samuel Taylor Coleridge ${ }^{24}$ afin de dévoiler la volonté de l'auteur " de mettre la théorie à contribution pour livrer un roman métafictionnel, sinon postmoderne ; tout le roman semble précisément travailler à faire en sorte que le lecteur ne puisse pas s'abandonner à cette suspension volontaire de l'incrédulité, ou encore qu'il s'y abandonne totalement et choisisse de tout accepter de ce que l'auteur fait subir au récit et à ses personnages ${ }^{25}$."

Comment le narrateur peut-il alors écrire aujourd'hui ?

Il est d'abord forcé d'admettre son ignorance. " Je ne connais pas d'histoire achevée. Même l'histoire des buffles d'Abū 'Ārif je ne la connais pas " ( $B \bar{a} b$, p. 348), est un leitmotiv qui vaudrait pour toute l'œuvre de Khūrī. Ou encore : "La scène apparaît maintenant du point de vue de Georges, et nous n’y voyons qu'une image imparfaite. " (Mamlakat, p. 77)

Le constat d'ignorance l'amène à suspendre sa recherche de la vérité. Prenons l'exemple de Majma‘ al-asrār — qui n'est pas le

23. Salwa Karoui-Elounelli, "Le récit de la quête dans le roman américain postmoderne: entre version parodique et stéréotype. L'exemple de John Barth », Cahier de narratologie, 2011. http://naratologie.revues.org/1192.

24. Cf. Taylor Coleridge, Biographia Literaria, volume II, 1983, p. 6.

25. Pierre Luc Landry, «Quand l'auteur joue avec la (méta) fiction », in Salon double, 2011. http://salondouble.contemporain.info. 
seul comme nous aurons l'occasion de le voir - pour illustrer la suspicion du narrateur à l'égard de la vérité. Dans ce roman, les questions restent sans réponse : 'Abduljalīl Nașșār a-t-il été assassiné pendant les massacres de 1860 ou bien a-t-il été pendu à Beyrouth comme le suggère une autre version des faits ? Victor 'Awwād est-il le véritable assassin des prostituées de la rue Mutanabbī ou bien a-t-il endossé le rôle du criminel afin d'éviter la torture ? Le doute enveloppe toutes les histoires. De même, au sujet des massacres de 1860, tant d'histoires ont été racontées qu'il est devenu impossible d'établir une version consensuelle. Les documents, non plus, ne sont pas crédibles. Le narrateur ne peut se fier aux archives ni aux témoignages directs :

La véritable histoire, c'est le massacre. Et là, il n'existe aucun document ni texte à ce sujet. Que des paroles dites et oubliées. Dites pour être oubliées, mais elles ne sont pas oubliées puisqu'elles ont été dites. On y ajoute des choses, on en supprime d'autres et personne ne connaît vraiment la vérité. (Majma', p. 150)

La vérité est symboliquement enfouie à l'intérieur du coffre abandonné dans une chambre de la maison fondée par l'aieul Ibrāhīm Nașșār. Après la mort de son fils Ya'qūb, personne ne l'a plus touché. Or, ce coffre dont l'existence laisserait croire que les secrets de la famille Nașșār y sont enfouis ne dévoile rien. Lorsqu' Ibrāhīm, le fils de Ya'qūb, l'ouvre, de la poussière mêlée à une odeur nauséabonde s'en dégage. Tous les papiers sont endommagés, quelques uns mis à part, rédigés en espagnol et qu'il ne sait pas déchiffrer. Sa tante Sāra lui dit: « Je chercherai moi-même un jour et nous trouverons tout ce que tu veux " (Majma', p. 190). Ces paroles de la tante Sāra laissent entendre que le coffre ne contient que ce que nous voulons bien y trouver. Il est le lieu de toutes les illusions. Ḥannā, l'ami d'Ibrahīm, est le plus sceptique; il conteste l'existence même du coffre, y voyant 
des élucubrations issues de l'imagination débridée d'Ibrāhīm et de sa tante.

N'ayant rien trouvé dans le coffre, Ibrāhīm décide de s'en débarrasser, mais change d'avis, le referme et le laisse à sa place. Pourquoi Ibrāhīm Nașșār garde-t-il le coffre tout en sachant qu'il ne renferme rien ? Est-ce par fidélité à la mémoire évanescente du passé de sa famille? Ou est-ce parce que la présence du coffre, même vide, le rassure et le réconforte ? C'est probablement pour les deux raisons. Il préfère vivre avec des histoires mortes que faire face au vide de l'histoire.

— [...] C'est incroyable comment l'histoire est morte!

— Quelle histoire? demanda Ḥannā.

— L’histoire de mon grand-père, répondit Ibrāhīm.

— Qu'est ce que tu lui veux à ton grand-père?

- J'en sais rien.

— Que Dieu te vienne en aide, t'as aucune cervelle. Toutes les histoires meurent. (Majma', p. 192)

Puisque "les histoires meurent ", s'effacent ou s'emmêlent dans la mémoire, il faut les recommencer. Majma' al-asrār ne peut être écrit que sous une forme ouverte et fragmentée. L'écriture perd sa cohérence. L'origine des récits est incertaine et leur fin inachevée. Les commencements répétés du récit témoignent de l'éclatement de la narration. Onze chapitres sur seize commencent par l'expression : "Voici comment l'histoire a commencé ». Le chapitre 8 commence par: "L'histoire, c’était Norma ». Tandis qu'au chapitre 12 nous lisons: "La véritable histoire, c'est le massacre ». Aucun point de départ n'est objectivement valable pour commencer une histoire, laquelle peut être reprise une infinité de fois.

Les multiples facettes de l'histoire ne sont pas autant de pièces d'un gigantesque puzzle qu'il suffit de réagencer de 
manière à reconstruire un paysage homogène et cohérent. La contradiction n'est pas juste l'effet d'un manque de savoir, ni la conséquence d'une mauvaise lecture de la réalité; elle n'est pas non plus une simple apparence qu'il s'agit de dépasser. La contradiction résiste à toutes les tentatives hasardées pour la dissiper ; elle est inhérente à l'ordre des choses et est essentiellement insurmontable. C'est pourquoi chaque histoire est relatée par au moins deux narrateurs différents, et c'est toujours à la disparité des versions que l'on se heurte, ces lectures distinctes ne pouvant aboutir à une histoire unique qui ferait la synthèse de tous les points de vue. Une lecture unifiante n'existe tout simplement pas et est synonyme de leurre. Le principe de vérité qu'est l'adéquation entre une version des faits et le réel est remis en question. Dans Bāb al-shams, Khalīl raconte l'histoire de Yūnus en la commençant chaque fois différemment. À chaque commencement correspond une version différente. La répétition engendre le trouble, car le narrateur se retrouve en face d'une multitude d'histoires concernant un même sujet et n'arrive plus à savoir laquelle est la vraie. Plus il fouille, plus il découvre des éléments contradictoires, ce qui l'oblige à recommencer chaque fois : " Je ne sais pas, et je dois savoir pour raconter; mais je ne connais pas l'histoire et je dois la chercher depuis le début. » (Bāb, p. 236)

"Il était ou il n’était pas, dans la nuit du temps » (Bāb, p. 31): ainsi nos ancêtres commençaient leurs histoires, explique le narrateur. Cette phrase résume le mieux la conception du jeu narratif chez Khūrī et annonce l'impossibilité de toute tentative de délimitation des sphères du réel et du fictionnel. Le réel est luimême fictionnel.

Plutôt que "vrai », le narrateur opte pour un récit " plausible " (Bāb, p. 6). Le plausible est le degré minimum de cohérence requis dans le récit sans lequel l'histoire devient un chaos 
insurmontable. L'adhésion du narrateur à ce qu'il raconte devrait entraîner celle du lecteur : "L'histoire que j'ai racontée à mon ami Emil Azayev est vraie parce qu'elle me convainc. » (Mamlakat, p. 76)

Il admet que l'écriture est une réécriture : « Nous écrivons ce qui est déjà écrit; si ce n’était pas écrit, nous n’aurions pas écrit. » (Mamlakat, p. 291)

"Écrire c'est mentir » (Mamlakat, p. 65), dit-il, reprenant à son compte l'expression de l'écrivain jordanien Ghālib Halasā. 



\section{Poétique de l'œuvre ouverte Modalités et perspectives}

\section{Les procédés de l’ouverture}

L'œuvre d’Ilyās Khūrī se veut ouverte. Șubḥi Ḥadīdīîn considère que les trois romans Riḥlat Ghandī al-ṣaghīr ("Le voyage du petit Ghandi »), Mamlakat al-ghurabä’ ("Le royaume des étrangers ») et al-Wujūh al-bayḍă’ ("Les visages blancs »), marquent à cet égard le début d'un tournant dans la technique narrative de Khūrī par rapport à ses premières nouvelles. La narration est désormais fondée sur le principe de "l'histoire ouverte " (الحكاية المفتوحة), celle dont les éléments, s’imbriquant les uns dans les autres, sont continuellement repris et modifiés et dont le commencement et la fin sont inattendus - Bāb al-shams est, selon lui, le roman qui exploite le mieux ce procédé.

Ainsi, la fin des histoires reste chez Khūrī en suspens, pouvant être reprise à l'infini. L'inachèvement de l'histoire et la possibilité de toujours la relancer sont exprimés par le narrateur dans Riḥlat Ghandī al-ṣaghīr : “ Je raconte une histoire qui n’est pas terminée. » (p. 7) Le narrateur de Mamlakat al-ghurabā' réitère l’idée : « Les histoires ne finissent pas, lui-dis-je. » (Mamlakat,

1. Șubḥi Ḥadīdī, "Majma al-asrār: jadal al-ḥāja ila l-ḥikāyāt » (Le Coffre des secrets: polémique autour de la nécessité du récit), al-Ṭariq, décembre-février 2001. 
p. 15) Ou encore: " Des histoires qui tournoient et tournoient, comme si elles ne finissaient pas. " (Mamlakat, p. 11)

Dans L'EEuvre ouverte, Umberto Eco présente la tendance à l'ouverture comme une forme de création ou de production "susceptible d'assumer des structures imprévues et matériellement inachevée ${ }^{2}$ ». Cependant, au sens large, la poétique de l'œuvre ouverte n'est pas une invention nouvelle. Toute œuvre d'art, quand bien même elle a une forme achevée et close, est ouverte et peut être interprétée de différentes façons sans que sa singularité soit épuisée pour autant. L'importance de l'interprétation subjective de l'œuvre d'art n'est pas non plus une découverte récente. Au Moyen Âge, la théorie de "l'allégorisme " entend interpréter les Écritures selon des axes de significations différents. L'esthétique baroque est aussi un exemple de «la négation même du défini, du statique, du sans équivoque, qui caractérisait la forme classique de la Renaissance ${ }^{3}$ ». La poétique de l'œuvre ouverte n'est plus seulement, désormais, la condition générale de toute interprétation : elle est devenue une exigence et une tendance à l'indétermination qui caractérise notre époque et notre culture contemporaine. En effet, la structure dynamique, ambiguë, plurivoque et discontinue, devenue aujourd'hui la fin explicite qui préside à la création de l'œuvre, n'est pas sans un certain rapport avec l'évolution de la science contemporaine. Il est possible, dit-il, d'établir un certain parallélisme entre la révolution copernicienne et l'esthétique baroque, entre l'avènement des géométries non euclidiennes et l'abandon des formes géométriques classiques par les cubistes, ou encore entre l'avènement de la peinture abstraite et l'apparition en mathématiques des nombres imaginaires. Les notions de probabilité, de

2. Umberto Eco, L'Euvre ouverte, Paris, Seuil, p. 25.

3. Ibid., p. 20. 
contradiction, d'entropie marquent la rupture de notre civilisation avec le rationalisme cartésien, alors que l'ouverture et le dynamisme se rattachent à l'indétermination et à la discontinuité de la physique quantique.

Aussi n'est-ce pas un hasard s'il a fallu attendre notre époque pour voir se développer une véritable problématique de l'ouverture. Celle-ci n'est plus seulement la reconnaissance de l'ambiguïté de l'œuvre, elle s'impose comme "un principe de création ${ }^{4}$ " qui met l'accent sur l'infinité et la virtualité des lectures, tout en instaurant un nouveau rapport de communication entre l'artiste ou l'auteur et son public, entre une intention et une réception. L'ouverture se rapproche de "l'Informel " qui mène, selon Eco, «non pas à proclamer la mort de la forme mais à en forger une notion plus souple, à concevoir la forme comme un champ de possibilités ${ }^{5}$ ". L'informel n'est pas le règne du chaos interprétatif. Il reste soumis à une dialectique liant l'œuvre et l'ouverture des lectures, une dialectique qui se pose comme un "seuil " préservant l'œuvre de devenir " un bruit et une réception qui n'est plus que délire solipsiste ${ }^{6}$ ".

En ce sens, nous pouvons dire que l'œuvre de Khūrī est bel et bien ouverte. Les narrateurs successifs de ses romans prennent d'avance position contre une fin nécessaire et prévisible. Le narrateur rapporte un récit lui-même relaté par des personnages différents. Les versions multiples échouent à reconstituer l'intégralité du récit. Elles se contredisent souvent entre elles sans que cette contradiction aboutisse à l'élimination d'une version au profit d'une autre. À cela s'ajoutent la transmission orale du récit, les trous de mémoire, la projection du présent dans le

\footnotetext{
4. Ibid., p. 18.

5. Ibid., p. 138.

6. Ibid., p. 136.
} 
passé, le travail de l'imaginaire, qui sont autant d'éléments qui viennent continuellement remodeler l'histoire. Toujours est-il que la contradiction n'est plus problématique et n'est plus amenée à être surmontée ; elle persiste car elle est acceptée comme faisant partie de l'ordre des choses.

Pour soumettre son œuvre à cette dynamique de l'ouverture, Khūrī recourt à plusieurs procédés comme la mise à mort du personnage, l'association d'idées, l'enchâssement et le collage.

\section{La mort du personnage, prélude à la libération du récit}

La mort est la condition sine qua non de l'ouverture : la prolifération des récits est rendue possible par la mort du personnage dont on raconte l'histoire. L'ouverture est entendue ici dans le double sens de commencement et de libération. Pour écrire l'histoire, il faut qu'elle soit, dès l'abord, achevée. Pour pouvoir parler d'un personnage, il faut que celui-ci soit, d'emblée, mort. La mort libère la parole. C'est pourquoi les romans de Khūrī commencent par la mort, aussi bien celle du personnage principal que celle des personnages secondaires.

L’ouverture est fondée sur un présupposé théorique perspectiviste ; Khūrī adhère à cette conception, qui récuse les propos unanimistes et ne reconnaît que la multiplicité des points de vue, forcément divergents et incapables les uns et les autres de saisir dans sa "vérité " la totalité de l'objet visé. Non seulement tout est point de vue, mais il n'existe pas de conciliation harmonieuse des points de vue disparates, et toute vérité unique et générale est par principe exclue.

Ce perspectivisme de Khūrī doit beaucoup à L'Être et le néant de Sartre, dont la pensée a eu, dans les années 1950, une forte influence au Liban et dans le monde arabe. Rappelons à cet 
égard que Suhayl Idrīs, le fondateur de la maison d'édition Dār al-ādāb, en traduisant Sartre et Camus en arabe, a largement contribué à diffuser la pensée existentialiste.

Selon L'Être et le néant, la conscience humaine ou le " poursoi ", est scindée, d'où le tragique de sa condition. L'homme ne colle à lui-même que dans la mort. Tant qu'il « existe ", il est projeté en avant de lui-même et est toujours réduit à la réplique de tel ou tel existant. Une fois mort, l'homme bascule dans l'« ensoi ", la coïncidence massive avec soi et devient « une proie du vivant ». La référence à Sartre permet de comprendre pourquoi la mort du héros survient au début du roman et non à sa fin ou même au cours des événements. Étant donné qu’autrui se pose en s'opposant à ma liberté et se dresse en face de moi, instaurant des limites à mon discours, une liberté sans entraves suppose son élimination. À sa mort, l'homme se transforme en objet, il est entièrement à la merci des vivants, prisonnier de leurs regards et de leurs paroles. En commençant par la mise à mort du personnage dont l'histoire est narrée, Khūrī écarte toute résistance possible au récit dont il fait l'objet et donne plein pouvoir au narrateur.

Al-Wujūh al-bayḍa $\bar{a}^{\prime}$ commence par le meurtre de Khalīl Ahmad Jābir : «Un meurtre atroce dans le quartier de l'Unesco. » (p. 9)

Riḥlat Ghandī al-șaghīr énumère, dès la première page, les noms de tous les protagonistes du roman en affirmant qu'ils sont tous morts :

Il y a Abdu-l-Karīm, Alice, Su'ād, le prêtre Amīn, Davis l'Américain, le chien, le coiffeur, Spīrū Abū- Țāqiyya, Salīm Abū'Uyūn, le docteur 'Āṭif, le docteur Nasīb, l'imprésario Abū Jamīl, le lieutenant Țannūs al-Zaîm, le second chien, Madame Nuhā 'Awn, Ḥuṣn, Rālf, Ghassān, Lilyān Șabbāgha, Qusțanținn Mukhbāț, Abū Saîd al- Munlā, le Chef suprême, Fawziyya, 
Ḥuṣn Ibn 'Abdulkarīm, 'Abdulkarīm Ibn Ḥuṣn, le chrétien syriaque Habīb Malkū, le fils al-Itānī, al-Askarī, etc., la Russe blanche, etc. Ils sont tous morts. Ils sont tous allés vers cet " etc. » et ne sont plus revenus. (Rihlat, p. 7)

Alice commence à raconter l'histoire de Ghandī par sa mort : "Alice dit qu'il était mort. " (Rihlat, p. 12) Alice mourra à son tour, laissant le narrateur seul face à des personnages-objets, devenus de simples "noms " dont il peut disposer désormais à sa guise. Mamlakat al-ghurabä ne faillit pas à la règle : "Les héros meurent, tandis que nous, nous racontons leurs histoires." (Mamlakat, p. 14)

Majma al-asrār commence par la mort de la tante Sāra, par celle d'Ibrāhīm Nașșār et par la disparition de Norma: "Maintenant que l'histoire est achevée par la mort de ses héros, les gens ont le droit d'en connaître le mystère. " (Majma; p. 9)

$B \bar{a} b$ al-shams obéit également à ce principe : la mort est au commencement afin que l'histoire soit possible. Le coma de Yūnus le transforme en objet et délivre de toute entrave la parole de Khalīl : « Il fallait que tu meures dans ce lit froid pour devenir une histoire. » (Bāb, p. 43) Et l'on apprend du narrateur que l'auteur palestinien Ghassān Kanafānī avait eu l'intention d'écrire l'histoire de Yūnus, qu'il lui avait rendu visite vers la fin des années 1950, avait pris des notes, mais que l'histoire n'avait pas été écrite; et Khalīl de dire à son ami comateux : "Sais-tu pourquoi ? Le jour où il était venu te voir, vers la fin des années cinquante, ton histoire n'était pas encore une histoire. » (Bāb, p. 69) Le Yūnus vivant d'alors, par opposition au Yūnus comateux de la fin, se posait du simple fait de son existence comme conscience opposée à celle du narrateur, entravant la liberté de ce dernier de modifier son histoire comme bon lui semble: "La liberté, père, c'est d'avoir le pouvoir de se tromper. Maintenant je me sens libre car, avec toi, je fais des erreurs à ma guise, je rectifie 
quand je veux, je raconte à n'en plus finir. » (Bāb, p. 336) L'être humain a tendance à présenter à l'autre un seul visage, alors qu'il en possède plusieurs. La mort du personnage en fait jaillir la multiplicité car, comme le dit Khalīl, « le personnage ne peut plus intervenir et essayer de faire de sa vie une de ligne homogène ». ( $(B \bar{a} b$, p. 60$)$

Ka'annahā nâ'ima (Comme si elle dormait) réitère le même principe : Manșūr s’adressant à son épouse Mīlyā, lui dit : « Nous pensons que l'histoire de l'homme commence quand il naît, mais c'est faux, ma chérie. L'histoire commence quand on meurt ou quand on est assassiné. " (Ka'annahā, p. 215)

Khūrī explicite le point de vue de ses narrateurs successifs : "Pour moi tous ces personnages, toi et moi y compris, sont quelque chose d'indéfini, qu'on ne peut pas capturer; on ne peut se saisir de l'homme qu'après sa mort, tu peux alors faire de lui tout ce que tu veux, mais tu ne peux te saisir de l'être vivant, même lui est incapable de se saisir de lui-même ${ }^{8}$. " Ou encore : "Ma narration de la mort est un prétexte pour raconter l'histoire, non l'arrêter, parce que la mort n'est pas celle du narrateur mais celle du personnage dont on raconte l'histoire ${ }^{9}$."

La mort se dévoile chez Khūrī comme la seule "vérité " dont on ne peut douter: "Mis à part la vérité de sa mort (haqīqatu mawtihi), tous les renseignements disponibles à son égard ne sont pas sûrs ", dit le narrateur dans Mamlakat al-ghurabä (p. 68) en racontant l'histoire du moine Jirjī. La façon dont une personne va à la mort permet non seulement de reconstituer son

7. Ilyās Khūrī, Ka 'annahā nā 'ima, Beyrouth, Dār al-ādāb, 2007. Traduit par Rania Samara, Comme si elle dormait, Arles, Actes Sud, 2007.

8. Ilyās Khūrī, « Filasțīn, Lubnān, al-riwāya wa kayfa tașīr al-ḥikāyāt riwāya » (« La Palestine, le Liban et la fiction: comment les histoires deviennent fiction »), al-Tarīq, nْ 1, janvier-février 2001.

9. Cf. Ilyās Khūrī, Al-Ādāb, nº 7-8, juillet-août 1993. 
histoire, mais d'appréhender une certaine vérité la concernant. Ainsi, Majma' al-asrār explique la condition d'étrangeté de l'Algérien, dans L'Étranger de Camus, par sa mort. La façon dont il a été tué par Meursault permet de relire et de figer son existence entière comme celle d'un " étranger arabe ". De même, d'après le narrateur de ce roman, la mort de Santiago Nasar chez Gabriel Garcia Marquez s'explique par ses origines arabes, le père de Santiago étant un émigré arabe.

Il faut donc bien l'admettre, la mise à mort préalable des personnages libère la parole. Mais quelle parole? Elle sert avant tout la volonté de puissance du narrateur qui procède à une élimination systématique de tout antagoniste susceptible de rivaliser avec lui dans une éventuelle prise de parole. Le narrateur désire être l'unique maître du jeu.

Nous saisissons alors le désir d'absorption qui s'empare du narrateur face à ses personnages. À défaut de pouvoir maîtriser la parole d'autrui, le narrateur l'absorbe entièrement. La relation contenant-contenu dévoile la vision que Khūrī a de l'écriture et qui consiste, en absorbant l'autre, à en faire la chair même du roman. Un exemple de cette assimilation est la relation entre Yūnus et Khalīl dans Bāb al-shams. En racontant son histoire, Khalīl s’approprie Yūnus. Yūnus, qui rappelle le héros biblique Jonas, englouti par une baleine, est avalé par le narrateur. Le roman est un processus d'incorporation. En se nourrissant de son personnage, le narrateur se l'approprie. Il ne lui est plus extérieur mais devient partie intégrante de lui. Il n'existe pas de frontière entre «Soi » et " Autrui ». Vouloir raconter l'histoire propre d'un personnage est un leurre. Le personnage n'existe pas en dehors de la narration, et la narration n'est rien en dehors du processus d'appropriation de la vie du personnage. Et l'on pourrait bien imaginer Khūrī inviter le lecteur, à l'instar de Saleem Sinai dans Les Enfants de minuit, à être à son tour un 
avaleur : «Et il y a tant d'histoires à raconter, trop, tant de vies, d'événements, de miracles, de lieux, de rumeurs, tous entrelacés, une telle imbrication de l'improbable et du terrestre! J'ai été un avaleur de vies; et pour me connaître, moi seul, il va vous falloir avaler également l'ensemble ${ }^{10}$."

Cette forme de découverte de l'altérité est, pour Khūrī, la condition de possibilité de l'écriture. Il raconte, par exemple, que le personnage de Țalāl dans al-jabal al-ṣaghīr (La Petite Montagne) a réellement existé. En écrivant son histoire, lui, Khūrī, est devenu lui-même Țalāl. Toutefois, l'absorption ne se réduit pas à l'appropriation des seuls personnages; elle est une caractéristique inhérente à la littérature qui, ainsi considérée, serait si l'on ose dire une variété d'anthropophagie. Tout écrivain est l'héritier d'autres écrivains. "Tout texte est un intertexte ", selon la formule de Julia Kristeva. La différence entre une bonne et une mauvaise littérature se reconnaît à la capacité de l'auteur d'effacer la trace de ses sources pour, tout en y puisant, créer du nouveau. Khūrī raconte, à ce sujet, la rencontre décisive entre le célèbre poète abbasside Abū-Nuwās et Khalaf al-Aḥmar, un autre poète de Bașra, connu pour sa mémoire phénoménale. Après avoir commencé son apprentissage avec Wāliba ibn al-Ḥubāb, Abū-Nuwās exprime à Khalaf al-Aḥmar son désir de devenir poète. Ce dernier lui demande d'apprendre par cœur mille poèmes. Lorsqu’ Abū-Nuwās revient le voir, fier d'avoir accompli l'immense tâche, Khalaf al-Aḥmar lui dit: maintenant entraîne-toi pour les oublier. À l'instar d'AbūNuwās, Khūrī a compris la leçon de Khalaf al-Aḥmar. L’art de l'oubli, qui coïncide avec la parfaite assimilation, est la condition de la création.

10. Salman Rushdie, Les Enfants de Minuit, Paris, Plon, 1997, p. 14. 


\section{Association d'idées}

L'écriture de Khūrī évolue par associations d'idées. Des souvenirs en appellent d'autres. Des personnages en évoquent d'autres. La parole et la pensée du narrateur n’obéissent pas toujours à une logique clairement identifiable. Le discours se trouve ainsi libéré des contraintes de maîtrise et de lucidité et s'ouvre à l'exercice spontané de la mémoire involontaire. Dans Mamlakat al-ghurabä' le narrateur reconnaît qu'il se laisse emporter par le déferlement de ses idées: "Je n'écris pas une histoire. Je laisse les choses venir. » (p. 21)

Dire qu'une écriture est spontanée ou qu'elle évolue par association d'idées ne signifie pas que l'enchaînement soit arbitraire. Le second chapitre de Mamlakat (p. 21-35) illustre ce procédé. Le nom de Georges Naffāe évoque pour le narrateur celui du poète Gabriel Naffā', tous les deux morts, leur sort provoquant chez lui un même apitoiement. Sur le balcon de Georges Naffā', il voit une poupée. Cette poupée renvoie à Widād, l'épouse de Georges Naffā' qui, comme elle, a la peau très blanche. Le trait commun de la blancheur permet au narrateur d'introduire un nouveau personnage et partant de là un nouveau récit. Puis la chaîne des associations s'interrompt. Le narrateur évoque sans transition Emil Azayev parce que ce dernier lui rappelle Wadī al-Sukhun. Quel est le rapport entre le récit sur la femme blanche et l'apparition de ces nouveaux personnages? On apprendra beaucoup plus loin, vers la fin du roman, qu'Emil Azaev est, comme la femme blanche, d'origine russe. Il est juif et a émigré en Israël. Il se révèle par la suite que Wadī‘ al-Sukhun est également juif, qu'il a vendu ses biens à Georges Naffā' pendant la guerre au Liban puis est parti vivre en Israël. Le personnage de Georges Naffā' condense en lui tous ces récits. Un personnage est ainsi constitué par une myriade d'histoires. 
Les fils qui lient ces récits les uns aux autres sont à peine perceptibles. Le narrateur dit ignorer pourquoi il s'est souvenu de Wadī al-Sukhun lors de sa rencontre avec Emil Azayev. Cependant, certains détails parsemés au cours des pages montrent que le passage d'une idée à une autre ou d'un personnage à un autre n'est pas fortuit, même si le narrateur ne semble pas tout à fait conscient de la logique interne qui préside à l'évolution digressive de son récit, en apparence décousu.

\section{Enchâssement}

L'enchâssement est une technique de discours ouvert qui coïncide avec la forme syntaxique de la subordination. Todorov la résumait ainsi: "L’apparition d'un nouveau personnage entraîne immanquablement l'interruption de l'histoire précédente, pour qu'une nouvelle histoire, celle qui explique le "je suis ici maintenant” du nouveau personnage, nous soit racontée. Une histoire seconde est englobée dans la première; ce procédé s'appelle enchâssement ${ }^{11}$.»

Cette construction en abîme se retrouve particulièrement dans les Mille et Une Nuits, un livre qui influence indéniablement l'œuvre de Khūrī. D'ailleurs, des auteurs arabes modernes ou contemporains revendiquent, de plus en plus, l'héritage de la tisserande des Nuits, à deux niveaux: concernant la forme, et concernant la valeur intrinsèque de la stratégie de parole de Schéhérazade. Le regard sur cette œuvre magistrale de la littérature arabe, longtemps considérée comme populaire, tend à évoluer au XIX ${ }^{\mathrm{e}}$ et $\mathrm{XX}^{\mathrm{e}}$ siècles. Mais c'est surtout à partir des années 1950 que son influence s'étend de plus en plus. Cette légitimation, particulièrement marquée dans la littérature contemporaine, est

11. Tzvetan Todorov, Poétique de la prose, Paris, Seuil, 1971, p. 37 
Elias Khoury - De l'engagement au postmodernisme

due à l'effacement des frontières entre littérature savante et littérature populaire.

Edgard Weber souligne que, dans les Mille et Une Nuits, les récits qui s'enchâssent peuvent " s'enchaîner les uns les autres comme des récits se juxtaposant sur une ligne chronologique, ou bien s'emboîter les uns dans les autres à la manière de récits-gigognes ${ }^{12}$ ».

À la façon des Nuits, les romans de Khūrī commencent par un récit-cadre qui sert de déclencheur aux récits. Une autre caractéristique qui s'apparente aux Nuits est celle de parsemer le récit de fragments poétiques. Les personnages, chez Khūrī, peuvent citer à tout instant des vers issus, pour la plupart, de la poésie préislamique et classique. Ka'annahā nā’ima, par exemple, abonde en vers adressés par Manșūr à sa bien-aimée Mīlyā. Et le narrateur, dans Majma' al-asrār, n’hésite pas à citer des vers du poète préislamique 'Imru' al-Qays. Cependant, et contrairement aux Mille et Une Nuits, l'emploi de ces fragments poétiques, marque la présence de l'auteur dans son œuvre. Sans être pour autant un intellectuel, Manșūr, tout comme l'auteur Ilyās Khūrī, connaît fort bien la poésie arabe classique et n’hésite pas à en faire le commentaire.

Dans Majma al-asrār par exemple, l'apparition d'un nouveau personnage sert d'introduction à un nouveau récit. La narration évolue ainsi :

Voici comment l'histoire a commencé. Ibrāhīm Nassār se rappelait les événements de manière très vague [...]

Ya'qūb raconte [...] Ya'qūb dit [...]

Sāra dit à son neveu (Ibrahīm) que la jeune fille était fiancée à un boxeur, ami de son père, et qu'elle craignait qu'il ne soit tué comme son cousin en Colombie [...]

12. Edgard Weber, Le Secret des « Mille et Une Nuits »: L'inter-dit de Shéhérazade, Toulouse, Eché, 1987, p. 62. 
Ibrāhīm confia à Norma l'histoire des tombes où l'or était enterré; Norma ne le crut pas; elle pensa qu'il inventait ces histoires pour l'épater [...] En vérité, l'histoire telle que la racontait Ibrāhīm, semblait incroyable [...]

Les histoires des bracelets en or qui entouraient les os des avant-bras captivèrent l'imagination de Norma. Elle demandait à Ibrāhīm de l'emmener au village pour chercher les tombes. Il lui dit qu'il ne savait pas où se trouvaient ces tombes, qu'il n’était plus très sûr [...]. (Majma', p. 19-22)

$B \bar{a} b$ al-shams évolue également par emboîtement. Les séquences de ce deuxième chapitre sont introduites de la sorte. Il en est ainsi du reste :

La femme venue de Kuwaykāt a dit que [...]

Ma mère m’a raconté [...]

Āmina m'a raconté toute ton histoire [...]

Dr Amjad a dit [...]

$\mathrm{Tu}$ as dit [...]

Umm Ḥasan a dit que [...] (Bāb, p. 13-30)

Chaque nouveau personnage peut introduire une nouvelle histoire, ou alors rectifier ce qui avait été dit auparavant, en y apportant de nouveaux éléments ou un nouvel éclairage. Les histoires naissent ainsi les unes des autres. Weber remarque que " la technique d'enchâssement ressemble à une forme d'avalage du conte par le conte, dont l'archétype est celui du poisson avalant Jonas ${ }^{13}$ ». Il n'est pas anodin à cet égard que le personnage principal de $B \bar{a} b$ al-shams, roman de Khūrī écrit entièrement sous la forme de l'enchâssement, soit Yūnus qui est l'équivalent de Jonas, le héros biblique avalé par la baleine.

La structure de l'enchâssement brise la linéarité du récit, permet de lutter contre le cours du temps et de conjurer la mort. La

13. Ibid., p. 65. 
Elias Khoury - De l'engagement au postmodernisme

profusion des contes est la preuve que le narrateur, tel Schéhérazade, est un conteur sans égal.

La multiplicité des récits et par conséquent la pluralité des langages, l'emboîtement, l'imbrication du réel et de l'irréel, l'oralité, la vérité qui habite le conte, la part importante de l'imaginaire populaire, le souci de distraire, le statut libérateur accordé à la parole - traits dominants de la narration chez Khūrī caractérisent également l'univers des Nuits. Toutefois, les récits chez Khūrī ne sont structurés par aucun dénouement et ne sont promus à aucune exemplarité. La réappropriation des Mille et Une Nuits ne dénote nullement un retour nostalgique aux sources, ni une revalorisation du passé. "Shahrazad postmoderne », le titre d'une étude de Ferial Ghazoul, professeur à l'université américaine du Caire, est éloquent. Ghazoul analyse trois ouvrages fictionnels postmodernes, intimement liés, selon elle, aux Mille et Une Nuits, bien que de façons différentes: "Dunyâzadiad", dans Chimera de John Barth, The Arabian Nightmare (1983) de Robert Irwin et Haroun and the Sea of Stories (1990) de Salman Rushdie. Elle conclut : « Sur notre scène littéraire postmoderne, avec la mise en valeur de la métafiction et de la fiction autoréflexive, les Mille et Une Nuits, qui mettent en œuvre ces deux tendances, sont devenues une source commode d'imitation, d'adaptation ou d'inspiration ${ }^{14}$. " La position de Ghazoul est partagée par Ahmed Cheniki: "Les contes des Mille et Une Nuits sont une source inépuisable pour les auteurs arabes, qui reprennent souvent les procédés narratifs des récits et conservent parfois les caractères des personnages et certaines situations tout en produisant un texte original, actuel ${ }^{15}$. " Tout

14. Ferial Ghazoul, « Shahrazad postmoderne », in Les Mille et Une nuits en partage (actes du colloque, 25 au 29 mai 2004), Aboubakr Chraïbi (éd.), Arles, Actes Sud, 2004, p. 162.

15. Ahmed Cheniki, «Les Mille et Une Nuits, la culture populaire et le théâtre 
emprunt est une réappropriation. L'actualité des Mille et Une Nuits est une "actualisation", dirait Hans Robert Jauss. L'actualisation est un autre nom de l'esthétique de la réception définie comme le principe critique de l'accueil et de la réintérprétation d'un texte, consistant à y voir, en permanence, « l'actualité de ce qui n'est plus actuel ${ }^{16} »$.

\section{Collage}

Le narrateur-auteur de Mamlakat al-ghurabä' se sent proche de Salman Rushdie, auteur et essayiste britannique d'origine indienne. Lors d'une rencontre à Londres en 1988, Rushdie lui a offert un exemplaire des Versets sataniques et ils ont discuté de Midnight's children (1980), un roman très connu de Rushdie: "J'étais, à l'instar de beaucoup de lecteurs, fasciné par le récit des trous de la couverture, écrit par Salman Rushdie dans les Enfants de minuit " (Mamlakat, p. 98).

Ghani, un grand propriétaire terrien aveugle, fait appel au docteur Aziz Adam pour qu'il soigne Naseem, sa fille souffrante. Introduit dans la chambre de la malade, le docteur Adam se retrouve en face d'un drap, tenu aux deux bouts par deux femmes robustes et ressemblant à un grand tableau blanc. Il finit par remarquer un trou au milieu du drap. Comme il ne voit toujours pas la fille, il demande au père où elle se trouve. Ghani lui explique que sa fille est honnête et ne montre pas son corps aux étrangers. Par conséquent, il doit l'ausculter par le trou du drap. Naseem tombe souvent malade; les visites du docteur deviennent plus fréquentes. À chaque fois, on lui offre une partie de son corps à

arabe », in Les Mille et Une Nuits et l'imaginaire du xxe siècle, Christiane ChauletAchour (éd.), Paris, L'Harmattan, p. 116.

16. Hans Robert Jauss, Pour une esthétique de la réception, Paris, Gallimard, 1978, p. 121. 
travers le trou. Le docteur Aziz constitue ainsi dans son esprit un portrait de Naseem, un portrait décrit comme « un assez mauvais collage des différentes parties qu'il avait auscultées " (les Enfants de minuit, p. 43). C'est pourquoi il l'appelle « la femme morcelée ».

Dans Mamlakat al-ghurabā', l'auteur-narrateur évoque l'histoire de la patiente en morceaux et fait un rapprochement entre l'histoire du docteur Aziz et celle, rapportée par Maryam, du docteur Luṭĩ qui, lui, soignait ses patientes au moyen d'une statuette. Entre le docteur Aziz et sa patiente est tendu un drap troué. De la même façon, la vision du médecin chez Khūrī est obstruée par un voile. Le narrateur se sert de cette histoire pour montrer la façon avec laquelle il explore son récit sous des angles réduits. Comme dans le cas de Naseem, il est devant une histoire morcelée, qu'il ne peut voir dans son ensemble et qu'il ne peut reconstituer, dès lors, que par un " mauvais collage ".

La technique de reconstitution par collage à travers le travail de la mémoire rapproche Khūrī de Rushdie.

Par ces différents procédés, Khūrī dote ses récits d'une dynamique ouverte, plus à même que toute autre forme de répondre aux incertitudes qui tiraillent aussi bien son art que l'époque à laquelle il vit.

\section{Problématisation de l'autorité fictive: entre déconstruction et instauration. L'exemple de Majma' al-asrār (Le Coffre des secrets)}

Le choix de la narration ouverte marque une forme de synchronisation avec notre temps en reflétant une époque ébranlée dans ses certitudes et, par conséquent, plus modeste. Il n'en reste pas moins que l'œuvre de Khūrī présente à nos yeux une certaine tension indicatrice d'une problématisation de l'énonciation narrative. Afin d'illustrer la tension à l'intérieur du texte entre 
perspectivisme et autorité fictive, on s'appuiera sur la lecture faite dans Majma' al-asrār de Chronique d'une mort annoncée de Gabriel Garcia Marquez, prix Nobel de littérature (1982). Dans ce roman de Khūrī, l'autorité narrative comme « figure responsable de l'ensemble du texte " est d'emblée mise à mal par un récit sans cesse repris. Sur seize chapitres, onze commencent par la phrase : "L'histoire a commencé ainsi ». Cette démultiplication permet de présenter les faits de manière à les rendre invraisemblables. Toutefois, la voix narrative, quand bien même plurielle, est dotée d'une force persuasive qui ne manque pas de susciter l'adhésion du lecteur à l'histoire racontée. La lecture du texte de Marquez, dans la mesure où elle s'attache à légitimer une certaine interprétation excessive, est un exemple de ce qui pourrait être considérée comme une surinterprétation.

\section{Relecture de Chronique d'une mort annoncée de Marquez}

Chronique d'une mort annoncée raconte le meurtre dans un village colombien, d'un certain Santiago Nasar — qui se trouve être un émigré d'origine arabe. Santiago y est décrit comme étant à la fois immigré et étranger. Quant à sa mort, elle est qualifiée d'étrange : "Le plus étrange c'est la mort de cet étranger. " (Majma', p. 37). Le prétexte de son assassinat est une vengeance d'honneur ; mais quelle en est la vraie raison? Majma' a al-asrār se risque à affirmer qu'il est mort, précisément, à cause de ses origines arabes : l'Arabe est l'étranger par excellence, condamné d'avance à la mort et à la persécution à cause de son origine. Cela interpelle dans le cas de Camus où l'Arabe recouvre le musulman (arabo-berbère) colonisé qui, en tant que tel, est marqué d'étrangeté, ou en tout cas dépouillé d'identité sous le regard européen. 
Majma' al-asrār émet l'hypothèse que des liens familiaux existent entre Santiago Nasar, le personnage du roman de Marquez, et la famille Nașșār dont celui de Khūrī retrace la généalogie. Il est vrai qu'on constate une différence dans la graphie et la prononciation du nom qui, en arabe, intègre une double consonne. Mais cette différence s'explique (une explication qui produit un effet supplémentaire de vérité) par l'incapacité de prononcer correctement certains sons propres à une langue donnée au passage dans une autre langue...

Dans le roman de Marquez, le père de Santiago s'appelle Ibrahim Nasar. Chez Khūrī, Ya'qūb est le fils d'Ibrāhīm Nașșār. Et le narrateur explique que Ya'qūb veut dire Santiago en arabe. Ya'qūb donnera à son fils le nom de son père Ibrāhīm. Santiago qui traduit Ya'qūb, ou Jacques, en référence à Saint-Jacques, pourrait traduire la volonté des émigrés de concilier la fidélité au prénom et la soumission à une nouvelle religion. Dans le roman de Khūrī, le tableau est plus complexe car il pourrait s'agir aussi, pour ces émigrés, de renouer avec leur propre religion, étant donné que les Nașșār étaient chrétiens avant d'être musulmans...

Les Arabes continuent à donner le nom du grand-père au petit-fils et l'on se retrouve ainsi avec des prénoms identiques qui reviennent d'une génération à l'autre au sein de la même famille. Cette coutume révèle l'angoisse de la mort et le désir de perpétuer, à travers la filiation, la mémoire des parents disparus.

La famille Nasar, chez Marquez et Nașșār, chez Khūrī, a une seule et même origine, la guerre ayant éparpillé ses membres, poussant certains d'entre eux à faire le choix de l'émigration : "Revenons à l'histoire de Marquez. Comment l'auteur colombien a-t-il choisi les noms de ses héros? Le nom de Santiago Nasar - Ya'qūb en arabe - a-t-il été choisi au hasard ou est-ce 
que Marquez écrivait à propos du personnage que nous avons rencontré dans cette histoire-ci ? " (Majma', p. 36)

L'hypothèse de l'appartenance des personnages des deux romans à une même famille se confirme d'ailleurs par leur ressemblance physique. Ibrāhīm Nașșār, fils de Ya'qūb Nașșār, ressemble à Santiago Nasar tel qu'il est décrit chez Marquez :

Santiago Nasar qui semblait porter des vêtements en aluminium et marcher comme un fantôme " était maigre, pâle et avait hérité des sourcils arabes et des cheveux frisés de son père ». Ce fantôme-là ressemble au nôtre, car Ibrāhīm, tel que Norma l'avait décrit à ses amies d'école, était maigre et pâle, avait les cheveux frisés et les sourcils épais. Norma n'a pas dit pas que c'étaient des sourcils arabes, parce qu'elle-même était arabe. Ce fantôme-ci ressemble à ce fantôme-là [...]. (Majma', p. 37)

Selon Majma al-asrār, la famille Nașșār, originaire d'Izri' dans le Hauran, s'appelait 'Ațī. Suite à un crime, les membres de la famille se réfugient à Qānā au Liban-Sud et se convertissent à l'islam. Lorsque l'aïeul, Ibrāhīm Naș̣̦ār, arrive à Qānā lors d'une seconde vague d'exode, il refuse de changer de religion et s'établit à 'Ayn Kisrīn, dans la montagne libanaise. De 'Ayn Kisrīn où sont perpétrés en 1860 des massacres entre chrétiens maronites et féodaux druzes, les petits-fils d'Ibrāhīm Nașșār, ou plutôt ceux d'entre eux qui ont échappé au bain de sang, subiront un autre exode qui conduira son petit-fils, Ibrāhīm Nașșār, à Achrafieh, à Beyrouth. Il y construira en 1889 une grande maison où il s'établira avec sa famille, tandis que les autres membres du clan Nașșār décideront de partir définitivement et émigreront en Colombie.

Santiago Nasar, implacablement assassiné dans le roman de Marquez par les frères Vicario, est, d'après cette généalogie, un cousin des Nașạār dont l'histoire est racontée dans le roman de 
Elias Khoury - De l'engagement au postmodernisme

Khūrī. Dans Majma' al-asrār, Ya'qūb Nașạār s'apprêtait à rejoindre sa famille en Colombie ; l'arrivée d'une lettre mystérieuse annonçant la mort de leur cousin à Bogota mène à l'annulation du projet d'émigration.

Ces deux familles, qui partagent les mêmes origines, n'ont pas que des liens de parenté, elles sont liées également par leur destin. Et c'est leur origine commune qui explique, selon Majma al-asrār, la mort étrange des membres de cette famille. Le roman apporte ainsi une réponse à la question laissée ouverte dans l'ouvrage de l'auteur colombien : pourquoi l'assassinat de Santiago Nasar, ce Colombien d'origine arabe, n'a-t-il pu être évité ?

" Jamais mort ne fut davantage annoncée " (Chronique, p. 53), dit pourtant le narrateur dans le roman de Marquez. La plupart des gens du village savaient que les frères Vicario allaient tuer Santiago Nasar. Leur sœur Angela avait été répudiée par son mari Pedro San Roman à la veille de leurs noces, lorsqu'il avait découvert qu'elle n'était pas vierge. Sans hésitation, Angela livre à ses frères le nom du coupable qui n'est personne d'autre que Santiago :

Elle avait à peine hésité à prononcer le nom. Elle le chercha dans les ténèbres, elle le trouva du premier coup d'œil, parmi tous ces noms qu'on peut confondre, aussi bien dans ce monde que dans l'autre, et elle le cloua au mur, avec son adresse de chasseresse comme un papillon dont le destin était écrit depuis toujours. "Santiago Nasar ", avait-elle dit. (Chronique, p. 49)

Pablo et Pedro Vicario, que leur tempérament ne prédestinait pas à une pareille violence, se retrouvent contraints de venger l'honneur de leur sœur. Ils sillonnent les rues du village, couteaux à la main, répétant à qui veut l'entendre qu'ils s'apprêtent à tuer Santiago Nasar, espérant par miracle que quelqu'un viendrait les arrêter ou avertir le coupable avant qu'il ne soit trop tard. Rien de 
tel ne se produit. Santiago va à sa mort certaine et sera sauvagement éventré par les frères Vicario devant la porte principale de sa maison sans nulle preuve tangible de sa culpabilité. Le mort, qui aurait pu répondre de son innocence, n'a pas eu voix au chapitre et a emporté la réponse dans la tombe.

La mort de Santiago en Colombie déclenche, dans Majma al-asrār, une réflexion sur les raisons inavouées de cet assassinat ainsi que sur la vanité de vouloir échapper à son destin :

Mais pourquoi Santiago Nasar a-t-il été poignardé de cette manière? Est-ce parce qu'il a défloré Angela Vicario, comme elle l'a prétendu devant son époux Bayardo? Pourquoi Angela a-t-elle désigné Santiago comme l'auteur de cet outrage? Et pourquoi les gens se sont-ils tus? Ils étaient tous au courant que Santiago allait être poignardé ce matin-là, pourquoi nul ne l'a averti? Est-ce parce qu'ils n'ont pas cru — ou ont prétendu n'avoir pas cru - au projet criminel des jumeaux ou est-ce que parce qu'il était arabe, qu'ils l'ont abandonné à la fatalité de son destin? [...] Est-ce parce qu'il était un étranger? L'exil signifie-t-il la mort? (Majma', p. 37)

Et de répondre :

Santiago Nasar était cet étranger, désarmé et solitaire. Son exil c'était la langue qu'il ne parlait pas et le crime qu'il n’avait pas commis. (p. 45)

Qu'il soit coupable ou non n'est pas la véritable question. Comme l'avait écrit le narrateur chez Marquez, sa mort s'abat comme un "destin qui était écrit depuis toujours " (Chronique, p. 49). Son sort n'est donc pas dicté par l'aveu d'Angela, ni par le devoir de vengeance des frères Vicario. Son entourage n'a pas pu ou voulu le sauver. Son destin est scellé de tout temps. Sa mère, connue pour ses dons infaillibles d'interprétation des rêves, n'a pas su déchiffrer ceux de son fils et lui épargner la mort. Et quand bien même les signes auraient-ils été correctement 
interprétés, le meurtre aurait-il pu être évité pour autant? L'exemple d'Edipe, livré sans défense à la fatalité malgré les révélations de Delphes, n'est-il pas, à cet égard, éloquent ? Cette idée de destin inéluctable sera reprise par Khūrī, qui mettra davantage l'accent sur la condition arabe : l'Arabe est cet étranger poursuivi où qu'il soit par le tragique de sa condition.

D'ailleurs, la mort d'Abduljalīl Nașșār, un des descendants des Nașșār dans Majma' al-asrār, assassiné alors qu'il tentait de fuir les massacres perpétrés dans la montagne libanaise en 1860, renvoie au meurtre de Santiago Nasar en Colombie. 'Abduljalīl meurt de la même façon que Santiago, le premier s'affale sur le sol de son pays, le second à l'étranger :

Il [Ibrāhīm] pensait y [dans le coffre] trouver aussi cette lettre mystérieuse à propos de l'assassinat de Santiago Nasar que le romancier colombien Gabriel Garcia Marquez décrirait comme il aurait pu décrire le meurtre d'Abduljalīl sur la place d'Ayn Kisrīn pendant l'horrible massacre de 1860, lorsque Abduljalīl Nașșār avait chancelé une heure sous les coups des dagues, avant de voir ses entrailles se déverser par terre et tenter de les ramasser, puis de s'affaler dessus et de rendre l'âme. (Majma', p. 185-186)

En montrant que les Nașșār n’ont pu échapper à la mort quels que soient le temps, le lieu et les circonstances dans lesquels ils ont vécu, le roman établit un rapport de cause à effet entre le nom de la victime libanaise qui est indicateur de ses origines arabes et la mort qui la poursuit comme un destin implacable. "Le nom est le destin " (Majma', p. 35), lit-on. Mais «ton nom n'est pas ton destin. C'est ton destin qui donne du sens à ton nom » (Majma', p. 36), affirme le narrateur un peu plus loin. La boucle est bouclée. À l'origine était la mort, et la mort est venue confirmer qu'ayant de telles origines, un Nașșār ne pouvait mourir autrement. En Colombie, cet étranger libanais est un intrus 
qui dérange. Sa mort était nécessaire pour que la sérénité soit rétablie dans le village.

Il ressort également de Majma al-asrār que non seulement le sentiment d'étrangeté ne naît pas suite à l'émigration, mais précède le départ et le provoque. Dans le cas plus spécifique du Libanais, celui-ci ne se sent pas étranger parce qu'il a émigré et se retrouve solitaire, mais émigre parce qu'il se sent étranger chez lui. L'étrangeté chez Khūrī est une condition existentielle liée à un contexte sociopolitique instable, sujet à des guerres à répétition, qui empêche le Libanais de s'enraciner et de se reconnaître dans son territoire. Il se trouve, par conséquent, contraint de vivre avec le sentiment d'être renié, abandonné, massacré par ses compatriotes quand il n'est pas carrément astreint à l'exil et à l'errance. Le premier degré de l'exil, celui vécu chez soi, annonce le deuxième, celui vécu à l'étranger. La leçon à tirer est que celui qui fut d'abord abandonné par les siens est maudit et qu'aucune terre étrangère ne peut le sauver.

\section{Surinterprétation ou narration inventive?}

Le choix des figures de l'étranger dans Majma' al-asrār correspond-il à un jeu de miroir, tel que nous le fait croire un narrateur avisé ? Le narrateur ne cautionne-t-il pas sa propre lecture de Marquez?

Marquez, lui, utilise un " discours à double entente ». Il s'agit de "l'utilisation d'énoncés qui offrent deux lectures possibles tout à fait opposées, ou du moins sensiblement différentes ${ }^{17}$ ". Dans Chronique d'une mort annoncée, la question de la culpabilité de Santiago reste ouverte. Impossible, d'ailleurs, de tirer parfaitement au clair les raisons qui se cachent derrière cet

17. Pierre Bayard, Qui a tué Roger Ackroyd?, Paris, Minuit, 1998, p. 53. 
assassinat. D’une part, le crime est reconstitué vingt-sept ans plus tard, la mémoire érodée laissant la place aux interprétations multiples et, d'autre part, les témoignages recueillis sont contradictoires et peu crédibles. En plus, Marquez offre deux lectures possibles, l'une rendant Santiago coupable et l'autre le présumant innocent, et engendre de la sorte de l'indécidabilité. La vérité est à la fois déguisée et exhibée; chaque phrase du texte peut se lire de deux manières différentes, selon la solution ultime qu'on voudrait faire prévaloir. Par contre, dans Majma' al-asrār, malgré les multiples figures que prend l'étranger, une seule lecture prévaut: l'Arabe est massacré non pour un crime qu'il aurait commis, mais parce qu'il est cet étranger condamné d'avance à être sacrifié. Or, Santiago vivait-il en Colombie comme un étranger ? N'est-il pas possible qu'il soit, après tout, le véritable coupable? La condition d'étranger de Santiago et son innocence sont deux thématiques majeures privilégiées dans Majma al-asrār et vont même de pair. Certains détails concernant Santiago, relevés d'ailleurs dans Majma al-asrār, trahissent ses origines arabes. Il ressemble physiquement à son père : " Il était svelte et pâle, avec les paupières arabes et les cheveux frisés de son père " (Chronique, p. 12) et "ils parlaient entre eux en arabe, mais jamais devant Placida Linero, pour qu'elle ne se sentît pas exclue "(Chronique, p. 13). Cependant, mis à part ces détails, rien dans le roman de Marquez ne dit qu'il se ressentait comme un étranger, bien au contraire. Il maîtrise aussi bien l'espagnol, la langue de sa mère. Il vit, non comme un marginal en difficulté d'intégration, dans une zone limitrophe au village avec la communauté arabe, mais dans le village même. Il est décrit comme un "homme de cœur", "gai " (Chronique, p. 13) et "plein de fric " (Chronique, p. 57). Il appartient à la deuxième génération, a tout d'un homme ayant réussi et est fiancé à Flora Miguel, jeune fille de bonne famille, pas à une Arabe : 
Les Arabes formaient une communauté d'immigrants pacifiques; ils s'étaient installés au début du siècle dans les villages des Caraïbes, même les plus pauvres et les plus lointains, et y étaient restés pour vendre des nippes de couleurs et des babioles de fête foraine. Ils étaient unis, travailleurs et catholiques. Ils se mariaient entre eux, [...] n'affichant qu'une passion tempétueuse: les cartes. Les plus âgés continuèrent à parler l'arabe de leurs campagnes natales et le conservèrent intact en famille jusqu'à la deuxième génération, mais ceux qui suivirent, à l'exclusion de Santiago Nasar, écoutaient leurs parents s'exprimer en arabe et leur répondaient en espagnol. (Chronique, p. 81)

Majma al-asrār considère la langue arabe que Santiago continue à parler, contrairement à ceux de sa génération, comme une preuve irrévocable qu'il reste un étranger aux yeux de la société d'accueil. Cette thèse, vraie en partie, exclut pourtant le rapport à la langue maternelle, un atout majeur d'intégration réussie.

Le narrateur dans Majma al-asrār considère le nom de la victime comme une piste privilégiée permettant d'expliquer l'attaque meurtrière dont elle a été la cible. Or, Chronique d'une mort annoncée n'est pas focalisé sur les origines arabes de Santiago. Quant à son prénom, il est assez commun en Amérique latine : il " lui a été donné par sa marraine " (Chronique, p. 26), la mère du narrateur lui-même, une autochtone. Santiago reste dans Chronique d'une mort annoncée un être hybride, un entre-deux.

Qu'en est-il de son innocence? Ne peut-on également penser le contraire ? Le narrateur chez Khūrī commet deux excès d'interprétation par rapport au texte de Marquez. Le premier est de ne voir en Santiago que l'étranger arabe. Le second est d'établir une équation, que rien ne justifie, entre " étranger " et "innocent ». Santiago ne peut-il être à la fois étranger et coupable?

Santiago est décrit chez Marquez comme un grand coureur de jupons, tout comme l'était son père Ibrahim. Victoria Guzman, 
leur cuisinière, rapporte au narrateur qu'elle avait jadis été courtisée par le père. À son tour, le fils essaiera de profiter de Divina Flor, la fille de la cuisinière :

Divina Flor, qui était la fille d'un mari plus récent, se savait destinée aux ébats furtifs de Santiago Nasar, et cette idée l'angoissait à l'avance. "Un homme comme ça, il n'en est jamais né d'autre ", me dit-elle, grasse et fanée, entourée par une progéniture issue d'autres amours. "C'était son père tout craché, lui répliqua Victoria Guzman. Une merde. (Chronique, p. 15)

Et le témoignage de Divina Flor est là :

Divina Flor le précédait pour lui ouvrir la porte, en essayant d'échapper à ses mains vagabondes [...] mais au moment de tirer la barre, elle n'avait pu éviter une fois de plus les serres carnassières de cet épervier. "Il m'a empoigné tout le machin, me dit Divina Flor. C'est ce qui se passait toujours quand il me coinçait seule dans la maison, mais ce jour-là je n'ai pas ressenti la peur que j'éprouvais à chaque fois; simplement, une horrible envie de pleurer. " (Chronique, p. 18)

Pourquoi ce grand séducteur, dont on sait par ailleurs qu'il fréquente les filles de joie, n'aurait-il pas profité d'Angela Vicario, belle fille de famille modeste, voire très pauvre, pour la délaisser par la suite sans aucun remords, comme le font les maîtres et les seigneurs de tout temps avec leurs sujets? L'insouciance de Santiago le jour de son assassinat, ne serait-elle pas, contrairement à ce que pense l'un des habitants du village - et à ce qu'avance le roman de Khūrī - non pas une preuve décisive de son innocence mais, paradoxalement, la preuve de sa culpabilité ? Angela ne méritant aucune considération d'un homme riche et puissant comme lui, il se sentait "intouchable". En livrant son nom, Angela n'aurait tout simplement dit que la vérité. Elle est d'ailleurs une fille honnête. Elle abhorre le 
mensonge. La preuve, c'est qu'au lieu de suivre les conseils de ses amies qui lui expliquaient, la veille de ses noces, comment camoufler sa perte de virginité, elle décide d'assumer les conséquences de son acte et de ne pas tromper son mari: " Je ne fis rien de ce qu'elles m'avaient conseillé, m'expliqua-telle, car plus j'y pensais et plus je me rendais compte que tout cela était une pure saloperie. »(Chronique, p. 90)

Aux tentatives du narrateur de lui arracher un aveu innocentant Santiago, Angela dit : "Cousin, ne cherche pas midi à quatorze heures. C'était bien lui » (Chronique, p. 90). Angela a certes de bonnes raisons de mentir, éventuellement pour protéger un amant auquel elle tient et dont elle sait le danger qu'il courra si elle révèle son identité. Mais elle peut également avoir dit la vérité. Pourquoi obstinément refuser de prendre sa parole en compte?

Une lecture allant dans le sens de la culpabilité de Santiago Nasar est ainsi également possible. Le narrateur, dans Majma al-asrār, serait-il allé "chercher midi à quatorze heures ", comme dit l'infortunée Angela? Il n'est pas exclu que Santiago ait péri non pas à cause de ses origines arabes, mais parce que, suivant les critères de sa société, il était un salaud et que justice devait être faite.

La corrélation entre étranger et victime sert également de prisme d'interprétation à l'Étranger d'Albert Camus. L'étranger, ce n'est plus seulement Meursault étranger à sa propre vie ; c'est aussi l'Algérien gratuitement tué par Meursault : celui-ci est deux fois victime, et de l'anonymat et de l'élimination physique, la première condition anticipant en quelque sorte la seconde. Ainsi s'établit, ou peu s'en faut, une corrélation étroite entre être arabe et victime absolue. Or, on ne sait quasi rien de l'Arabe de Camus. En faire un étranger parce qu'il a été tué sans raison par un étranger français est une thèse intéressante dans la mesure où, 
en inversant la donne, elle éclaire le positionnement politique du narrateur sur les relations tendues entre Orient et Occident. Par contre, faire de cette équation une vérité valable pour l'Algérien et l'Arabe en général est un excès d'interprétation.

La posture du narrateur, consistant à s'avancer par questionnements, n'a rien d'un tâtonnement. 'Abdulmajīd Zarāqiț l'a bien vu dans sa critique de Rihlat Ghandī al-șaghīr. Le narrateur, ditil, est omniprésent et maîtrise parfaitement le déroulement de son histoire. L'égarement et l'aveu d'ignorance qu'il affiche ne sont tels qu'en apparence, et font partie de son jeu narratif:

En réalité, le roman de Ghandī al-ṣaghīr "ne se construit pas au fur et à mesure de l'écriture”, et ceci parce que la narration a pour matière un ensemble d'histoires advenues dans le passé, c'est-à dire qu'elles sont déjà là. Ce que le narrateur fait, et que nous pourrions considérer comme expérimentation, il le poursuit en toute connaissance de cause ${ }^{18}$.

Force nous est d'avouer que, s'engouffrant dans l'infini de la réécriture, le narrateur s’impose comme l’unique maître du jeu.

Le retour au texte de Marquez montre une problématisation de la voix fictive. Le roman peut se lire à la fois sous l'angle d'une légitimation de la posture d'un narrateur fiable attaché à légitimer sa vision, comme sous l'angle d'une déconstruction de l'autorité narrative. Quoi qu'il en soit, une interprétation donnée doit-elle pour autant être refusée au nom d'une éthique ou d'une méthode de lecture ? Eco lui-même admet ${ }^{19}$ que les conjectures concernant l'intention du texte (intento operis) et celle du lecteur

18. 'Abdulmajīd Zarāqiț, Fì binā ' al-riwāya al-lubnāniyya (1972-1992), (" De la construction du roman libanais »), tome 1, Beyrouth, éditions de l'Université libanaise, 1999, p. 215.

19. Umberto Eco, Interprétation et surinterprétation, op. cit., p. 58 
(intentio lectoris) peuvent être infinies et qu' « il n'y a pas une seule conjecture dont on puisse dire qu'elle est "la seule exacte" ". Il opère également une distinction entre lecture " méthodique " et « lecture " inspirée ". La première respecte la structure interne du texte, la seconde, comme son nom l'indique, est plus créative. La lecture " inspirée ", écrit Eco, est « une occasion de transformer ou de donner un nouveau tour à une histoire précédemment racontée ${ }^{20}$ ". Le narrateur, chez Khūrī, s'adonne ainsi à une lecture créative, marquée par le vécu réel des Arabes, qui les accule à se voir et à être vus comme des étrangers. Jonathan Culler, cité par Eco, prend d'ailleurs la défense de la surinterprétation et la considère comme " une qualité que nous devons cultiver au lieu de chercher à éviter ${ }^{21}$ ", étant donné qu'elle peut être plus intéressante et intellectuellement valable que l’interprétation juste et modérée.

20. Ibid., p. 98.

21. Jonathan Culler, in Interprétation et surinterprétation, p. 58. 



\section{3}

\section{Bāb al-shams, Yālū, Ka'annahā nā'ima Trilogie de la Sainte Famille}

Bāb al-shams (La Porte du Soleil) Yālū (Yalo) et Ka'annahā nā'ima (Comme si elle dormait) racontent des périodes de grande crise politique avec ce que cela engendre de désintégration sociale, psychologique, humaine : Bāb al-shams est le récit de la nakba. Yālū a pour sujet la guerre civile libanaise. Ka'annahā nā ¿ma est l'histoire du vécu trouble d'une jeune femme libanaise qui épouse un Palestinien et va habiter avec lui à Jérusalem, où elle assiste aux débuts des conflits en Palestine dans les années 1920. Situés à des périodes différentes, dans des lieux différents et mettant en scène des personnages que rien ne semble rapprocher, ces trois romans se ressemblent, néanmoins, dans leur structure et leur dessein. Ils poursuivent, d'une part, un même projet narratif, rien moins, l'analyse le montrera, qu'une remise en question de la Sainte Famille biblique: Bāb al-shams déconstruit essentiellement la figure du Père; Yālū, celle du Fils, et Ka'annahā nā'ima celle de la Mère. Ils reproduisent, d'autre part, au niveau de la forme narrative, un schéma triangulaire, identique dans chacun de ces trois romans. Cette parenté, aussi bien au niveau du fond que de la forme, nous a amené à les considérer comme une trilogie et à les lire comme un seul et 
même roman. C'est pourquoi nous ne les analyserons pas séparément, mais relèverons les recoupements les plus marquants, afin de mettre en exergue le schéma triptyque sur lequel ils sont construits et la charge critique qu'ils véhiculent envers la Sainte Famille - formée des figures archétypales du Père, de la Mère et du Fils.

Autour de ces trois figures s'élaborent de grands récits. Par " grands récits ", nous n’entendons pas, ici, les métanarrations de légitimation de l'histoire propres à l'Occident au sens développé par Lyotard, mais, plutôt, toute " grande narration " occupant une place dominante dans une société déterminée. Dans le contexte moyen-oriental, ces figures continuent, aujourd'hui encore, à avoir une emprise culturelle sur les représentations individuelles et collectives. Ce sont, justement, les grands récits et les valeurs véhiculées par les figures du Père, de la Mère et du Fils qui sont, dans ces romans, la cible d'une dévalorisation. Une dévalorisation qui reste, cependant, ambiguë, car accompagnée d'une revalorisation. Un point sur lequel nous reviendrons ultérieurement.

\section{Déconstruction de la Sainte Famille biblique}

Le père, la mère et le fils comme vecteurs idéologiques. $B \bar{a} b$ al-shams procède à une déconstruction de l'héroïsme, Yūnus faisant figure de héros en déclin. En coma, vieilli, son combat valeureux pour récupérer la terre perdue est emporté par les ténèbres. Cet héros mort, ou quasi, est nommé "père ». Il est père de la patrie, mais aussi père de famille, père d'Ibrāhīm, père de Khalìl. C'est cette dimension que nous retiendrons.

Ka'annahā nā'ima fait un parallèle entre la personnalité instable et schizoïde de Mīlyā et les périodes de troubles politiques aigus en Palestine: elle est née le 2 juillet 1923, date des 
premières grandes émeutes du début des années 1920, à Jérusalem, à Jaffa et Haïfa contre le mandat britannique et de l'immigration massive des Juifs. Les violences n'ont cessé de s'envenimer et de s'amplifier par la suite. Elle épouse Manșūr le 12 novembre 1947, à la veille de la défaite des Arabes de 1948 et de la perte du territoire palestinien. Elle meurt en couches, le 24 décembre 1948. L'histoire individuelle devient une forme d'allégorie politique. Or, les délires mystiques de Mīlyā sont chargés de représentations religieuses. Elle s’identifie à la Vierge Marie. Pour dormir, elle porte une chemise de nuit longue de couleur bleue. Dans ses rêves, "la femme bleue " lui remet un enfant enveloppé d'un linceul blanc, en allusion à l'enfant Jésus : « La femme bleue, surgie de nulle part, portait dans ses bras un nouveau-né emmailloté d'un linge blanc qui ressemblait à un linceul. Elle le déposa dans les bras de Mīlyā et disparut. Mīlyā était seule, elle portait un petit enfant brun respirant profondément. " (Ka'annahā nā'ima, p. 97) Nous nous focaliserons sur son rôle de mère.

Dans Yālü, nous centrerons notre approche sur la figure principale de Yālū qui, en même temps qu'elle illustre le visage hideux de la guerre civile, est une représentation du fils. Comme figure de la guerre civile libanaise, Yālū ressemble aux autres personnages des romans de Khūrī. Dérangé, étranger et étrange à la fois, il est victime d'une guerre qui transforme en monstres ceux qui sont pris dans son engrenage. En tant que fils, Yālū constitue, avec Yūnus et Mīlya, le troisième pilier de la Sainte Famille.

Famille triangulaire. Bāb al-shams, Yālū et Ka'annahā nā'ima sont identiques sur plusieurs points. La famille triangulaire est l'une des caractéristiques communes à ces ouvrages. Le personnage principal de chacun de ces romans (Yūnus, Yālū, 
Mīlyā) ne vit pas seul, mais fait partie d'une famille ; il est pris dans une structure relationnelle aux trois pôles : le père, la mère et le fils unique. Cette structure familiale ternaire est identique dans chacun de ces romans : elle est formée dans Bāb al-shams par Yūnus, Nahīla et leur fils aîné Ibrāhīm, relayé à sa mort par Khalīl, qui est un autre nom d'Ibrāhīm. Dans Yālū, la même composition tripartite se répète avec le Kohno, le prêtre syriaque qui prendra la place du père absent de Yālū, Yālū et sa mère Gābī. Ka'annahā nā'ima reproduit le même schéma avec les figures de Mansūr, son épouse Mīlyā et leur fils, dont la naissance est prévue le 24 décembre à Nazareth.

La structure triangulaire transcende le cadre de chaque roman pris séparément, chacun mettant l'accent sur l'une des figures. Dans Bāb al-shams, c'est Yūnus le père comateux qui est la figure principale; dans Yâlü, c'est le fils et dans Ka'annahā nā'ima c'est Mīlyā, la mère. La structure triangulaire ainsi potentialisée au niveau de l'ensemble justifie qu'on lise ces titres comme une trilogie en cohérence de vision.

Cette structure est ébranlée, car chacun des membres de la famille souffre d'un trouble identitaire et relationnel. Loin d'être un symbole de cohésion, la famille dans chacun de ces romans est démembrée. Yālū ne connaît pas son père, il vit avec sa mère libanaise, hystérique, et son grand-père, un prêtre syriaque, le Kohno. Yūnus ( $B \bar{a} b$ al-shams) est en exil dans les camps des réfugiés palestiniens au Liban où il a eu plusieurs relations extraconjugales, son épouse Nahīla n'ayant jamais voulu le rejoindre. Mīlyā (Ka'annahā nā'ima), une Libanaise orthodoxe, épouse un Palestinien et part vivre avec lui en Palestine. Il la délaisse pour l'épouse de son frère défunt. Le destin de leur fils " unique " reste inconnu.

Ces figures renvoient aux symboles bibliques. Yūnus est appelé "Père "; c'est ainsi que Khalīl l'appelle dans Bāb 
al-shams. Il porte aussi le nom de Jonas, celui qui, dans la Bible, a été avalé puis recraché par la baleine.

L'histoire de Jonas annonce également la mort puis la résurrection du Christ. C'est d'ailleurs l'une des raisons pour laquelle, lorsque Yūnus s'enfonce irrémédiablement dans le coma, Khalīl l'appelle aussi "fils ». Après avoir été "père ", Yūnus devient " fils ». Cumuler les deux pôles du père et du fils évoque, sur un mode désabusé, la consubstantialité dans le dogme de la Trinité. Le lent passage du "père " au " fils " ne s'opère, en vérité, que par la désubstantialisation du premier au profit du second et, en somme par une inversion des rôles. Suite au coma, le corps de Yūnus rapetisse. Khalīl lui prodigue tous les soins. Yūnus est à sa merci. Cette inversion des rôles signifie la libération de Khalīl de l'autorité du père. C'est à lui maintenant de réinventer la figure du père.

Yālū, lui, est identifié au Christ. Et Mīlyā, dans ses hallucinations schizophréniques, se prend pour la Vierge Marie et donne naissance, le 24 décembre à Nazareth, à un fils unique qu'elle aurait voulu appeler 'İsā, qui est la transcription arabe de "Jésus".

Mise à mort du Père, du Fils et de la Mère. Chacun de ces romans opère la mise à mort d'une figure ancestrale : du père (Yūnus) dans Bāb al-shams, du fils (Yālū) dans Yālū, de la mère (Mīlyā) dans Ka'annahā nā'ima. La mort de ces trois personnages est annoncée dès l'ouverture des romans comme un fait accompli et irréversible. Yālū erre dans le bois où il s'attaque aux couples venus prendre quelques plaisirs clandestins, vole et viole. Il est mis en prison où il subit d'atroces tortures. Le bois et la prison sont des lieux de mort et de perdition. Yūnus est dans le coma. Quant à la mort de Mīlyā qui survient en couches, elle est anticipée par une photo d'elle que son frère accroche au mur comme 
Elias Khoury - De l'engagement au postmodernisme

on fait pour les défunts. La mise à mort de chacun de ces personnages-type s'accompagne d'une désacralisation, la mort ne suffisant pas, seule, à les détrôner ; souvent, au contraire, la mort élève des personnes qui n'ont rien d'héroïque au rang de martyrs et de saints - un exemple récurrent chez Khūrī. S'ensuit, dès lors, la tâche de leur démantèlement par l'ironie et la suspicion. Ainsi effondrées, ces figures ne sont plus d'aucun soutien pour les autres et ne peuvent plus servir de monnaie d'espoir à un monde désormais livré à lui-même, sans fondement.

Yūnus est dans le coma, alité à l'hôpital « Galilée ». Il n’intervient pas dans le champ de l'action; il est pourtant omniprésent, et c'est à lui que s'adresse Khalīl en permanence. La Galilée ne renvoie pas uniquement à la Palestine et le coma de Yūnus n'est pas seulement la métaphore du pays suite à la catastrophe de 1948. Les noms propres, outre le contexte géopolitique auxquels ils sont liés, charrient également un sens religieux. La Galilée est la terre de naissance de Jésus. Khalīl signifie littéralement « l’ami de Dieu " et renvoie à Abraham ${ }^{1}$. Yūnus, l'occupant principal de la chambre est, comme nous l'avons déjà souligné, appelé " père ». D’ailleurs, le seul et unique décor qui orne le mur de la chambre d'hôpital où gît Yūnus est un tableau représentant le nom d'Allah en caractères coufiques. La relation entre Yūnus et Khalīl est une figure de celle du Père et du Fils. La présence du père est vécue sur le mode de l'absence. Son coma évoque le retrait du divin. L'acharnement de Khalīl à maintenir Yūnus en vie exprime le refus d'accepter la mort de Dieu.

\footnotetext{
1. «Ibrahim »: en arabe comme en syriaque, c'est le nom du patriarche biblique Abraham, qualifié par chrétiens et musulmans de Khalil Allah, "ami de Dieu ». Khalil Allah est aussi l'un des surnoms du prophète Mohammed. Selon l'étymologie hébraïque, il aurait le sens de "père d'une multitude ».

« Younès »: Younès est l'adaptation de la prononciation grecque du nom de Jonas, Yanoh dans la Bible, qui signifie « colombe », en hébreu et en araméen. » Cf. Jana Tamer, Dictionnaire étymologique, Maisonneuve et Larose, Paris, 2005.
} 
L'absence du Père est également évoquée à travers l'histoire d'Ibrāhīm, le fils aîné de Yūnus, mort dans des circonstances jamais éclaircies. Les Israéliens l'ont-ils tué ou bien une pierre lui est-elle tombée sur la tête pendant qu'il jouait avec d'autres gamins? Quelles que soient les causes de sa mort, le sentiment que son père n'était pas présent au moment du drame et n'a rien pu faire pour lui taraude Nahīla. Sans autorisation des Israéliens pour le transporter à l'hôpital, situé dans une zone sous leur contrôle, et ne pouvant compter sur l'aide du père de Yūnus, le seul homme dans la maison, mais vieux et aveugle, elle a eu le sentiment d'être abandonnée et impuissante.

Là où le mythe d'Abraham, dans la Bible, accorde une place privilégiée à la foi, Dieu envoyant au dernier moment un agneau qui sera égorgé à la place d'Isaac, sauvant ainsi le fils, $B \bar{a} b$ alshams met l'accent sur l'idée du sacrifice et de l'abandon du fils par le père. Dieu, chez Khūrī, abandonne ses fils et les laisse mourir sans intervenir pour les sauver. Khalìl, lui aussi, a perdu son père lorsqu'il était enfant, assassiné par les Israéliens. Yūnus l'adopte après la mort de son fils Ibrāhīm. Mais voilà que Yūnus tombe dans le coma, le laissant dans le vide. La mort du père entraîne celle du fils ou du moins sa perdition, l’un étant inséparable de l'autre : "Dis-moi, est-ce ainsi l'héroïsme ? Vous abandonnez vos enfants à la peur et au désespoir et vous mourez? Je te l'ai dit, j'ai détesté mon père et vécu seul avec ma grand-mère. Est-ce que tu sais ce que c'est que de vivre dans le vide? " (Bāb, p. 316). Khalīl avait également perdu la trace de sa mère qui s'était enfuie après l'assassinat de son père.

L’idée d'un père indifférent au sort de son fils est également prégnante dans Ka'annahā nā’ima. Mīlyā craint pour son fils et sait qu'elle ne peut pas compter sur Manșūr pour le protéger. Dans un rêve qu'elle fit durant l'accouchement, elle voyait son fils, sous la forme d'un poisson, mourir sous le regard indifférent 
Elias Khoury - De l'engagement au postmodernisme

de son père. Manșūr, serrant dans ses bras la veuve de son frère Amīn, est aveuglé par le désir et ne prête pas attention à son fils agonisant à ses pieds. Le poisson, comme l'agneau, est un symbole du Christ :

Mīlyā courut vers l'enfant brun. Il gisait par terre, le sang coulant de ses yeux. "Que Dieu t’accable ", cria-t-elle à Manșūr. "Est-ce que tu ne vois pas le garçon? " Elle se pencha pour emporter son fils et fuir avec lui, lorsque tout devint noir. Elle se vit nageant dans une eau visqueuse, alors que le petit enfant brun gigotait comme s'il étouffait. Un petit poisson dont la peau grise brillait sous l'effet de l'eau et du sel, étouffait; il ouvrait et fermait les yeux comme s'il demandait du secours. [...] Manșūr s'approcha, prit le poisson mort et le jeta dans la mer. (Ka'annahā, p. 341-342)

Les dernières vingt pages de Ka'annahā nā'ima décrivent Mīlyā en train d'accoucher, complètement déconnectée de ce qui l'entoure, en proie à la douleur et à des hallucinations mystiques. Le moine Țānius est à son chevet ; ils abordent l'histoire d'Abraham et d'Isaac et se demandent si le Christ, qui connaît l'histoire d'Abraham, s'attendait ou non à ce que son père envoie un agneau pour lui épargner la mort, comme si tout le roman n’était écrit qu'en vue de ce tableau final:

Țānius dit que le Seigneur, la paix soit sur lui, est allé à sa mort de plein gré. [...] Elle l'a vu marcher dans les rues de Jérusalem, sur le chemin du Golgotha, portant une énorme croix en bois, entouré des soldats. Il marchait et le fouet lui lacérait le dos. [...] Il regardait au loin et voyait Abraham l'ami de Dieu (Ibrāhīm al-Khalīl) marcher derrière son fils. Isaac portait sur le dos le bois que le père avait préparé pour le sacrifice et ployait en signe d'obéissance.

"Avait-il eu connaissance de l'intention de son père, ou alors le père avait-il caché la vérité à son fils " ? Telle était la question que Jésus de Nazareth avait posée à son père Joseph, le 
charpentier, lorsqu'ils s'étaient assis ensemble et s'étaient réconciliés, après que le père eut avoué à son fils qu'il avait voulu le tuer, mais qu'il avait compris maintenant que c'était la volonté divine.

"Alors tu es comme Abraham, dit Jésus. Tu avais l'intention de me tuer, comme il avait l'intention de tuer son fils pour l'offrir en sacrifice à son Dieu. "

"Mon fils, le père ne tue pas son fils", dit Joseph, le regret se lisant dans ses yeux. "J'hésitais, car mes yeux étaient couverts d'un nuage gris. C'est fini maintenant. Tu es mon fils unique. Un homme peut-il tuer son fils unique?»

«Et lui?»

"Je ne sais pas, mais je pense qu'Abraham ignorait l'existence de l'agneau. Il avait entendu l'ordre de Dieu en rêve et ne pouvait rien faire d'autre. "

" Je t’interroge à propos d'Isaac. » (Ka'annahā, p. 372)

La crucifixion est le point culminant du roman. Le Christ n'est pas représenté comme un symbole lointain, il s'incarne en permanence dans l'histoire. Chaque être livré à lui-même et étranger dans le monde est un crucifié. Chacun porte sa vie comme une croix. Le calvaire des peuples opprimés par les tyrans, au Liban et en Palestine, en l'occurrence, répète également la passion du Christ. Derrière la montée du Christ au Golgotha, se lit, en filigrane, la souffrance d'un pays en plein chaos.

Mīlyā soutient que le Christ, qui connaissait fort bien l'histoire d'Abraham, ne s'attendait pas à être abandonné par Dieu, sinon il ne serait pas allé, sans peur, à la mort. Mais pourquoi a-til été sacrifié ? Le Christ savait-il qu'il était l'agneau ? Questions auxquelles ni Mīlyā, ni le moine Țānius n’ont de réponse :

Le Christ connaissait cette histoire [celle d'Abraham et d'Issac], il l'avait lue un millier de fois, c'est pourquoi, lorsqu'il a été condamné à la crucifixion, il n’a pas eu peur, il savait que 
son père, qui avait envoyé l'agneau pour sauver Isaac de la mort, ne pouvait pas abandonner son propre fils. »

"Mais pourquoi l'a-t-il abandonné? " demanda le moine.

" Je n'en sais rien! C'est toi qui poses la question? C'est à toi de répondre."

"Parce que, comme je te l'ai dit, il l'attendait depuis tout ce temps-là. »

"Mais il ne le savait pas. Non, ne me dis pas qu'il savait. Il pensait qu'il y aurait un agneau, sinon il n’y serait pas allé. » « Je ne sais pas, dit le moine. » (Ka'annahā, p. 376)

Au cri d'angoisse de Mīlyā : " Non, je ne veux pas que mon fils meure. Est-ce que c'est possible ? Est-ce que c'est possible qu'un père tue son fils? " (Ka'annahā, p. 374), fait écho la scène de la crucifixion comme une réponse implacable:

Là-bas, quand ils l'avaient crucifié et lui avaient fait boire du vinaigre. Là-bas, quand ils l'avaient transpercé avec une lance. Là-bas, quand sa mère et ses Marie étaient debout, leurs visages couverts de brouillard. Là-bas, il regarda vers le haut dans l'attente de l'agneau. Mais l'agneau ne vint pas. Ses yeux cherchèrent son père, et le père ne vint pas. (Ka'annaha $\bar{a}$, p. 388-389)

Mīlyā, revoyant dans son rêve la montée du Christ au Golgotha, comprend que son fils sera sacrifié et que sa prière, transmise par la nonne Mīlāna: "Dieu, épargne-nous le sang ", ne sera pas exaucée. Elle entend les cris d'un nouveau-né et sent l'agneau ramper sur sa poitrine. Elle essaye d'ouvrir les yeux pour se réveiller de ce long rêve, mais n’y parvient pas; elle réalise alors qu'elle est en train de mourir.

Le Christ, dans le roman, ressemble à Mīlyā telle qu'elle se voyait la nuit; il est un jeune homme frêle, aux cheveux noirs, bouclés et aux yeux verts. L'enfant qu'elle a mis au monde seraitil un nouvel agneau? Tout nous laisse penser cela. 
Le roman rompt avec la conception d'un Dieu paternel, protecteur, porteur de soutien et d'espoir. Le Dieu d'Abraham n'est plus le socle de la foi. Aujourd'hui, il est vieux, malade, indifférent, lointain, affaibli et impuissant. Pouvons-nous y voir un indicateur de la fin du patriarcat, de son affaiblissement en milieu oriental et de la montée en puissance du pôle féminin?

Toujours est-il que l'image d'un père absent affecte le fils et le désoriente. Il sera perdu à son tour. C'est à partir de cette idée, introduite dans $B \bar{a} b$ al-shams, que la perdition de Yālū est anticipée.

Yālū, comme Ibrahīm le fils de Yūnus et comme Khalīl dans $B \bar{a} b$ al-shams, ne connaît pas son père légitime. Georges Jal'ū a décidé d'émigrer en Suède alors que sa femme était enceinte. Il est parti sans jamais revenir ni donner de ses nouvelles.

Cette configuration (père absent, relayé par un substitut) semble se retrouver dans Ka'annahā nā'ima, si l'on considère Iskandar comme le fils légitime de Manșūr et non comme le fils de Mūsā, tel qu'il est présenté dans le roman. Son oncle maternel, Mūsā, l'aurait recueilli à la mort de sa mère, sans lui révéler la vérité. Le roman reste évasif sur le sujet d'Iskandar et ne dit rien sur sa naissance et son enfance. Et, hormis une seule apparition où il vient apporter à manger à sa grand-mère malade, rien ne filtre sur sa vie. L'on apprend seulement, et bien plus tard, qu'il est devenu journaliste. La supposition que Mūsā serait le substitut du père légitime n'est à aucun moment explicitement suggérée. Aucun signe, non plus, ne permet de la démentir. Bien au contraire. Manșūr lorgnait sur Asmā, l'épouse de son feu frère Amīn, tué à Jaffa. Sa mère faisait pression sur lui pour qu'il vienne habiter la maison familiale et s'occuper de ses neveux. Et "Mīlyā constatait que tout avait changé depuis la mort d'Amīn " (Ka'annahā, p. 334). Nous pouvons bien imaginer que Manșūr aurait abandonné son fils après le décès de sa femme et se serait 
installé avec Asmā, laissant à son oncle maternel le soin de l'élever. Le fait que Mārīkā, une ancienne prostituée, appelle Iskandar, lorsqu'il l'interroge sur son passé, "fils de Mīlyā ", n'est pas anodin venant d'une femme qui a entendu beaucoup d'histoires, racontées par ses clients. Ces mots échappés à Mārīkā permettent d'avancer cette supposition. Une supposition d'autant plus plausible que le roman est hanté par la question de l'abandon du fils par le père. L'angoisse du meurtre du fils (réel ou symbolique) reproduit l'abandon du Christ par Dieu, ou d'Isaac par Abraham : "Abraham avait deux fils. Il a abandonné l'aîné dans le désert avec sa mère Hagar et il a emmené l'autre pour l'immoler comme offrande " (Ka'annahā, p. 274). Cette thématique s'applique, comme nous l'avons montré, aux cas de Yālū (Yālū), d'Ibrahīm et de Khalīl (Bāb al-shams), qui ont tous trois vécu avec des pères adoptifs et âgés.

Yālū, disions-nous, ne connaît pas son père et vit avec son grand-père, un prêtre syriaque, et sa mère Gābī. Dans Yālū, la composition trinitaire de la famille est mise en exergue de façon encore plus explicite que dans Bāb al-shams et Ka'annahā nā'ima. Cette famille est présentée, dès le début du roman, comme une reproduction de la famille divine composée des trois hypostases, Dieu, le Fils et le Saint Esprit - la Mère tenant, dans le roman, le rôle du Saint Esprit. L'assimilation de la mère de Yālū au SaintEsprit, en même temps qu'elle dévoile la foi naïve du grand-père et homme de religion, laisse planer, en créant de l'impropriété, une légère ironie :

Le Grand-père est le père de cette petite famille composée de Yālū et de sa mère Gābī. Yālū n’avait pas de père. Celui-ci avait émigré, il y avait longtemps, en Suède et n'avait plus donné de nouvelles. Et il n’y avait ni frère ni sœur. « Seulement nous trois ", répondait Yālū à l'enquêteur qui l'interrogeait, en prison, sur sa famille. « Nous sommes une famille composée de 
trois personnes seulement: le Père, le Fils et le Saint Esprit, et c'est moi le Fils. »

"Qu'est-ce que tu racontes? Est-ce que je plaisante avec toi? avait crié l'enquêteur.

" Nous sommes ainsi, le Père, le fils et ma mère est le Saint Esprit. C'est ainsi que j'ai appris depuis que j'étais enfant. Mais mon grand-père a arrêté de m’appeler " birru », il a dit que je n'étais pas un bon " birru "; Jésus est le " birru ». Moi je suis comme Judas, mauvais et bon à rien, c'est pourquoi il a commencé à m’appeler Yālū. (Yâlū, p. 38)

Le roman remet en avant, plus loin, ce caractère trinitaire de la famille; ce rappel manifeste l'importance du fait pour Yālū, mais s'adresse également au lecteur :

Je m’appelle Yālū, Danyāl Jal'ū, fils de Georges Jal'ū et mon surnom est Yālū. Je viens du quartier des Syriaques dans la région de Muṣayțiba à Beyrouth. Ma mère est Gābī, Gabriyāl Hābīl Abyaḍ. Je suis fils unique, je n’ai ni frères ni sœurs. J’ai vécu avec ma mère et mon grand-père. Mon père, je ne le connais pas du tout. Si untel ou untel était mon père, cela ne changerait rien à la vie, car mon vrai père est le Kohno. (Yầlū, p. 179-180)

Dans cette structure triangulaire, Gābī, la mère de Yālū, ressemble fortement à Mīlyā dans Ka'annahā nā'ima. Elles sont, toutes deux, perturbées et angoissées par la mort. Elles désirent ardemment un fils et se vouent à Dieu qui exauce leur vœu. Toutes deux ont été abandonnées par leur époux. Elles ont reçu une éducation religieuse qui a conditionné leur rapport au monde. Leur foi, mêlée aux superstitions, devient leur seul remède contre le désespoir.

L'histoire non écrite d'Iskandar, le fils dont Mīlyā a accouché avant de mourir, pourrait être, selon ce raisonnement, celle de Yālū, transposée dans le cadre d'un nouveau roman. D’ailleurs, Yālū est né en 1961. Quatorze ans seulement séparent sa naissance de celle d'Iskandar dans Ka'annahā nä'ima: 
L'enfance de Yālū était remplie de l'histoire de la mère qui s'était vouée à Dieu pour qu'il lui donne un garçon. Elle est allée à l'église Saint Severus et a fait un vœu. Elle était enceinte et pressentait que son mari n'allait pas rester avec elle. Le mari était comme un fantôme. " Je savais qu'il allait partir; je ne voulais rien d'autre de cette vie qu'avoir un fils. Je savais dès le départ, dès l'instant où je me suis mariée. Son odeur était étrange. Il avait dit qu'il voulait partir en Suède, et qu'il enverrait me chercher plus tard. Alors j'avais tout compris. J'avais compris qu'il partirait et ne reviendrait pas. Alors je m'étais vouée à Dieu. Mon père, le Kohno, était à la maison et m'avait entendu jurer, débout sous l'icône de la Vierge. Il m’avait réprimandée et accusée de blasphème. Et le blasphème s'était accompli. Non, ce n'était pas du blasphème, c'était du désespoir et le désespoir avait fonctionné. J'avais juré que si Dieu me donnait un fils, je mangerais de sa merde. Dieu m'avait exaucée et j'en avais mangé ». (Yālū, p. 132-133)

Comme Mīlyā, Gābī, la mère de Yālū, porte pour dormir une chemise de nuit bleue (Yālū, p. 64). Les deux femmes s'identifient à la Vierge Marie, représentée en tunique bleue, avec Jésus dans les bras.

Mīlyā, nous l'avons vu précédemment, se scinde en une personnalité diurne et une personnalité nocturne; la nuit elle est une autre: "la Mīlyā de la nuit n'était pas celle du jour " (Ka'annahā, p. 15)

Gābī, également, n'est pas la même la nuit. Là où Mīlyā s'enfonce dans les rêves, Gābī, la nuit, perd son visage et ne se voit plus lorsqu'elle se regarde dans le miroir. Ne pas se voir est pour elle le signe d'une mort imminente. L'une et l'autre sont en proie à des troubles identitaires :

Le jour elle se comportait normalement; elle ne parlait pas de son image, mais se tenait debout devant le miroir et se peignait. Tandis que la nuit, le miroir devenait un souci pour elle 
et pour lui, son visage disparaissait et la femme était frappée de terreur. (Yālū, p. 65)

Mīlyā meurt en couches. Jusqu'au dernier moment de sa vie, elle a peur pour l'avenir de son fils. Son angoisse est due à des causes à la fois internes et externes. Elle nourrit, d'une part, la conviction profonde, pour l'avoir expérimentée à travers son histoire personnelle et les différentes histoires de sa famille, que le père et l'homme en général sont dénués de véritable attache. La situation politique en Palestine présente, d'autre part, une source sérieuse d'inquiétude. Les événements sanglants qui éclatent dans diverses villes palestiniennes et qui coûtent la vie au frère de Manșūr, ne présagent rien de bon pour l'avenir de son fils.

Mīlyā ne survivra pas à l'accouchement et ne verra pas son fils grandir. Mais pourquoi le narrateur, qui connaît fort bien ses personnages, ne dit-il absolument rien sur le fils de Mīlyā ? Est-ce parce que le sujet ne l'intéresse pas ? C'est peu probable de la part de quelqu'un de féru d'histoires comme lui. Ou bien est-ce parce que l'histoire du " fils " avait déjà été racontée dans Yālū et que, dans Ka'annahā nā’ima, l'intérêt principal va à la " mère " ? D'ailleurs Yālū ne s'achève t-il pas sur les paroles de Yālū exprimant son désir d'écrire une histoire digne de sa mère Gābī, une histoire qu'il lui est impossible d'écrire par manque d'imagination?

Je n'aime pas les histoires dont les héros sont des hommes. Mon héroïne sera Gābī. [...] Je veux une fin heureuse à l'histoire. Je ne veux pas que mon histoire se termine avec comme héroïne Gābī Hābīl Abyaḍ, ma mère et ma sœur, marchant seule dans les rues de la ville et trébuchant sur son ombre.

Je veux une autre fin. J'essaie d'imaginer la fin qui est tout autre, mais mon imagination ne m'est d'aucun secours. Je ne possède pas suffisamment d'imagination pour trouver à Gābī 
une fin digne de son histoire d'amour. Et si je ne trouve pas cette fin, comment pourrai-je écrire? (Yālū, p. 379)

Yālū ne parvient pas à écrire, non seulement par manque d'imagination, mais parce qu'il « se sent perdu » (Yālū, p. 299), formulation qui n'est pas sans rappeler l'impasse de l'écriture à laquelle est confrontée le narrateur.

Ka'annahā nă'ima serait-il le roman que Yālū aurait voulu écrire sans y parvenir ? Le narrateur réalise-t-il dans ce roman le rêve impossible de Yālū, celui d'écrire une histoire différente pour sa mère ? Et Yālū ne raconte t-il pas l'histoire du fils que la mère dans Ka'annahā nā'ima n'a pas vu grandir?

Yālū fait la guerre et s'enrôle dans les milices chrétiennes des Forces libanaises car, paradoxalement, la guerre est devenue la seule perspective, une planche de salut. Il cherche à échapper aux superstitions et à la folie de sa mère, à l'impasse qu'est son existence. Par son choix, qui n'en est pas vraiment un, il précipite sa mère dans le désespoir. Elle a attendu sa naissance advenue par miracle, a placé en lui tous ses espoirs, mais il prend le mauvais chemin et court à sa ruine.

Est-ce la guerre qui a perdu Yālū ou bien est-il allé à la guerre parce qu'il était déjà perdu ? Ces deux questions, chez Khūrī, sont difficiles à démêler. Manque de ressources financières, échec scolaire, père absent, ambiance religieuse étouffante, absence de culture et d'éducation, autant de raisons qui ont poussé Yālū dans les feux de la guerre. Les conditions sont réunies pour conduire à une explosion individuelle aussi bien que collective.

Récapitulons. Par leur structure commune, ces trois romans renvoient constamment l'un à l'autre. Nous l'avons déjà dit, $B \bar{a} b$ al-shams a essentiellement en ligne de mire « le père », Yālū « le fils " et Ka'annahā nā'ima " la mère ". La mise en exergue d'un personnage principal n'occulte pas les deux autres membres de la famille pour autant. Ainsi, dans les trois romans, le père est 
soit absent, soit mort. Il se désintéresse du sort de son enfant. Le substitut du père est un homme vieilli et impotent. La mère, abandonnée, est seule face à ses angoisses. Le fils est l'agneau. Il est la victime par excellence. Il sera sacrifié. La structure familiale est ainsi démantelée.

La structure tripartite, avec son référentiel religieux évident, renvoie également à la structure psychique retenue par la théorie psychanalytique de Freud, formée par le triptyque ça, moi et surmoi. Ces trois instances interagissent selon un processus dynamique, régissent le comportement humain et permettent d'expliquer le déséquilibre psychique et le malaise profond de la civilisation. À se caler sur la configuration freudienne, Yūnus (Bāb al-shams) représente le surmoi, l'image de Dieu ou du Père. Son coma est la métaphore de l'absence de l'autorité. Mīlyā (Ka'annahā nā'ima), en proie à des rêves hystériques et à des hallucinations, symbolise le ça ou le chaos des émotions, et Yālū (Yâlū), le moi en désarroi, devant supporter les menaces qui proviennent du monde extérieur, du ça et du surmoi. Le fils (le moi), fragile, souffrant de la rupture des deux premières instances père absent, mère névrosée — ne peut que sombrer dans le déséquilibre, et c'est le cas de Yālū.

Mais Yālū, nous l'avons déjà dit, c'est aussi l'histoire de la guerre civile libanaise ; il est né de l'effondrement des valeurs prétendument héroïques de la nation arabe (Yūnus) et/ou libanaise et d'une terre-mère (Mīlyā) incapable de transmettre la stabilité à sa progéniture. Khalīl ne s'estime-t-il pas, dans $B \bar{a} b$ al-shams, privé « de la confiance en soi que, seule, la mère peut donner » (Bāb, p. 357)?

En démythifiant les figures archétypales du Père, de la Mère et du Fils, Bāb al-shams, Yālū et Ka'annahā nā'ima déconstruisent la structure familiale dont les composantes, religieuse, sociale et affective, sont devenues pathologiques. À travers cette 
déconstruction se lit l'histoire de l'effritement d'un pays en perte de repères et de valeurs.

\section{Autres convergences}

D'autres convergences entre les trois romans sont à signaler, comme le dédoublement des personnages principaux, l'expérience cathartique de la mort et l'impossibilité de l'amour liée à la dislocation des lieux.

Dédoublement. L'une des caractéristiques essentielles de ces trois personnages est leur dédoublement. Chacun est en même temps lui-même et un autre. Yūnus se dédouble en Khalīl, Yālū en Danyāl, et Mīlyā en une figure diurne et une figure nocturne. Dédoublement caractéristique d'une personnalité schizophrénique. Ce dédoublement de chacun des personnages principaux, où le second est issu de la mort du premier, symbolise la déconstruction d'un grand récit au profit de la prolifération narrative. Dans les trois romans, l'Histoire officielle est mise à mort pour que soit sauvée la petite histoire. Khalìl, qui est le double de Yūnus, re-raconte dans Bāb al-shams le passé héroïque de ce dernier, tout en le confrontant à ses contradictions et en lui déniant tout héroïsme. Danyāl, le double de Yālū, écrit une multitude de fois, sous la torture, l'histoire de sa vie. Tandis qu'Iskandar part sur les traces de sa tante (ou sa mère), décidé à écrire son histoire.

Expérience de la mort et catharsis par la parole. Dans les trois romans, la mort est une expérience cathartique : la mort de Yūnus permet à Khalīl de raconter et reprendre à l'infini tout le passé, le présent, mais aussi l'avenir, à travers des histoires pleines de trous, de mettre à distance ces trois temporalités et de s'en libérer. Yālū, à qui l'on intime l'ordre d'écrire sa vie sans 
rien omettre, voit ses tentatives répétées échouer. Il est contraint de recommencer, en endurant à chaque fois les pires tortures, jusqu'à la torture suprême, appelée " le trône ", consistant à s'asseoir sur une bouteille de coca-cola brisée. C'est après cette épreuve ultime, au cours de laquelle il goûte à la mort, qu'il se dédouble en Yālū et Danyāl. La souffrance endurée par Yālū est rédemptrice et mène à un « réveil » :

Lorsque je suis monté sur le trône et que la douleur m'a transpercé de bas en haut et de haut en bas, j'étais sûr que j’allais mourir. Je suis monté et la mort a commencé. [...] Tu as l'impression d'être traîné sur un sommeil blanc. [...] Quelque chose a éclaté et après je me suis retrouvé au dessus du sommeil, c'est-à-dire que je dormais et ne dormais pas, et après je me suis réveillé. (Yālū, p. 300-301)

À la faveur de ce réveil, Yālū prend du recul vis-à-vis de luimême et se regarde de loin avec compassion. À son bourreau, il explique que la souffrance lui a permis d'atteindre des sphères que seuls ceux qui ont vécu de grandes tragédies peuvent comprendre. Désormais, il voudrait, lui aussi, écrire son histoire :

Je crois, Monsieur, que je vous ai expliqué les circonstances qui ont poussé Yālū à commettre ses erreurs et crimes. Maintenant, je vais essayer d'écrire toute l'histoire, du début jusqu'à la fin. Considérez que je suis sa voix qu'il a perdue depuis qu'il s'est assis sur son trône. Il est là-bas, il ne se plaint ni ne gémit. Je suis certain qu'il vit un moment grandiose, que personne avant lui n'a vécu, à part ceux qui ont atteint les souffrances suprêmes. (Yālū, p. 298)

Dans ces deux romans, l'écriture se révèle être une planche de salut. Par contre, dans Ka'annahā nā’ima, c'est l'expérience de la mort qui ouvre à Mīlya les portes du rêve. Incapable d'exprimer ses émotions par une parole consciente et rationnelle, elle développe alors une compréhension intuitive et profonde de la réalité. 
L'amour en otage. Un autre point commun est l'usure du sentiment amoureux. Ces trois romans sont des histoires d'amour: Yālū et Shīrīn (Yālū), Yūnus et Nahīla / Shams et Khalīl (Bāb alshams) et Mīlyā et Manșūr (Ka'annahā nā’ima). Mais ces histoires d'amour racontent plutôt l'impossibilité de l'amour. Chacune d'elles est démantelée par la séparation physique des amants. L'éloignement et la séparation, loin d'attiser le désir, le démystifient; il s'use et dépérit. Comment en serait-il autrement lorsque, entravé, emprisonné, le désir n’arrive plus à circuler librement dans le corps, tout comme les corps reclus dans des espaces clos sont empêchés de franchir les frontières (check points, barbelés, lieux transformés en ghettos, fermeture des frontières...) ? La décomposition des couples est à l'image de la dislocation des lieux.

\section{Stratégies de rédemption}

Nous avons tenté de mettre en évidence la parenté qui lie et structure Bāb al-shams, Yālū et Ka'annahā nā'ima. Il s'agit bien d'une trilogie, où se joue la destruction d'une représentation de la famille : celle que forme le triptyque père, mère, fils, supposé être un rempart solide, protecteur, sans faille; cette trinité relationnelle cesse d'apparaître comme un refuge, elle se révèle au contraire être une menace, que cela soit sur le plan psychique ou sur le plan politique.

La famille est décrite dans ces trois romans comme une structure dynamique faisant jouer les segments binaires mère/père, père/fils, fils/mère. Une rupture altérant les rapports entre les deux termes de la relation affecte chacun de ces trois segments relationnels. Le dysfonctionnement, décelable à tous les niveaux, engendre un sentiment de désarroi et de solitude. Cependant, l'aspect tragique, régnant en maître absolu, est-il le fin mot de l'histoire? 
L'analyse de ces mêmes romans montre qu'ils portent aussi une vision d'espérance et de salut, cette vision instaurant, non pas un dépassement du tragique, mais un tiraillement constant entre l'Être et le Néant.

À la démythification de la Sainte Famille, soldée par la mort et la désintégration des personnages à référentiel biblique, se superpose une lecture ouvrant la voie à une renaissance. L'œuvre de Khūrī parle des guerres au Liban et en Palestine, des tueries, du malheur arabe, de l'étrangeté humaine, de l'injustice subie et imposée, de l'angoisse face à la mort, de l'expérience des prisons et de la torture, de tous les marginaux et laissés-pourcompte... Nous sommes portés à croire que, dans une telle vie, l'espérance n'a plus sa place. Et l'on voit mal quelle lumière pourrait encore rejaillir à l'horizon. Pourtant, du fond de l'obscurité, un espoir luit. Quel est le message de renaissance qui soustend ces romans et comment se manifeste-il?

Naissance miraculeuse. L'idée de renaissance préside à la naissance du personnage principal dans chacun de ces romans (Yūnus, Yālū, Mīlyā); leur naissance est décrite comme une revanche miraculeuse sur la mort. Cette survie initiale inattendue annonce celle qui adviendra à la fin, comme nous le verrons un peu plus tard.

Yūnus, dans $B \bar{a} b$ al-shams, nous l'avons déjà vu, est un miraculé ; son triomphe sur la mort lui a valu d'être appelé Jonas par son père, en référence dûment motivée au personnage biblique. Khalīl fait écho au récit d’Āmina, la cousine du héros :

Elle a dit que Cheikh Ibrāhīm bin Sulaymān al-Asadī avait la quarantaine lorsqu'il s'est marié. Pendant vingt ans, sa femme avait mis au monde des enfants qui mouraient quelques jours après leur naissance. Elle était atteinte d'une maladie sans nom. Ses mamelons s'infectaient et tombaient 
lorsque l'enfant commençait à allaiter, et le bébé mourait alors de faim. Puis tu es né. Toi seul avais réussi à prendre un sein sans mamelon. Tu mordais le sein et tétais, et ta mère criait de douleur. Tu avais ainsi échappé à la mort et survécu. (Bāb, p. 18-19)

Yālū, de même, a échappé par miracle à la mort. Durant l'accouchement, il a failli s'étrangler à cause du cordon ombilical qui s'était enroulé autour de son cou: " Mon grand-père dit que je suis né sous le signe de la mort parce que mon cordon ombilical s'était enroulé autour de mon cou. La sage-femme, Linda Șalībā m’a sauvé de la mort par miracle » (Yālū, p. 352).

Mīlyā, quant à elle, avait onze ans lorsqu'une forte fièvre l'a terrassée. La nonne Mīlāna arrive à temps et, parvient à la sauver en implorant saint Élie. La survie de Mīlyā est attribuée à une intervention divine : "Saint Élie lui avait sauvé la vie, son avenir dépendait de cette visite, lui avait dit la religieuse » (Ka'annahā, p. 330)

Passage initiatique. Les trois romans s'ouvrent, respectivement, sur un état de coma (Yūnus), un état de déchéance (Yālū) et un état de trouble psychique (Mīlyā). Cette situation préfigure une descente en enfer. Yūnus est dans la mort: "Le début de l'histoire dit que tu es quasiment mort, et il n'y a aucun espoir de te réveiller. » (Bāb, p. 32) Yālū passe son temps assis dans l'obscurité ; il vit dans les ténèbres: "Yālū avait passé sa vie dans la nuit; la nuit était sa couverture. Le jour, il se sentait nu et son long manteau noir ne lui suffisait pas pour se couvrir. " (Yālū, p. 291) Mīlyā, quant à elle, se réfugiait dans ses rêves et se démenait avec les démons d'un inconscient ténébreux : "Elle est partie vivre dans le sommeil et à l'intérieur d'un monde entouré par les murs de la nuit. » (Ka'annahā, p. 62)

La descente aux enfers est imputable à un acte de violence initial: la nakba dans $B \bar{a} b$ al-shams, un massacre puis la guerre 
civile libanaise dans $Y a \bar{l}$, un traumatisme sexuel lié à nécessité de devenir adulte et des crises politiques dans Ka'annahā nā'ima. L'individu est, dans ces romans, victime d'une violence qu'il n'a pas provoquée et qui apparaît liée, à chaque fois, à l'histoire politique de la région. La déchéance du personnage principal est liée aux troubles de l'histoire. D'où l'interrogation sur la part de responsabilité de chacun dans ce qui lui arrive. L'homme est-il complice du sort qui lui est réservé ou en est-il la victime? Aurait-il pu en être autrement? "Que pouvait-on faire? Rien ", lisonsnous dans Bāb al-shams (p. 394).

Le séjour dans les ténèbres est un passage initiatique conduisant à la métamorphose du héros et à sa résurrection. À l'horizon lointain poind une lumière. Cette lumière, nous y reviendrons plus loin, se manifeste sous les traits du Christ.

Khalīl est convaincu que Yūnus retournera un jour à Bāb alshams, la Palestine retrouvée, et exprime son attente dès les premières pages du roman; cet espoir est un acte de foi :

Je t'ai promis de commencer par la fin. La fin arrivera lorsque tu te lèveras de ce lit qui ressemble au cercueil. Tu te lèveras, tu seras grand, tu auras de larges épaules, tu tiendras à la main un bâton et tu retourneras dans ton pays. Là-bas, tu iras d'abord à la caverne de Bāb al-shams et non pas sur la tombe de Nahīla où tout le monde t'attend. Tu iras à Bāb al-shams, entreras dans ta caverne-village et disparaîtras. (Bāb, p. 34)

À la fin du roman, Sālim, le fils cadet de Yūnus, réexprime sa foi en une résurrection future de son père :

Sālim recommanda aux enfants de garder le secret de la caverne. " C'est le secret de Yūnus; gardez-le dans le ventre de la baleine, leur dit-il. Dans trois jours, ou trois ans ou trois dizaines d'années, votre grand-père Yūnus sortira du ventre de la baleine comme en est sorti le premier Jonas. La Palestine sera récupérée et nous appellerons notre village, que nous reconstruirons, Bāb al-shams. » (Bāb, p. 510) 
L’expérience de la prison, décrite par Yālū comme « un long voyage de souffrance » (Yālū, p. 363) ainsi que l'épreuve ultime, celle de la torture consistant à s'asseoir sur une bouteille de cocacola brisée, mèneront au salut de son âme et à la réunification de ses deux moi : «Vous m’avez fait parvenir à l'éternité, et m’avez fait comprendre le sens de la vie parce que j’ai goûté et bu la mort par en bas et par en haut. » (Yālū, p. 301)

Quant à Mīlyā, allongée sur son lit d'accouchement, elle reçoit de la bouche du moine Țānius sa sanctification suprême comme mère du Christ: " Maintenant, Seigneur, tu laisses ton serviteur s'en aller en paix, selon ta parole, car mes yeux ont vu ton salut, salut que tu as préparé devant tous les peuples, lumière pour éclairer les nations, et gloire à ton peuple. " (Ka'annahā, p. 388). Ces paroles récitées par le moine Țānius sont celles qu'avait prononcées Siméon en prenant Jésus dans ses bras au Temple, ainsi que le rapporte l'Évangile selon saint Luc. Siméon, un vieillard " juste et pieux ", vivant à Jérusalem, avait été divinement averti qu'il ne mourrait pas avant d'avoir vu le Messie. Dès qu'il vit son attente comblée, il bénit Marie et Joseph et sut qu'il pouvait s'en aller en paix (Évangile de Luc 2 :25-38). L'Église commémore cet événement par le rituel de "la présentation du seigneur au Temple », auparavant appelé « la purification de Marie ». Ces paroles sont un message intense d'espérance et de résurrection.

La mort de Mīlyā, après avoir donné naissance à son fils, est comparée à un long sommeil. Or, le sommeil ou l'endormissement n'est pas l'extinction de la vie, mais un état léthargique qui suppose, à terme, le réveil. En dessous de sa photographie, figure cette phrase paradoxale que son neveu - ou fils - tentait de déchiffrer, et d'après laquelle Mīlyā ne serait pas morte mais endormie: "La jeune fille n'est pas morte, mais elle dort. " (Ka'annahā, p. 387) D’ailleurs, dans les religions monothéistes, la mort est un passage menant à l'au-delà. Surtout, dans l'orthodo- 
xie, on parle de la dormition de la mère de Dieu, dont le corps est enlevé aux cieux.

L’idée selon laquelle la mort s'apparente au sommeil est également évoquée dans $B \bar{a} b$ al-shams. Yūnus, atteint d'une lésion cérébrale, est considéré comme cliniquement mort. Cependant Khalīl refuse d'accepter sa mort et parle d' "endormissement " : " Je suis sûr, dit-il, qu'il dort et qu'il n'est pas mort. » (Bāb, p. 11). L'explication de la différence entre la mort et le sommeil, il l'avait entendue de la bouche d'Umm Hasan : "Est-ce vrai que celui qui dort est comme un mort? C'est ce que disait Umm Hasan. L'âme quitte le corps du dormeur puis le réintègre au moment du réveil, tandis que l'âme du mort quitte son corps et ne revient plus. » (Bāb, p. 11)

De même dans Yālü. Le prêtre syriaque Ifrām explique à son petit-fils Yālū que la mort n'est qu'un endormissement : "La mort n'existe pas, dit le grand-père, nous appelons la mort dormition, c'est-à-dire endormissement. Le mort dort ; son corps le quitte, puis il se réveille après chez Abū Isā. » (Yālū, p. 160-161) [Abū 'Isā, littéralement le père de 'Isā, est le nom arabe de Dieu en référence au Coran.]

État initial, chute et résurrection sont les moments forts qui structurent l'évolution dramatique de ces romans. Le temps premier de la narration reste, certes, celui de la chute et de la dépossession, puisque les trois romans se situent ici-bas et parlent de l'existence humaine avec son lot de souffrances et de malheurs: "L'héritage que les hommes ont en commun c'est leurs larmes ", lit-on dans Yālū (p. 128). Le paradis perdu n'est pas explicitement évoqué. Cependant, en faisant de la chute la conséquence d'une violence primordiale et en laissant poindre un dépassement de la crise à l'horizon, ces récits présupposent un état originel et en expriment une certaine nostalgie. L'Avant et l'Après sont posés in absentia. Le premier est perdu, oublié, tandis que le second, 
représenté de façon symbolique, est attendu ; il y va d'un acte de foi qui constitue en même temps le dépassement métaphysique de chacun des romans et son véritable achèvement.

\section{Modalités initiatiques}

Voyons de plus près comment s'articule le processus initiatique dans ces trois romans.

Dans Bāb al-shams, Khalīl tente de tirer Yūnus du coma et de l'extirper de la mort par la thérapie de la parole. Ces deux personnages, liés par une mémoire commune, se révèlent être une seule et même personne. Ils portent d'ailleurs le même nom d'Ibrāhīm : Yūnus possède plusieurs noms dont Ibrāhīm. Et sa femme Nahīla, atteinte de vieillesse et de maladie, confond son époux avec son fils aîné Ibrāhīm : " Nahīla voyait Ibrāhīm son fils sous l'aspect d'un homme qui s'appelait Yūnus et voyait son époux Yūnus sous l'aspect d'un enfant qui ressemblait à Ibrāhīm. » (Bāb, p. 512)

D’ailleurs Yūnus affirmait à Khalīl qu'il ressemblait à son fils aîné Ibrāhīm : "Tu m'avais dit toi-même que je ressemble à ton fils aîné Ibrāhīm " (Bāb, p. 22). À son tour, Khalīl explique à Yūnus qu'il est, lui aussi, Ibrāhīm : « Moi aussi je porte le nom de ton père. Il était Ibrāhīm, et moi Khalīl. Ibrāhīm est l'aimé de Dieu, c'est pourquoi nous avons appelé la ville d'Abraham al-Khalīl. » (Bāb, p. 444). Une autre expérience laisse également entendre qu'ils ont la même identité. S'écoutant parler, c'est la voix de Yūnus que Khalīl entend: «Les mots viennent comme la sueur qui suinte de mes pores et, au lieu d'entendre ma voix, j'entends la tienne sortir de ma bouche. » (Bāb, p. 52)

Pour que s'accomplisse le destin de Yūnus, tel que l'anticipe la figure biblique de Jonas, la mort est une étape incontournable à franchir. La mort, telle qu'elle est présentée dans ce roman 
n’apparaît pas comme une image exclusivement négative. Contrairement à la mort ressentie comme un scandale des scènes de tueries, le trépas de Yūnus est un tremplin vers un ailleurs. Il est vrai que Khalīl tue Yūnus à coups de mots : au fil des souvenirs racontés, Yūnus, au lieu de se réveiller tel que le réclament les élucubrations mythologico-thérapeutiques de Khalīl, s'enfonce davantage encore dans le sommeil, mais cette descente au sein de la mort est accompagnée du mouvement contraire, celui de l'émergence de Khalīl du fond même de cet abîme. Ce mouvement est dialectique, dans le sens où la mort donnée à Yūnus ne le rejette pas hors du processus mais au contraire l'y intègre. Khalīl, tout en niant Yūnus par la parole, l'inclut en même temps en lui: «Je t'invente comme je le veux; je m'invente moi-même en toi. " (Bāb, p. 413). C'est la raison pour laquelle Khalīl, vers la fin du roman, se proclame lui-même Jonas. Cette proclamation est une assimilation dans le sens déjà explicité : "C'était moi, Jonas, pas toi. » (Bāb, p. 470). Et plus loin : « Ta vérité est en moi maintenant. " (Bāb, p. 499)

La mort de Yūnus a valeur de renaissance. Dans son livre sur Bachelard, Michel Mansuy explique que le ventre est le symbole de la sécurité et de l'aspiration au repos ; c'est pourquoi les histoires d'avalés n’ont rien d'effrayant: " Le complexe de Jonas marque toutes les figures des refuges de ce signe primitif de bien-être doux, chaud, jamais attaqué. C'est un véritable absolu d'intimité, un absolu de l'inconscient heureux ${ }^{2}$ ". De même que Jonas fut avalé par une baleine, Yūnus est plongé dans le coma depuis sept mois. Sa résistance à sortir de son sommeil ne pourrait-elle signifier le refus de s'arracher à un sein à l'intérieur duquel il ne se sent pas si mal? 
Toujours est-il que Yūnus passe par une lente métamorphose qui le rend méconnaissable aux yeux de ses anciens amis, dont petit à petit les visites se raréfient: Zaynab finit par le trouver monstrueux, et Abū Kamāl, un ancien réfugié du camp, voit en lui l'image de la déchéance. En opposition à ce regard extérieur, Khalīl, de plus en plus conscient du sens initiatique que cette mort va revêtir pour lui, voit en cette métamorphose un retour au stade du nourrisson qui embellit le dormeur et le prépare à un accouchement imminent: "Tu es dans l'utérus de la mort depuis sept mois, je dois attendre ta naissance dans deux mois. Tu es mon fils; les pères n'ont pas peur devant leurs enfants. » (Bāb, p. 447)

L'accouchement a lieu, à l'image de l'expulsion de Jonas hors du ventre de la baleine. Mais le craché est Khalīl. C’est pour cette raison que ce dernier se proclame lui-même Jonas, partageant ainsi avec Yūnus un destin à la fois imbriqué et parallèle, même et autre. L'image de l'inondation sur laquelle s'achève le roman n'est pas sans rappeler le rôle de l'élément aquatique dans l'engloutissement de Jonas, avant qu'il ne soit rendu à la terre ferme, c'est-à-dire à la vie ; elle évoque, également, le plasma dans lequel baigne le nourrisson dans le ventre maternel. L'image du baptême est également associée à l'abondance de l'eau, figurée à la fois par les larmes et la pluie:

Je suis sorti de chez moi pieds nus et j'ai couru vers ta tombe. Je suis debout, ici, la nuit me couvre et la pluie de mars me lave, et je te dis, non, mon ami, les histoires ne se terminent pas ainsi. Non.

Je suis debout, les cordes de pluie se déploient du ciel jusqu'à la terre, mes pieds s'enfoncent dans la boue, je tends la main, je tiens les cordes de pluie et je marche je marche je marche. (Bāb, p. 527) 
La résurrection de Khalīl passe par l'enterrement final, avoué et assumé de Yūnus, celui qui fut son père, son fils, mais également l'ami et le frère d'armes.

Parmi les multiples histoires relatives à Yūnus, figure celle de son entrevue avec une Yéménite qui, l'ayant découvert caché dans le tronc d'un arbre, le prend pour le prophète Élie. Khalīl relève ce détail et demande à Yūnus de ne pas l'oublier. Élie, monté au ciel sur un char de feu sans passer par la mort, est un symbole de vie: « Tu es Élie. C'est le nouveau nom qui doit s'ajouter à la liste de tes autres noms. Je te raconte cette histoire, mon fils, afin que tu n'oublies pas qu'Élie est l'un de tes noms. Élie c'est le prophète du feu, celui qui n'est pas mort. C'est le seul qui est monté au ciel sans traverser la mort. » (Bāb, p. 511)

Le destin de Jonas, dont se réclament Yūnus et Khalīl, reproduit schématiquement la vie auprès de Dieu, l'éloignement puis le retour. Ce schéma, que nous retrouvons lié à tous les autres noms de Yūnus - Ādam, Khalīl, Ayyūb (Job), Ibrāhīm, 'Īliyyā (Élie) - est en dernier ressort celui-là même du parcours accompli par le Christ. Ce dernier, avant de ressusciter, a séjourné trois jours au sein de la mort. Khalīl invite logiquement Yūnus à s'identifier à l'image du crucifié :

'Īsā, que la paix soit avec lui, ne disait-il pas aux montagnes de se déplacer, n'était-il pas le fils qui avait tracé l'image de son père, lorsqu'il est mort sur la croix? Sois donc le fils. Que ton lit soit ta croix. Qu'en dis-tu? Tu n'aimes pas l'image du fils? N'est-elle pas mieux que toutes celles que nous avons esquissées pendant les six mois passés ensemble ici? (Bāb, p. 445)

Ce n'est pas par hasard, d'ailleurs, que l'hôpital où séjournent Khalīl et Yūnus porte le nom d'hôpital Galilée (mustashfā al-Jalīl) :

La Galilée est une terre chaude et tendre, c'est pour cela qu'elle convient au Christ. Il n'est pas possible d'imaginer 
'Īsā, que la paix soit avec lui, sans la Galilée. Cette terre lui ressemble et ne convient qu'aux étrangers, c'est pourquoi elle fut appelée la Galilée des Nations. (Bāb, p. 413)

La Galilée, région située au nord de la Palestine, baignée par le Jourdain et bordée par le lac de Tibériade, est connue pour être le lieu où se déroula la majeure partie de l'enfance de Jésus. Et c'est en Galilée que ce dernier donne, après sa résurrection, rendez-vous aux apôtres. "Allez dire à ses disciples, et notamment à Pierre, qu'il vous précède en Galilée : là vous le verrez, comme il vous l'a dit " (Marc 16, 5-7) dit l'Évangile. L’hôpital Galilée, transposition de la Palestine dans le camp de réfugiés d'Ayn al-Hilwa, est dans un même souffle un lieu chargé de symbolisme religieux et porteur d'une promesse de salut.

Le titre du roman, Bāb al-shams, qui signifie littéralement « la porte du soleil ", inclut à la fois le sens de l'enfer et son dépassement. Le soleil évoque, dans le roman, un moyen de torture utilisé par les Israéliens, appelé " ensoleillement ", consistant à exposer les prisonniers à sa chaleur brûlante :

Ce jour-là, j'ai entendu pour la première fois le mot « ensoleillement». Un homme à côté de moi a dit qu'ils allaient nous « ensoleiller " avant de nous tuer. Je n'ai compris le sens du mot que plus tard, à la prison d'al- Anșār. L'« ensoleillement », dans cette immense prison construite par les Israéliens après l'invasion du Liban en 1982, constituait le moyen de torture principal. Ils t'attachaient les pieds et les mains et te jetaient au soleil. Tu te tortillais, te retournais, te roulais à la recherche de quelques secondes qui réduiraient ta brûlure. Tu demeurais ainsi du lever jusqu'au coucher du soleil. (Bāb, p. 233)

Rijāl fi-l-shams (Des hommes dans le soleil ${ }^{3}$ ), le roman de Ghassān Kanafānī recopié maintes fois par Nahīlā, l'épouse de

3. Ghassān Kanafānī, Rijāl fî-l-shams, Beyrouth, Usāma Mūlād, 1963. Trad. par Michel Seurat, Des hommes dans le soleil, Arles, Sindbad. Actes Sud, 1990. 
Yūnus, évoque également le soleil comme feu brûlant, ce qui renvoie aussi à l'Enfer. Dans ce roman, trois Palestiniens cachés dans la citerne d'un camion devant les conduire, illégalement, au Koweit où ils espèrent trouver de meilleures conditions à leur vie, vont mourir, brûlés par le soleil ardent du désert. Par ailleurs, les taudis dans lesquels vivent les réfugiés des camps, construits en tôle, deviennent "des fourneaux en été " (Bāb, p. 475) et ne sont pas sans rappeler eux-mêmes l'enfer vécu par les Palestiniens enfermés dans la citerne de Kanafānī. À l'inverse, "Soleil " est le nom de l'amante de Khalīl, Shams; il est l'autre nom de l'amour. Dans ses bras, Khalīl s'initie à la vie. Le soleil désigne enfin le Christ comme figure de douleur, de compassion et de transcendance, l'amour étant le message porté par sa parole. Rappelons pour conclure et achever la boucle du sens que la caverne, fondée par le héros, qui préfigure la nouvelle Palestine, s'appelle Bāb al-shams.

Ce roman, tout en décrivant la répudiation des Palestiniens hors de leur terre, leurs souffrances et leurs privations, porte donc un espoir et une foi dans l'avènement d'une nouvelle vie.

Dans Yãlū également, le prêtre syriaque ne manque pas de rappeler à son petit-fils que le Christ est appelé "Soleil de Justice » :

Nous avons marché dans l'obscurité de l'Histoire, nous resterons dans l'obscurité jusqu'à ce que le Soleil de Justice apparaisse ». Quand Yālū l'interrogeait sur ce " soleil de Justice », le Kohno répondait qu'il s'agissait du Christ: "nous attendons le royaume du Christ, petit, et Il a dit que Son royaume n'était pas de ce monde. (Yālū, p. 153-154)

De même, Yālū livre explicitement la clé d'interprétation du message messianique inhérent à l'histoire de Yūnus dans Bāb alshams, permettant de voir dans la promesse de résurrection de ce dernier — de père devenu fils — ou de son double Khalīl, une 
image du Christ. Le prêtre Ifrām explique à Yālū que l'histoire de Jonas n'est que le symbole de la mort et de la résurrection du Christ : "Comment expliquer l'histoire du prophète Jonas qui a passé trois jours dans le ventre de la baleine, avant de retourner au rivage sain et sauf? Ifrām dit que l'histoire du prophète Jonas n'est qu'un symbole de la mort et de la résurrection de Jésus. » (Yālū, p. 76)

Comme Bāb al-shams, Yālū reproduit le schéma d'une éviction d'un lieu originel, d'une descente aux enfers puis d'une résurrection. À la nakba des Palestiniens fait écho, dans Yālū, le massacre de la minorité syriaque de 'Ayn Ward par les Turcs. Le Kohno décrit à Yālū les massacres qui l'ont conduit jusqu'à Beyrouth. Hābīl Abyaḍ, qui prit plus tard le nom d'Ifrām, ne s'en souvient pas. Il avait deux ans à l'époque. L’histoire lui a été contée par son oncle maternel :

L'histoire commence par un enfant qui s'appelle Hābīl Jibrā ' il Abyaḍ, né au village de 'Ayn Ward, non loin de Țawr 'Abidīn, dans un pays sans nom parce que c'est le pays d'un peuple qui n'existe plus. Là-bas, au début du $\mathrm{Xx}^{\mathrm{e}}$ siècle, un énorme massacre perpétré par les Turcs emporta un million et demi d’Arméniens. (Yālū, p. 352)

Par ailleurs, les destins de Yūnūs et de Yālū se ressemblent à tel point qu'on se demande si le personnage de Yālū ne serait pas un décalque de celui de Yūnus : le nom de Yūnus est Jonas, en arabe. Yalū est le diminutif de Danyāl, nom d'un prophète biblique. La vie des deux commence par un massacre qui les contraint à un exil forcé. Yūnus se réfugie dans les camps palestiniens au Liban. Yālū est contraint par la guerre civile de fuir à Paris; son errance renvoie à celle de son grand-père contraint à fuir les massacres des Arméniens et de la minorité syriaque par les Turcs. Les deux ont effectué, tel Jonas, un passage dans les ténèbres. L'épreuve de la prison symbolise l'engloutissement et 
le passage par la mort. Yūnus, lui, a été avalé par un coma profond.

Les deux personnages, comme nous l'avons évoqué précédemment, sont sujets à un dédoublement où l'un des deux protagonistes meurt au profit de la résurrection de l'autre: nous avons, d'une part, Yālū et Danyāl, son double, et, de l'autre, Khalīl et Yūnus. Les deux s'identifient à la figure du Christ et refont le chemin de la croix.

En essayant de décrire l'état dans lequel il avait sombré lorsque ses bourreaux lui ont imposé de s'asseoir sur la bouteille, Yālū dit avoir senti la mort. La mort que Yālū traverse ressemble, comme pour Yūnus et Mīlya, au sommeil.

Les tortures constituent l'apogée de la souffrance vécue dans son enfer carcéral. Or, de cette souffrance ultime va émerger Yālū, le double de Danyāl, qui sera désormais son compagnon et veillera sur lui. La mort n'est pas, encore une fois, l'extinction de la vie, mais sa condition de possibilité : c'est pourquoi elle est évoquée sous le nom de sommeil, pour annoncer, justement, la possibilité d'un réveil. "Après je fus réveillé " s'entend ainsi comme la renaissance de Yālū :

C'est moi Danyāl qui écris. J'écrirai tout ce que vous voudrez, sur lui, sur moi et sur tout le monde. Mais pas sur Yālū. Je voudrais être franc avec vous et vous dire que Yālū m'a abandonné et parti au loin. Je suis corps, il est âme. Je souffre et il vole. Je suis descendu de la bouteille alors que lui, il est assis sur le trône. (Yālū, p. 288)

Le processus que nous venons de décrire se répète dans $K a^{\prime}$ annahā nā'ima. Mīlyā, comme Yūnus et Yālū, est une miraculée : elle a survécu à la forte fièvre qui aurait dû l'emporter. Le lieu originel qu'elle a perdu est à la fois son enfance et sa chambre dans la maison familiale, chambre qu'elle partageait avec son frère Mūsā avant que le père ne procède à l'agrandissement de 
la maison et au réaménagement du territoire occupé par chacun. Elle se sent en errance. La demande en mariage de Manșūr arrive à point nommé. Elle l'accepte immédiatement et part avec lui pour Nazareth. Cet acquiescement inconditionnel - qui n'est pas sans évoquer le Fiat! de la Vierge Marie - est dû au fait que plus rien ne la retient en un lieu auquel elle ne se sent plus appartenir. Elle était déjà prête pour ce long voyage, voyage qui ressemble à un chemin de croix et au terme duquel elle accouchera, conformément à sa foi, du fils de Dieu.

Mīlyā, elle aussi, est double : il y a une Mīlyā diurne et une Mīlyā nocturne. De la mort de la première naîtra la seconde. Sa résurrection est annoncée, dès le départ, par le titre lui-même ("Comme si elle dormait») qui la représente comme endormie et donc dans l'attente du réveil, et par la symbolique de ses rêves dans lesquels elle s'identifie à la Vierge Marie. La mort est, ici aussi, la promesse d'une assomption que suit la dormition. L'idée d'assomption est également invoquée, dans les trois romans, à travers l'image du prophète Élie qui, d'après la croyance, est monté au ciel sur un char de feu sans passer par la mort: son histoire est un message de transcendance et de dépassement. Rien d'étonnant à ce qu'Élie soit présent dans la vie de chacun des personnages principaux des trois romans.

Il est, rappelons-le l'un des visages de Yūnus (voir supra p. 69) et le symbole de la victoire de la vie sur la mort. Dans Ka'annahā nā'ima, le prophète est également représenté comme l'archétype du triomphe de la vie sur la mort. Enfin, Yālū ne fait pas non plus l'économie de l'histoire du prophète du feu. Yālū entend de la bouche de la mère de son ami Alexis, originaire de Russie, son explication sur le rapport existant entre la boisson à l'eau de rose et le prophète Élie :

"C'est à l'occasion de la fête de saint Élie le vivant ", dit la femme en montrant l'eau de rose. "Nous buvons l'eau de 
rose avec des glaçons cassés non pas [...] parce que la fête tombe au mois de juillet, quand il fait très chaud, non, mais parce que saint Élie est le prophète du feu; il est monté au ciel dans une carrosse tirée par des chevaux de feu. Les glaçons cassés c’est pour le feu. (Yālü, p. 229)

L'histoire, telle que la raconte en quelques traits la femme russe, si elle n'est pas mise en rapport avec les autres allusions au même prophète dans les autres romans, passerait pour un bavardage dépourvu de sens, révélateur, tout au plus, de certaines coutumes de bonnes femmes orthodoxes. La présence du prophète, étant donné qu'elle revient d'un roman à l'autre, est un élément qui montre l'existence d'une parenté des différents narrateurs. Elle tranche de façon abrupte avec le côté ténébreux du roman et participe de sa lisibilité.

Élie est par ailleurs le nom de l'auteur, Ilyās en arabe. Une certaine proximité ente l'auteur et les différents narrateurs de ces trois romans (voir l'introduction) nous autorise-t-elle à avancer la possibilité d'un lien indirect entre le prophète vivant et la fonction de vie que l'instance narrative aspire à remplir? Nous reviendrons à cette question ultérieurement.

Il est ainsi permis d'affirmer que Bāb al-shams, Yālū et Ka'annahā nā'ima sont portés par l'espoir d'une renaissance. Ce mouvement vient contrebalancer la destruction du schéma triangulaire.

Les deux mouvements se superposent l'un à l'autre et créent une tension. À travers cette tension, se lit également le parcours personnel de l'auteur, un mélange de foi et d'athéisme, d'espoir et de désespoir. De là surgit aussi la puissance de la littérature. Les narrateurs respectifs de ces trois romans ne reprennent-ils pas à leur compte la parole du prêtre syriaque disant, dans Yālü, 
Elias Khoury - De l'engagement au postmodernisme

que « les livres sont, comme les icônes, des fenêtres que nous ouvrons sur l'éternité, et à travers lesquels nous contemplons l'autre monde » $(Y a \bar{l}$ ū, p. 111)? 


\section{4}

\section{Histoire et littérature \\ Le roman comme contre-narration}

\section{Métafiction historiographique}

«L'écriture est toujours une performance dans les deux sens du terme : elle est le lieu où se déploient tout à la fois une compétence et une intention ${ }^{1}$ ", écrit l'historien Christophe Prochasson dans un essai consacré aux controverses qui affectent l'histoire contemporaine. Nous ne dirions pas autrement de l'écriture fictionnelle ; à plus forte raison lorsqu'il s'agit d'une fiction historique, comme c'est le cas chez Khūrī. Ses romans sont la mise en tension d'une intentionnalité. Non seulement le narrateur recourt à la fiction pour relater des événements historiques, mais il n'hésite pas à livrer, de commentaire en commentaire, sa vision de l'histoire - celle du Liban et de la Palestine en particulier.

Cependant, l'histoire et la littérature sont deux disciplines indépendantes. La première s'efforce d'élaborer une science du réel, de l'objectif, en se fondant sur une méthode d'étude et d'expérimentation. Elle s'est toujours donnée des règles, a toujours recherché des arguments grâce à des techniques et au moyen de

1. Christophe Prochasson, L'Empire des émotions: les historiens dans la mêlée, Demopolis, 2008, p. 32. 
preuves, de raisonnements, d’opérations de vérification. Dans son sillage, la sociologie s'est distinguée également de la littérature par son approche épistémologique, même si son projet, celui de comprendre la société, est identique au propos littéraire.

La littérature revendique pour sa part une fonction esthétique, la " littérarité ». Quand bien même elle est ancrée dans le réel qu'elle interprète et auquel elle cherche à donner sens, elle ne renvoie qu'à elle-même : "le texte est enclos en lui-même, autotélique, seul producteur de son sens ${ }^{2}$ ", écrit Ivan Jablonka. Cependant, le concept de littérarité est fuyant. Greimas le reconnaissait, « la littérature comme discours autonome comportant en lui-même ses propres lois et sa spécificité intrinsèque est presque unanimement controversée ${ }^{3}$ ". C'est peut-être dans la fonction poétique du discours qu'il faudrait chercher la spécificité de l'œuvre littéraire. Ce qui distingue probablement celle-ci en propre est qu'elle s'offre comme une création qui n’obéit pas à la seule logique du monde. S'émancipant de la réalité du monde, elle ne se réduit plus à une mimesis. Par sa valeur symbolique, elle devient révélation à soi, expérience intérieure, processus de métamorphose de l'humain, appropriation. Cette dimension fondatrice, qui la distingue de l'approche historique et des autres sciences humaines et lui confère son aura particulière, ne doit pas être perdue de vue. D'autant plus que les sciences de l'homme, sous prétexte de fournir une connaissance objective du monde, tendent à gommer cette dimension originale du regard littéraire, sans parvenir à hisser leur discours à un niveau d'indiscutable scientificité.

Si elle n'est pas asservie au seul régime de la lecture réaliste, si elle n'est pas un simple document, la littérature entretient

2. Ivan Jablonka, L'Histoire est une littérature contemporaine, Paris, Seuil, 2014, p. 187.

3. Algirdas Julien Greimas, Essais de sémiotique poétique, Paris, coll. L, Paris, 1972, p. 73 
toutefois avec le monde des relations étroites. Et, pour nous en tenir aux liens qu'elle entretient avec l'histoire, Ivan Jablonka estime qu' « il n'est pas difficile de leur trouver des points communs : volonté de peindre la réalité sans l'expurger ni l'idéaliser, intérêt pour la vie du peuple et les choses du quotidien, évocation des grands problèmes du temps ${ }^{4}$ ". Au-delà de leur intérêt commun pour l'histoire mouvementée du monde, leurs approches narratives ne sont pas si éloignées qu'on voudrait le croire. Hormis quelques rares survivants du courant positiviste, les historiens d'aujourd'hui sont conscients des limites de leur démarche scientifique; ils ont de plus en plus de mal à établir des frontières permettant de camper en maîtres incontestés sur un terrain qui leur appartiendrait en propre. Jablonka va même jusqu'à ne voir, dans l'histoire, qu'une littérature contemporaine. Demandons-nous, de notre côté, comment la littérature pourrait être une histoire contemporaine.

La littérature, notamment chez Khūrī, rejette la notion même de vérité et fait sienne le constat de Richard Rorty et de Pascal Engel :

Puisque le concept de vérité est aussi mince et aussi peu substantiel, il s'ensuit que le rôle épistémique que l'on accorde habituellement à la vérité - celui d'être une norme ou un but de nos enquêtes, et en particulier de l'enquête scientifique ne peut tout simplement pas être rempli: la vérité n'est ni une norme, ni un but ultime ${ }^{5}$.

Ce constat rejoint Michel Foucault dans sa remise en question de notre volonté de vérité. Cette dernière se pose comme principe d'ordonnancement du discours afin d'y maîtriser le hasard, le discontinu et le différent :

4. Ivan Jablonka, op. cit., p. 71.

5. Richard Rorty et Pascal Engel, À quoi bon la vérité? Paris, Grasset, 2005, p. 25. 
[...] Si on se pose la question de savoir quelle a été, quelle est constamment, à travers nos discours, cette volonté de vérité qui a traversé tant de siècles de notre histoire, ou quel est, dans sa forme très générale, le type de partage qui régit notre volonté de savoir, alors c'est peut-être quelque chose comme un système d'exclusion (système historique, modifiable, institutionnellement contraignant) qu'on voit se dessiner ${ }^{6}$.

Une représentation fragmentaire et antitotalisante de la réalité devra donc guider, désormais, l'écriture historique :

Instead of seeking common denominators and homogeneous networks of causality and analogy, historians have been freed, Foucault argues, to note the dispersing interplay of different, heterogeneous discourses that acknowledge the undecidable in both the past and our knowledge of the past. What has surfaced is something different from the unitary, closed, evolutionary narratives of historiography as we have traditionally known it ${ }^{7}$.

Une leçon qui devrait profiter à l'écriture fictionnelle. Pour répondre à la question de l'écriture de l'histoire dans la littérature contemporaine, Linda Hutcheon fait appel au concept de "métafiction historiographique" (historiographic metafiction ${ }^{8}$ ). Ce concept, spécifiquement adapté à l'écriture postmoderne, permet de saisir la double référentialité de la littérature, notamment de la fiction historique. Celle-ci mêle, dans la narration, histoire, parodie, politique et métafiction : « The postmodern historiographic metafiction merely foregrounds this inherent paradox by having its historical and socio-political grounding sit uneasily

6. Michel Foucault, L'Ordre du discours, Paris, Gallimard, 1971, p. 16.

7. Linda Hutcheon, The Politics of postmodernism, London and New York, Routledge, 1989 , p. 66.

8. Ibid., p. 2. 
alongside its self-reflexivity ${ }^{9}$. " La pratique de la métafiction historiographique fait appel à la paratextualité, aux archives et aux témoins dans l'intention parodique et subversive de briser les métarécits. Elle n’implique pas pour autant la disparition des frontières entre ce qui est historique et ce qui ne l'est pas, entre ce qui relève de la fiction et ce qui tient de la réalité, entre le passé et le présent. Et de se référer à Shame de Salman Rushdie, (La Honte, 1983 : 29) : " The country in this story is not Pakistan, or not quite. They are two countries, real and fictional, occupying the same space. My story, my fictional country exist, like myself, at a slight angle to reality. I have found this off-centring to be necessary; but its value is, of course, open to debate. My view is that I am not writing only about Pakistan ${ }^{10}$.»

L'œuvre de Khūrī obéit à cette double référence, au réel et au fictionnel, évoquée par Rushdie.

\section{Une crise de confiance et un exemple: l'enquête sur la mort de Khalīl Jābir}

Prochasson expose comme suit les raisons qui l'ont amené à s'interroger sur l'histoire contemporaine : "Ce livre a d'abord voulu tenter d'élucider quelques-unes des raisons qui expliquent la crise de confiance venue ébranler l'histoire savante depuis une vingtaine d'années ${ }^{11}$. " Nous constatons que le malaise qui s'empare de l'historien fait écho à celui auquel est confronté le romancier. (Voir supra chapitre 1, émergence de l'écriture métafictionnelle.)

\footnotetext{
9. Ibid., p. 15.

10. Ibid., p. 77.

11. Christophe Prochasson, op. cit., p. 205.
} 
D’ailleurs, Prochasson cite Julien Gracq qui a émis un constat analogue pour la littérature : «Une impression de désarroi, d'incertitude, de distance entre eux et le public se fait jour chez beaucoup d'écrivains, et comme le sentiment désagréable d'avancer sur une planche pourrie ${ }^{12}$. " Et de continuer avec un parallèle avec l'histoire: "C'est ce que l'on peut éprouver aujourd'hui lorsqu'on est un historien travaillant dans les travées de l'histoire savante. Celle-ci affronte une très préoccupante crise de légitimité ${ }^{13}$."

Cette crise de confiance impacte également l'écriture de Khūrī. Nous reviendrons brièvement sur l'histoire de Khalīl Aḥmad Jābir, dans al- Wujūh al-bayḍ̄à' (Un parfum de paradis), qui se présente comme une enquête sur une affaire criminelle. Le meurtre est annoncé dès la première page : " J'avais lu par un beau matin une nouvelle brève dans le journal: Meurtre atroce dans le quartier de l'Unesco. » (Wujūh, p. 9) Le narrateur-enquêteur se retrouve avec des informations multiples dont il n'arrive pas à tirer grand-chose :

En effet, après avoir rassemblé toute cette quantité immense d'informations, je me retrouve désemparé; il n'y aucun motif pour le décès, et rien ne justifie ce meurtre atroce et fascinant. Et moi, en vérité, je me retrouve dans un embarras total. Rien ne confirme aucune des suppositions et rien ne les nie, c'est pourquoi j'ai préféré laisser la parole aux documents et ne pas interférer dans le sujet. (Wujūh, p. 13)

Le roman mine la possibilité même de la vérité. L'enquête ne peut se terminer que par l'échec:

Mais j'ai mené des investigations. J'ai passé de longs mois à tourner, chercher et lire afin de savoir et j'ai fumé des mil-

12. Christophe Prochasson, op. cit., p. 206.

13. Ibid. 
liers de cigarettes, assis derrière la table à en avoir le dos brisé; tout cela pour savoir, mais en vain. (Wujūh, p. 303)

Un embarras qui risque de gagner le lecteur :

J'éprouve réellement un grand embarras.

L'auteur de cette histoire se sent perdu, il ne sait pas, il ne sait rien, alors qu'habituellement un auteur connaît tous les détails de l'histoire, surtout sa fin, et la présente graduellement et lentement, et le lecteur déduit.

Cependant, dans cette histoire, l'auteur ne sait pas, et ne sait pas comment présenter les choses graduellement et lentement, afin de convaincre le lecteur et le distraire. Et lorsque l'auteur est ainsi perdu, le problème devient plus compliqué. Est-ce possible que le meurtrier soit 'Alī Kalākish ou Fātima Fakhrū ou Samīr 'Amrū ou Fahd Badr al-Dīn ou Zayn 'Allūl ou 'Abū Saîd ou Nadīm al-Najjār ou Ilyās Khūrī ou, etc. (Wujūh, p. 300)

Le narrateur se tourne vers les archives : peut-être se révéleront-elles plus concluantes, là où les versions des témoins directs et indirects sont contradictoires. Or, un ami du narrateur, travaillant lui-même aux archives, lui apprend qu'ils ne font que traduire ce que leur transmettent les nombreuses agences d'informations. Là aussi, les sources écrites se révèlent aussi douteuses que les versions orales.

Le roman s’achève ainsi sur des suppositions : "نفترض " ("supposons "), répète le narrateur. Et de s'en remettre à Dieu, comme le font les gens de cette région : «Il y a donc trois possibilités et Dieu seul le sait. »(Wujūh, p. 338)

Une démarche analogue régit l'histoire de l'assassinat du moine Jirjī dans Mamlakat al-ghurabä’: " Nous sommes face à une information brève dans un journal. » (p. 119) L'énigme ne trouvera pas son élucidation, « quand bien même nous vivrions aujourd'hui à l'âge des archives " (p. 118). C'est que « ni l'archive ni le témoignage ne peuvent être considérés comme lieux 
d'accueil neutralisés d'informations inertes remplissant la besace de l'historien ${ }^{14}$ ", ainsi que le reconnaît Prochasson. L'auteur-narrateur doit renoncer à la recherche de la vérité. Son histoire est condamnée à rester une somme de possibles. Faut-il s'en désoler? Jablonka remarque que l'histoire n'est pas soumise à l'ordre supérieur que serait la vérité et qu'elle peut parfaitement se conjuguer au conditionnel :

La plausibilité structure [donc] un espace d'évaluation où, en une sorte de dégradé, le probable l'emporte sur le possible, plus acceptable que le douteux, supérieur à l'implausible (comme on dit en anglais). Elle entre pleinement dans la logique du contre-argument, qui consiste moins à administrer la preuve qu'à détruire des hypothèses mises en concurrence. Mais le vraisemblable, fût-il arc-bouté au bon sens le plus absolu, ne saurait constituer une preuve ${ }^{15}$.

Enquête méthodique mue par un processus de connaissance, investigations, archives, recours aux témoins, recherche des sources - autant de démarches qui autorisent un rapprochement avec les méthodes historiographiques - sont en tout cas fragilisées. Cette fragilité touche aussi bien la narration littéraire que l'écriture historique. Et rares sont encore ceux qui se focalisent sur les frontières, de plus en plus minces, qui opposent les deux approches.

L'histoire est elle-même fiction, car elle relève d'une interprétation. En histoire comme en fiction, les versions dominantes et unilatérales sont forcément erronées. La recherche de la vérité est une illusion. L'expérience de Khalīl en témoigne :

À chaque fois que je vous ai demandé ce qui s'était passé, vous avez commencé à mêler les événements de façon désordonnée, à bondir d'un mois à un autre, d'un village à un

14. Christophe Prochasson, op. cit., p. 33.

15. Ivan Jablonka, op. cit.,p. 202. 
autre, comme si le temps s'était effondré entre les pierres des villages en ruines. Ma grand-mère racontait comme si elle déchiquetait les histoires. Au lieu de les rassembler, elle les déchiquetait. Du coup, je n’ai rien compris, ni pourquoi notre village est tombé, ni comment. (Bāb. p. 172)

Les événements sont tributaires du temps et du « je " qui raconte. L'écriture devient réécriture. Toute tentative pour imposer un sens unique au récit est fallacieuse, car l'histoire achevée n'existe pas. Elle est toujours à reprendre, sous peine de se transformer en une histoire morte. Lyotard l'a bien dit: notre époque postmoderne se distingue par «l'incrédulité à l'égard des métarécits ${ }^{16}$ ». Dans Le Postmoderne expliqué aux enfants, il explique : «Cela ne veut pas dire que nul récit n’est plus crédible. Par métarécit ou grand récit, j'entends précisément les narrations à fonction légitimante. Leur déclin n'empêche pas les milliards d'histoires, petites et moins petites, de continuer à tramer le tissu de la vie quotidienne ${ }^{17}$. "

L'œuvre de Khūrī travaille précisément à la " délégitimation " de l'autorité des grands récits inhérents à sa société et libère des " milliards de petits récits ". Les récits seront, dès lors, à reconstruire en permanence. Dépouillée de son caractère d'évidence, l'histoire devra se résoudre à cette fragmentation et à l'acceptation de la part de fiction qu'elle recèle inévitablement.

\section{Déconstruction des figures de l'héroïsme: le fedayin, le martyr}

Le héros. Bāb al-shams est le roman de la nakba. Il relate la résistance et la lutte du peuple palestinien pour récupérer sa terre perdue en 1948 face à Israël. Yūnus, fils d'Ibrāhīm, fils de

16. Jean-François Lyotard, La Condition postmoderne, Paris, Minuit, 1979, p. 7.

17. Id., Le Postmoderne expliqué aux enfants, p. 38. 
Sulaymān al-Asadī, est né dans le village de 'Ayn al-Zaytūn en Palestine, d'un père aveugle et d'une mère souffrant d'une maladie étrange qui lui faisait perdre ses mamelons et l'empêchait d'allaiter ses nouveau-nés qui mouraient aussitôt. Yūnus n'est pas le seul nom du personnage. Sa mère préfère l'appeler 'Izz al-Dīn (" gloire de la religion »). Pour mettre fin au litige avec son épouse, son père lui donne également le nom de 'Abdulwāḥid (" adorateur/serviteur du dieu unique »). Le narrateur lui trouve d'autres pseudonymes comme Ādam («Adam») ou Dhi ’b ("Loup »).

Yūnus est considéré comme un héros pour avoir résisté à l'occupation israélienne et participé aux combats. C'est un homme d'exception qui a pris sur lui la tâche de récupérer la Palestine perdue. On ne saurait trop le louer: les mots "héros " et " héroïsme " بطل / (بطولة) reviennent au moins une cinquantaine de fois au fil des pages. Yūnus s'impose comme un repère hiérarchique : c'est à lui que s'adresse le narrateur tout au long du texte.

Le roman est porté par un souffle épique ${ }^{18}$ perceptible, par exemple, dans ces lignes où le narrateur ressuscite la mythologie grecque :

[...] En me dirigeant vers le stade, je me suis imaginé faire partie d'une épopée grecque, partir pour une nouvelle Odyssée palestinienne. Je ne suis plus tellement sûr: avais-je pensé à l'Odyssée ce jour-là, ou est-ce que je dis cela seulement aujourd'hui après avoir lu le long poème écrit par Maḥmūd Darwīsh à ce sujet, bien que le poète lui non plus, ne se soit pas embarqué sur les bateaux grecs qui ont porté les Palestiniens vers leur nouvelle errance. ( $B \bar{a} b$, p. 96)

18. Cf. Gérard Lambin, Genèse d'un genre littéraire en Grèce, Rennes, Presses universitaires de Rennes, 1991. 
Certaines caractéristiques du héros épique se retrouvent chez Yūnus. Sa naissance quasi miraculeuse est une célébration du combat initial entre Éros et Thanatos, entre le monstre qui menace symboliquement le soleil et la victoire sur ce monstre. Voici ce que raconte la légende au sujet de Yūnus :

Elle a dit que Cheikh Ibrāhīm bin Sulaymān al-Asadī, fils de Sālim, fils de Sulaymān al-Asadī, avait quarante ans lorsqu'il s'est marié. Pendant vingt ans, sa femme avait mis au monde des enfants qui mouraient quelques jours après leur naissance. Elle était atteinte d'une maladie sans nom. Ses mamelons s'infectaient et tombaient dès qu'elle commençait à allaiter, et le bébé mourait alors de faim. Puis tu es né. Toi, seul, avais réussi à prendre un sein sans mamelon. Tu mordais le sein et tétais, et ta mère criait de douleur. Tu avais ainsi échappé à la mort et survécu. ( $B \bar{a} b$, p. 18)

Qui plus est, pour le rappeler une fois encore, par la symbolique du nom qu'il porte, Yūnus répète cette victoire contre les ténèbres. Yūnus, pareil aux héros antiques, souvent représentés à cheval pour suggérer la victoire remportée en franchissant les frontières, doit souvent passer d'un pays arabe à un autre pour chercher armes et secours. Les allers retours du camp de Shātīlā, au sud du Liban, à la Galilée pour rejoindre sa bien-aimée Nahīla sont risqués, les Israéliens étant à sa recherche. Chaque fois qu'il réussit à atteindre sa destination, c'est une victoire sur la mort.

Dans l'épopée, la conquête de la femme va de pair avec celle de la patrie, et sa perte est un signe annonciateur de la perte de cette dernière. Ainsi en est-il dans Bāb al-shams : " Nous devons être à un tournant dangereux, car quand on n'a plus de nouvelles des femmes, cela signifie qu'on approche de la fin. La femme ne s'enfuit que lorsque la vie s'éteint. » (Bāb, p. 498.)

Yūnus et Nahīla ne s'accouplent que dans la caverne de Bāb al-shams, la terre mythique fondée par le héros et qui préfigure 
la nouvelle Palestine. Le rapport sexuel anticipe symboliquement le retour au pays. Le héros ne peut véritablement s'accoupler qu'avec son rêve : une grande cause. Dès lors, les soucis de la vie quotidienne ne le préoccupent plus guère.

Bāb al-shams comporte également des scènes de tueries, ne nous épargne pas la description minutieuse des violences perpétrées dans les combats et fait la part belle aux affres des Palestiniens durant la période marquée par l'expulsion de leur terre en 1948 et les combats qui s'ensuivirent. La description des massacres de Shātīlā et de Șabrā constitue un des points forts du catalogue morbide du roman.

Une autre constante de l'épopée est la symbiose entre le héros et la masse qu'il galvanise à l'occasion d'actions collectives, parfois sanglantes, où l'unité mythique du groupe se réalise. La bataille de Kābrī est, à cet égard, exemplaire: «Une véritable épopée. Les tirs s'étaient poursuivis jusqu'à l'aube [...] et n’avaient cessé que lorsqu'ils [les Israéliens] avaient tous été tués. » (Bāb, p. 180)

Cependant, ces traits épiques, supposés rejaillir glorieusement sur le personnage du héros, agissent en fait comme un contre-chant, l'exagération finissant par décrédibiliser le chant héroïque, et révèlent une intention parodique de désacralisation. Devant la version " surnaturelle " de l'histoire de la naissance du héros, le narrateur affiche un scepticisme sarcastique. Se demandant pourquoi cette femme n'a pas choisi tout simplement d'aller consulter un spécialiste capable de la guérir de sa maladie, le narrateur nous fait brusquement chuter dans le trivial - faisant ainsi ressortir le contraste entre une mentalité traditionnelle et une autre, plus rationnelle.

Quant aux pérégrinations à saute-frontières, apanage des héros épiques, elles cessent très vite. Yūnus prend prétexte de la fermeture des frontières du Liban-Sud par les forces de 
l'occupation, après 1978, ce qui rend, selon lui, les traversées impossibles. Le narrateur, pour sa part, semble pencher pour des raisons moins avouables, comme le refroidissement des rapports entre Yūnus et sa femme à la suite de leur entrevue ultime sous l'olivier ou, plus fondamentalement, «l'embourgeoisement » du héros qui s'est transformé en fonctionnaire sans relief d'un État embryonnaire, un dirigeant parmi d'autres, aimant le luxe et le confort. "Yūnus était devenu un rouage de cette immense machinerie. Il n'était plus ce fedayin errant » (Bāb, p. 409)

Soulignant ainsi la confiscation et la domestication de la lutte armée par l'institution étatique, le narrateur porte un jugement sévère sur les nouvelles institutions palestiniennes, coupables à ses yeux de corruption, de bureaucratisation et de ternissement de l'image du fedayin, telle qu'on pouvait encore la voir exalter chez un Jean Genet, par exemple ${ }^{19}$ :

Les fedayins ne ressemblaient plus aux fedayins et, là, il ne s'agit pas de corruption, de pots-de-vin ou des discordes d'avant l'invasion de 1982. Je sais que cela existait et que nous en avions honte. Pourtant, il y avait alors quelque chose qui nous permettait de tolérer la situation, disons, qu'il y avait d'abord notre cause primordiale qui prévalait sur les pourris et les salauds. (Bāb, p. 404-405)

La valorisation du héros côtoie sa démythification. Le coma transforme Yūnus en non-sujet; il lui ôte toute possibilité de prendre véritablement part à l'action, le marginalise d'emblée et anticipe la fin proprement dite du roman. Quant à l'hypertrophie du signifié héroïque, loin de rehausser le héros, elle cache au contraire une intention ironique dévalorisante. Ces paroles, rapportées par le narrateur, prouvent que le roman prend ses distances par rapport à cette notion désuète, d'autant plus que celui

19. Cf. Jean Genet, « Les Palestiniens », in Genet à Chatila (textes réunis par Jérôme Hankins), Paris, Solin, 1992. 
qui est considéré comme héros par les autres ne se prend pas lui-même au sérieux et ne s'estime pas lui-même comme tel :

Tu m'as dit: "Les gens pensent que les combattants sont des héros, mais ce n'est pas vrai. L'homme se bat comme il respire, comme il mange ou comme il va aux toilettes. Pour faire la guerre, il ne suffit pas de combattre pour combattre. L'héroïsme est quelque chose d'autre. L'héroïsme n'existe pas. Le courage même n'a aucune valeur; un homme courageux peut devenir un lâche et vice versa. » (Bāb, p. 30.)

Les combattants, supposés accompagner le héros dans ses exploits, sont également dévalorisés. Ce sont de simples paysans qui se sont vus obligés de défendre leur terre, de porter les armes, tout en n'ayant jamais appris les techniques de la guerre :

Nous ne nous sommes pas battus. Aujourd'hui je dis que nous l'avons fait, que la Palestine a été perdue parce que les pays arabes nous ont trahis, mais ce n'est pas vrai. La Palestine a été perdue parce que nous ne nous sommes pas battus. Nous étions pareils à des idiots, nous portions nos fusils et nous les attendions dans nos villages et, lorsqu'ils arrivaient avec leur artillerie lourde, leurs mitrailleuses et leurs avions, nous nous retrouvions défaits sans nous être battus. ( $B \bar{a} b$, p. 90.)

$\mathrm{Au}$ demeurant, Yūnus est une incarnation d'autres figures bibliques, telles que Job, Abraham, le Christ. Mises en abyme, ces figures reproduisent le mouvement inhérent à l'histoire de Yūnus, celui d'une prospérité originelle, d'une descente dans l'humiliation et d'un retour à la prospérité. L'insertion de Yūnus dans la mythologie biblique conforte la conviction du peuple palestinien dans le caractère provisoire de ses souffrances et dans l'imminence de sa rédemption future.

Mais c'est justement sur le fond de cette mythologie, qui est en même temps celle de tous et dont tous veulent avoir l'exclusivité, que prend naissance une guerre sans merci et sans fin. 
L'allusion à une origine commune trouve sa légitimation dans la figure emblématique d'Abraham, car c'est de son union avec Agar que naquit Ismaël et que sa lignée prospéra. De par les références mythologiques, le roman affiche une prise de position contre le discours sioniste qui, en fondant la création d'EretzIsraël sur la mythologie biblique, prétend évincer le droit d'autres peuples à la même terre.

Le martyr. La figure du héros côtoie celle du martyr et peut se confondre avec elle. Le sacrifice de sa vie est considéré, dans certaines cultures, comme un acte héroïque. Le roman de Khūrī, tout en dévoilant les conditions humaines et politiques qui mènent à la valorisation du martyre, dénonce le non-sens de tels actes.

Le martyre s'inscrit dans deux cadres différents. Le premier est celui d'une lutte nationale — c'est le cas en Palestine - , le second est celui de la guerre civile libanaise. Si la mort est considérée par celui qui fait sacrifice de sa vie et par sa communauté comme porteuse de sens, elle n'a pas le même poids dans le roman selon qu'elle s'inscrit dans l'un ou l'autre cadre. La lutte pour la cause palestinienne a une autre valeur que les tueries auxquelles se sont livrés les différents partis politiques libanais. Malgré cette différence qui n’a rien de minime, le martyre, censé être un argument déterminant dans le combat pour les valeurs, est présenté, dans les deux cadres, comme un acte vain.

Qui est le martyr ? Selon Pénélope Larzillère, sociologue qui a travaillé sur la question des kamikazes palestiniens, «le vocable shahīd est utilisé par les Palestiniens pour désigner indistinctement tous les morts du conflit qui les oppose à Israë ${ }^{20}$ ". Ce

20. Pénélope Larzillère, « Le martyre des jeunes Palestiniens pendant l'intifada al-Aqsa: analyse et comparaison », in Repères, 4-2001, p. 937. Consulté en ligne sur le site www.ifri.org, le 2 décembre 2016. 
Elias Khoury - De l'engagement au postmodernisme

terme, dit-elle, a éclipsé celui de fedaï : " Le mot shahīd - martyr - a toujours existé pour décrire les morts au combat, mais la figure héroïque était celle du fedaï, lequel devenait shahīd une fois décédé21."

Dans un article consacré à l'analyse des sociétés arabes suite aux défaites de 1948 puis de 1967, Bassma Kodmani situe la glorification de la mort dans le contexte d'une société qui se considère en état de guerre légitime, comme c'est le cas en Palestine. Le martyre, d'abord à connotation nationale, a été sacralisé par les islamistes :

Certes, une famille n'est pas moins désespérée par la disparition de son enfant; mais les sociétés se considèrent en état de guerre, une guerre légitime dont la douleur fait partie. C'est de cette époque que date la glorification de la mort, d'abord par le mouvement des fedayins palestiniens, qui se sacrifient pour la terre et la sauvegarde de l'identité nationale, puis par les mouvements islamistes qui la récupèrent et la sacralisent ${ }^{22}$.

Agnès Devictor souligne la connotation religieuse du terme shahīd:

Le mot qui désigne un martyr, shahid/shohadâ, signifie littéralement « témoin ». Il est celui qui " atteste ». Selon certaines traditions, le martyr verrait Dieu (comme expérience intime) au moment où il serait choisi par lui, c'est-à-dire, au seuil de sa mort. Mais le martyre est-il pour autant synonyme de mort? Est-il un " entre deux ", une forme de transit, entre la vie et la mort? Dans le Coran, les martyrs sont les combattants d'Allah tombés pour faire triompher la foi et la Justice (haqq). S'ils atteignent le paradis par cet acte, ils ne sont pas pour autant considérés comme morts. « Ne crois surtout pas que ceux qui

21. Id., "Palestine: les attentats suicide comme arme ultime », entretien conduit par Jean-François Mayer le 24 juin 2003. Consulté sur www.terrorisme.net, le $3 / 12 / 2016$.

22. Bassma Kodmani, « Une génération arabe traumatisée par la défaite », op.cit. 
sont tués sur le chemin de Dieu sont morts, ils sont vivants " (Coran, III-169, La famille d'Imran). « Ne dites pas de ceux qui sont morts sur le chemin de Dieu "Ils sont morts". Non! Ils sont vivants, mais vous n'en n'avez pas conscience " (Coran II-154, La Vache). Toute une littérature de guerre révèle les perceptions du martyre qu'avaient les volontaires: une mort mise en scène, déréalisée, désirée, esthétisée, voire érotisée ${ }^{23}$.

Dans un contexte de lutte nationale, la dimension religieuse reste, selon Larzillère, moins prégnante que la connotation militante - mais cela n'exclut pas, à long terme, que cette dernière soit incluse dans une dimension de « jihad».

Se sacrifier pour un idéal est considéré comme un acte héroïque qui sanctifie son auteur sans que celui-ci soit nécessairement doté d'aptitudes supranaturelles. Yūnus, après sa dévalorisation, a été dépossédé de ses habits d'apparat et s'est découvert à nous comme un être fragile connaissant, comme tout le monde, des moments de faiblesse, d'humiliation, de rage, d'espoir et de désespoir, un homme tout simplement. Entre les fissures du masque rigide d'un héroïsme en désuétude, émerge la blessure fondamentale de l'être, en contraste avec la cuirasse héroïque. Ainsi réduit à sa pure humanité, Yūnus garde toutefois le privilège d'être mort pour la patrie, martyre qui l'élève au rang des héros. Le martyre est pourtant loin d'être valorisé dans Bāb al-shams. Mourir pour un idéal, notamment la cause palestinienne, est certes légitime, la mort étant alors vécue comme "douce " et exploitée dans l'élaboration d'un discours mythologique assurant la cohésion du groupe. Mais il arrive que la mort du martyr devienne absurde et ne manifeste que sa vacuité. Comme saga de l'exode massif d'un peuple en quête d'identité, le

23. Agnès Devictor, "La notion de martyr en sciences politiques: des croyances aux mobilisations », congrès AFSP, Strasbourg, 2011, consulté en ligne, le 8 août 2017, sur le site www.congres-afsp.fr. 
roman est prisonnier de son thème à connotation nationale et ne peut faire table rase du culte dédié à la mort des héros ; en même temps, il porte sur eux un regard sévère et explique la raison qui fait de leur mort un non-sens.

Depuis le XIX ${ }^{\mathrm{e}}$ siècle, et en réaction à l'implantation sioniste, la conscience de soi des Palestiniens est devenue plus assurée et une réflexion identitaire a vu le jour. Cela s'accompagne d'un discours nationaliste réservant une place éminente aux héros et aux martyrs ; le terrain nationaliste, révolutionnaire, combatif, engendre ses propres images culte, les investit d'une aura transcendant les limites de la personnalité historique de ceux qui sont dès lors transformés en morts "symboliques".

Le sentiment d'appartenance à la patrie est renforcé par la mise en avant des images de héros légendaires. Le nationalisme ne va pas de soi, il doit élaborer ses propres textes fondateurs comme autant de mythologies dans lesquelles se reconnaît la conscience collective d'un peuple. Il a besoin d'images de héros comme autant de modèles à imiter. Et la frustration, la misère et l'humiliation consolident le besoin d'un discours fondateur: le nationalisme a ainsi besoin de la mort comme ciment à son discours. Dans un ouvrage intitulé La Nation et la mort, Idith Zertal montre que les catastrophes se transforment en fables nationalistes héroïques : "Au carrefour de la mémoire et de l’identité nationale gît une tombe, habite la mort ${ }^{24}$. " Par le sacrifice qu'il fait de sa vie, le héros se métamorphose en " projet mémoriel " sur lequel se fonde « la sainte trinité patriotique qui unit la mort, le territoire et la mémoire ${ }^{25}$ ".

Des défaites qui n'ont à la base rien d'héroïque sont transformées en symboles de triomphe, et en modèles d'émulation pour

24. Idith Zertal, La Nation et la mort, Paris, La Découverte, 2004, p. 15.

25. Ibid., p. 31. 
les jeunes, modèles propres à enflammer leurs esprits et exacerber leur désir de mourir à leur tour. Ce qui compte n'est pas l'événement concret en tant que tel, mais son appropriation et sa retransmission par les vivants en vue de créer un imaginaire national. La transformation du héros-martyr en symbole national sacré permet la consolidation du groupe et la formulation d'un discours mobilisateur:

La promesse de vie éternelle faite aux jeunes gens qui tombent au champ d'honneur, le culte des morts et leur sanctification à travers des rituels mémoriels, correspondent à ce que Georges Moss définit comme la création d'une nouvelle religion civique au sein des États-nations du début du $\mathrm{xx}^{\mathrm{e}}$ siècle. Ils fonctionnent également comme instrument de mobilisation et de préservation d'une société guerrière et conquérante et comme compensation des sentiments refoulés de culpabilité engendrés par le " meurtre " de ses fils; un meurtre incessant et conscient qui se voit simultanément sanctifié et justifié par une situation permanente de lutte et de conflit ${ }^{26}$.

Cependant, lorsque la mort pour la nation devient absurde, lorsqu'elle n'est plus transfigurée et ne donne lieu à aucun récit fondateur, elle est condamnable. C'est la raison fondamentale pour laquelle l'image du martyr constitue dans Bāb al-shams la cible d'une critique sans merci.

La consécration de la mort permet d'effacer fantasmatiquement la honte qui terrasse les Palestiniens depuis leur défaite. Comme le disait Laylā Shahīd, " quant on prend la terre à un paysan, c'est comme si on le déshonorait, comme si on le castrait, on lui enlevait son âme. " Ces « fils de la honte ${ }^{27}$ " développent

26. Ibid., p. 28.

27. C'est le titre d'un texte d'Alain Milianti paru in Genet à Chatila, et publié également dans la Revue d'études palestiniennes, n 42 (hiver 1992). 
une imagerie révolutionnaire incluant le culte du fedayin. À la mort de ce dernier, une affiche le représentant est collée sur les murs. Anticipant sa propre mort, le fedayin se regarde dans l'image qu'il s'est inventée de lui-même, se dédouble, se voit différemment et finit par éprouver un désir - en soi contradictoire — d'assister à la cérémonie de sa propre mort glorieuse : « Avant de mourir, le fedayin est fasciné par sa propre mort, c'est pourquoi il y va consentant. » (Bāb, p. 315). Et de commenter :

Te rappelles-tu comment nous tremblions devant les affiches des martyrs? Comment nous avions l'impression que le martyr allait déchirer les photos en couleurs, qu'il allait jaillir vers nous. Les affiches faisaient partie intégrante de notre vie. Nous en couvrions les murs du camp et de la ville. Nous rêvions d'y voir nos photos. Nous avions tous rêvé d'avoir notre photo encadrée d'une bande rouge vif et entourée de l'auréole des martyrs. Il y avait dans tout cela une contradiction à laquelle nous ne prêtions pas attention: nous voulions avoir nos photos sur l'affiche et nous voulions pouvoir les regarder en même temps. Nous voulions être des martyrs sans mourir! (Bāb, p. 127-128)

Cette idée, Khūrī l'avait illustrée dans une performance cinématographique, réalisée avec Rabih Mroué, à partir des enregistrements vidéo du kamikaze Jamāl al-Sātī. Aliocha Imhoff et Kantuta Quiros en parlent dans leur article « Nouvelles géographies visuelles » :

En 2000, Rabih Mroué et Elias Khoury retrouvent sur les étagères poussiéreuses du siège du Parti communiste libanais l'enregistrement vidéo VHS de Jamal El Sati, qui, en 1985, enregistrait un témoignage à destination de la télévision, avant d'entreprendre une opération suicide contre l'armée israélienne qui occupait le Sud-Liban. Elias Khoury et Rabih Mroué découvrent sur les rushes quatre prises différentes de l'enregistrement, où Jamal El Sati répète, tel un acteur, 
la phrase "Je suis le martyr ". La prise retenue à l'antenne fut celle contenant le moins de traces d'émotion et la plus à même d'alimenter la " Fabrique du Héros ". Le paradoxe de cette phrase « je suis le martyr " qui équivalait à dire « je suis mort " produisait un trouble quant au statut de la vidéo, celleci étant supposée être un enregistrement de ce qui a déjà eu lieu. Confrontés à l'image de ce sujet vivant qui se déclare comme étant un corps déjà mort, Rabih Mroué et Elias Khoury décident de réaliser une performance intitulée «Three Posters " et d'examiner ce geste vidéographique, entamant une interrogation autour d'une épistémologie de l'image. La performance fut invitée à voyager dans de nombreux festivals étrangers, principalement européens. En 2004, Rabih Mroué décide de ne plus jamais réaliser cette performance constatant son appropriation erronée par les médias et la presse étrangère. Il réalise alors " On three posters » (18 min, 2004), vidéo où, Rabih Mroué, face caméra sur fond blanc, explique les raisons qui l'ont mené à ne plus jouer cette performance ${ }^{28}$.

La prolifération hasardeuse de telles figures finit par les vider complètement de leur sens et par les dévier de leur fonction initiale, celle de fonder la cohésion du groupe et de donner lieu à l'élaboration d'une mémoire collective. Le martyre, tel qu'il est vécu dans un Moyen-Orient éclaté et déboussolé, ne donne plus sens à la mort des victimes et ne justifie plus leur sacrifice. Il devient une figure banale, souvent abjecte, où la mort n'est transcendée vers aucun horizon et ne témoigne que de son nonsens absolu. C'est pourquoi cette figure, récurrente, peut être atteinte par la dérision. L'exemple de 'Adnān Abū 'Awda est entaché de l'ironie du narrateur face à la mort héroïque des combattants. À sa sortie de la prison israélienne, 'Adnān est interné dans un hôpital psychiatrique où il finit ses jours enchaîné et soigné

28. Aliocha Imhoff et Kantuta Quiros, Artpress, Cinémas contemporains, n²1, maijuin-juillet 2011, article en ligne: http:// wwwartpress:com. 
par électrochocs. Sa fin tragique n'est pas sans rappeler à Khalīl l'état végétatif de Yūnus; c'est pourquoi il imagine une autre fin à l'histoire de 'Adnān, plus héroïque, dans laquelle Yūnus lui tire une balle dans la tête et le déclare martyr. Cette version est la seule qui sied à un combattant. Mais elle est, à son tour, tournée en dérision : "puis il se pencha sur son ami couvert de sang, le prit dans ses bras en pleurant et dit: "Ce n'est pas moi, c'est Israël qui t’a assassiné. Adnān mourut en martyr. Sa photo fut imprimée sur de grandes affiches rouges. Il eut des funérailles grandioses. " (Bāb, p. 139)

La transformation de la défaite en un acte héroïque correspond au besoin de donner un sens à la mort absurde des combattants. Tout en donnant les clefs d'une compréhension profonde des mécanismes psychologiques de ce besoin, la transformation de l'histoire par Khalīl exerce le pouvoir dissolvant de l'ironie. En effet, ce sens donné à la mort, inventé de toutes pièces, ne parvient pas à transformer le réel. En prenant une distance critique vis-à-vis des actes de martyre, le roman tend, d'une part, à les délégitimer et les désacraliser et, d'autre part, à dévoiler le désespoir que cette pratique dissimule mal. La mort " héroïque » de 'Adnān est réduite à une simple affiche et oubliée aussitôt. Qu'il est facile de s'acheter une bonne conscience avec une photo!

La dévalorisation de l'image du martyr est liée à l'absence d'un authentique récit mémoriel, capable d'ériger les morts en monuments pour la nation. Cette idée émerge dans des ouvrages antérieurs. Dans al-Wujūh al-bayḍ̄à', par exemple, Aḥmad, un jeune garçon d'intelligence moyenne, féru de sport, enrôlé par les milices lors de la guerre civile libanaise, meurt dans des circonstances mystérieuses. Aucune allusion dans le texte ne permet de dire que sa mort soit advenue dans l'arène du combat. Elle ne donne lieu d'ailleurs à aucune enquête ni tentative 
d'élucidation. Le cadavre du garçon est retrouvé trois jours plus tard dans un état de décomposition avancé. Il est déclaré martyr, une somme d'argent est versée aux parents et un grand nombre de photos sont imprimées et collées aux murs. La sacralisation de la mort de son fils constitue pour le père un dérivatif à sa douleur et fait communier l'ensemble du voisinage dans un deuil dont il finit par tirer une certaine fierté. Les photos ont consolé le père dans un premier temps mais, lorsque le tirage s'est raréfié avec le temps et que son fils a été englouti par les forces de l'oubli, il sombre dans une tristesse profonde et développe une maladie étrange, muette, dont les symptômes s'expriment par l'obsession de peindre les murs de la ville en blanc. Face à l'indifférence croissante du monde qui l'entoure, le père se venge sur la ville. En couvrant les murs de peinture blanche, il essaie d'envelopper la ville d'un linceul pareil à celui dont a été couvert son fils, anéanti par la guerre. En apparence, il a cessé de parler de son fils et tout semble être rentré dans l'ordre. Or, les apparences se révèlent trompeuses, car l'homme n'oublie jamais les mutilations subies. Cet oubli est une mémoire refoulée qui continue à agir dans les profondeurs de la psyché humaine et dont la résurgence est inévitable.

\section{Une contre-histoire: figure sacrale de la victime}

Les personnages marginaux et les laissés-pour-compte font volontiers des héros. La souffrance est une épreuve initiatique qui grandit la personne et la transfigure. C'est l'humain dans ce qu'il a de plus profondément tragique qui est héroïque. C'est pourquoi le narrateur, écoutant l'histoire d'un certain Kamāl Abū Snūnū dont le village, le kiosque à journaux, la femme et la vie, ont été détruits, s'écrie : «Comment avez- vous pu supporter la vie? Comment avez-vous pu supporter ce qui vous est 
arrivé ? " (Bāb, p. 451) Le tragique est scandaleux. La capacité de l'homme à l'endurer relève de l'héroïsme ou de la sainteté. Les héros de Khūrī sont les descendants de Job et héritent de son destin. Ils sont les victimes d'une grande injustice. En révélant le tragique de leur condition, le roman déclenche, en outre, une réaction émotionnelle face à l'injustice, relançant, par là-même, les valeurs à défendre.

Dans Bāb al-shams, la population est contrainte à l'exil ; elle a fait preuve de courage et d'endurance et a risqué sa vie dans des tentatives isolées pour rentrer au pays. Ces gens pourraient être considérés comme les véritables héros de cette odyssée palestinienne. C'est dans Yālū que la sanctification de la victime est le mieux développée. Les souffrances de Yālū le purifient. Ce milicien chrétien qui vit en marge de la société, tue, vole et viole, est emprisonné et endure les pires tortures. Mais il est d'abord une victime. Son père l'avait abandonné enfant, ensuite la guerre en a fait un paria. Sa souffrance est une catharsis qui l'élève au rang des héros: "Yālū n'est pas un des héros de l'Histoire, mais il est un héros, c'est-à-dire qu'il y a quelque chose d'héroïque dans sa vie. » (Yālū, p. 311) D’ailleurs, il n'est pas sans rappeler l'Idiot de Dostoïevski. Le Christ devient le symbole de la souffrance humaine.

Sobhi Boustani souligne que le titre des romans historiques est habituellement le nom propre d'un grand personnage de l'histoire. En prenant pour titre le nom propre d'un marginal et d’un déviant, le roman Yālū désacralise le personnage-héros : "Contrairement aux personnages historiques chargés a priori de signifiés parfois mythiques et légendaires, le nom propre non historique est un signifiant sans aucun signifié29. " Lorsque

29. Sobhi Boustani, «Violence et marginalité: essai sur le roman Yâlû d'Elias Khoury ", in Aux marges de la littérature arabe contemporaine, Laurence Denooz et Xavier Luffin (éds.), Helsinki, Academia Scientiarum fennica, 2013. 
l'histoire est reconstituée par la victime, cela conduit, dit-il, à la cohabitation de l'histoire et de sa contre-narration : "Le roman Yālū exprime, en filigrane, une nouvelle approche historique. Aux personnages reconnus comme "historiques " dans la mesure où ils sont acteurs de l'histoire dans sa conception conventionnelle, Elias Khoury oppose un personnage/héros qui illustre la face méconnue de l'histoire, la contrehistoire ${ }^{30}$. »

De la même façon, les romans de la trilogie ( $B \bar{a} b$ al-shams, Yālü, Ka'annahā nā'ima), en plus de leur dimension religieuse, pourraient être lus comme des entreprises de désacralisation de l'histoire. L'ambivalence du double installée au sein d'un même personnage - Yālū et son double Danyāl (Yālū), Khalīl et son double Yūnus ( $B \bar{a} b)$, Mīlyā la diurne et Mīlyā la nocturne (Ka'annahā nā'ima) - représente le croisement et la séparation d'un grand récit et de son contre-récit parodique.

La littérature a pour devoir de combler la terreur du vide : "Les gens disparaissent parce qu'ils n'ont pas de nom; ils sont réduits à des numéros. Voilà ce qui est terrible, mon fils. La terreur c'est le numéro. Et c'est pourquoi les gens portent sur eux les photos de leurs morts et de leurs proches disparus, ils en font le substitut des noms. » (Bāb, p. 497-498.)

L'œuvre de Khūrī se donne pour la voix des sans-voix. Cette tendance à la prise en charge de la mémoire des victimes nourrit également l'écriture de l'histoire depuis la fin de la Seconde Guerre mondiale. Sans chercher à délégitimer les devoirs mémoriels, et tout en leur accordant une fonction historiquement utile, celle de conférer aux victimes les droits à l'histoire dont elles ont été privées, Prochasson ${ }^{31}$ voit dans ce resurgissement de la

30. Id., p. 12.

31. Christophe Prochasson, op. cit., p. 113. 
souffrance des victimes une manière de combler le vide laissé par l'affaiblissement des grandes causes : «Le même élan compassionnel [qui] agite désormais notre époque, en lieu et place de nos anciennes passions politiques. "

Le narrateur, dans Bāb al-shams, découvre la fin des grandes idéologies de gauche: la puissance que sa foi dans l'Histoire aurait pu lui conférer cède la place au découragement. Envoyé en Chine pour participer à un entrainement militaire, Khalīl s'était auto-imaginé au cœur de l'Histoire et avait cru au projet marxiste de changement de la société. Dans les camps palestiniens, les idéologies ne furent pas d'un grand secours, et n'ont pas évité que les combattants se transforment en " projets de martyrs » (Bāb, p. 155).

"L'Histoire est un monstre qui nous avale ", écrit d'ailleurs Khalīl (Bāb, p. 156). Elle est "démente " (p. 158), ou encore : «l'Histoire est un animal sauvage » (p. 435).

La première leçon est un constat de l'absurdité de l'histoire. Les victimes de la Shoah sont devenus les nouveaux bourreaux des Palestiniens: "Je ne peux pas voir la victime se transformer en bourreau, cela signifie que l'Histoire n'a pas de sens. " (Bāb, p. 419)

Étant irrationnelle, l'histoire finit par vaincre tout le monde. Ceux qui pensent être victorieux aujourd'hui sont les vaincus de demain. Khalīl est ainsi en droit de conclure que, comme il n'y a pas de vainqueur éternel, le jour viendra où Israël sera vaincu à son tour :

Tu n’aimes pas le mot «éternel ». Tu disais: "Les Juifs sont bornés, c'est quoi ce slogan stupide qu'ils brandissent: Jérusalem capitale éternelle d'Israël ». Quiconque parle d'éternité sort de l'Histoire, car l'éternité est contraire à l'Histoire et il n’y a rien d'éternel. Paroles de merde tout cela. Foutaises. 
Cela veut dire qu'ils commencent à devenir comme nous, c'est-à-dire susceptibles d'être vaincus. (Bāb, p. 128)

Une leçon de plus que les vainqueurs feraient bon de ne pas oublier.

Khūrī ne succombe toutefois pas à une vision manichéiste :

Tu crois, et j'aimerais le croire aussi, que nous n'avons pas tué nos fils et ne les avons pas jetés sous les arbres. Tu veux les choses claires et simples: l'assassin est bien décidé, sa victime aussi, et à nous d'établir la justice. Mais non, Monsieur, les choses n'étaient malheureusement pas aussi simples qu'eux et nous, c'était quelque chose de différent et difficile à définir. (Bāb, p. 211)

Le projet littéraire de Khūrī tente justement de sonder la complexité d'une Histoire douloureuse et ténébreuse.

\section{Réinventer le Palestinien}

Fidèle à son désir d'être la voix des laissés-pour-compte, Khūrī entreprend une lecture de la figure du Palestinien dans les littératures palestinienne et israélienne. Dans une allocution prononcée à l'Institut national des langues et civilisations orientales ${ }^{32}$ (INALCO), il souligne l'identité problématique du Palestinien. Contrairement à l'identité juive, qui comporte des connotations religieuses, celle du Palestinien est principiellement liée à un territoire, la Palestine. Et la perte de ce territoire a rendu la question extrêmement complexe. Avec l'annexion de la Cisjordanie par le roi Abdallah, les Palestiniens de la Jordanie sont devenus Jordaniens. Par contre, ceux du Liban et de Syrie sont devenus, comme on les appelle, des "réfugiés ". Une réinvention du

32. Ilyās Khūrī, « Réinventer le Palestinien », INALCO. 6 juillet 2017, conférence tenue dans le cadre du Groupement d'intérêt scientifique sur le Moyen-Orient et les mondes musulmans. 
Palestinien s'impose. C'est ce que nombre d'écrivains et d'artistes ont tenté de faire à partir des années 1950. En témoignent les œuvres de Rajab Ḥussayn, Samīr Azzam, Maḥmūd Darwīsh, Ghassān Kanafānī, Samīḥ al-Qāsim, Jabrā Ibrahīm Jabrā et Imīl Habībī.

Or, cette réinvention littéraire se heurte au silence de la victime. La littérature aussi bien palestinienne qu'israélienne en témoigne. Le personnage du Palestinien dans la littérature israélienne après la nakba est toujours muré dans le silence. Chez Abraham B. Yehoshua (Facing the forests, 1967), le Palestinien est muet. Dans Mon Michaël (Gallimard, 1998) de Amos Oz, les jumeaux palestiniens n'ont pas d'existence réelle; ils sont issus des fantasmes et des obsessions sexuelles de Hanna. Il est, chez David Grossman, un fou. Le Palestinien n'a pas droit au langage. Il en est ainsi, non seulement dans le roman, mais dans la vie même des Palestiniens. Khūrī ajoute que lors de l'écriture de $B \bar{a} b$ al-shams (en Galilée) et ensuite des Enfants du ghetto de Lidddu nom du village palestinien transformé en ghetto par les soldats israéliens -, romans qui racontent les événements de 1948, il a été confronté au silence des gens. Ils refusent de raconter l'expérience de la nakba. C'est pourquoi, à son avis, elle n'a pas été relatée, mise en écriture par les auteurs palestiniens.

Le refoulement de son histoire par le Palestinien fait couple avec le silence du Palestinien dans la littérature israélienne. Dans un contexte colonial où l'existence de l'autre est niée, la parole devient problématique. L'Autre, ici le Palestinien, a accepté, dans un certain sens, de disparaître.

La poésie palestinienne a reformulé l'existence du Palestinien, longtemps refoulée par la nakba. Dans son poème Sajjil anā 'Arabī ("Inscris, je suis Arabe »), Maḥmūd Darwīsh a évoqué l'Arabe en adoptant le point de vue de l'Israélien. Ce n'est que trois ans plus tard qu'il écrit 'Āshiqun min Filasțīn («Un 
amoureux de la Palestine ») où le mot palestinien est répété vingt-cinq fois comme une déclaration d'existence.

Cette question de l'identité palestinienne fait partie d'une problématique plus large, celle de la mémoire perdue : « En ce lieu, nous représentons presque un scandale. Un scandale perpétuel, on ne peut le camoufler qu'en l'oubliant. » (Bāb, p. 360). Pour les Palestiniens, l'oubli est le refoulement de leur malheur. De la part de la communauté internationale, il représente la cécité face à une crise qu'elle n'est pas prête à résoudre. Du côté des Israéliens, l'effacement de l'image et du nom de la victime équivaut à l'effacement du crime lui-même. Dans un article intitulé « l'assassinat des noms ${ }^{33}$ ", Khūrī dénonce les massacres de Jénine et décrit la destruction du camp par l'armée israélienne et l'ensevelissement des cadavres dans une fosse commune qu'elle recouvre de béton. Cet effacement tend, d'une part, à détruire les images susceptibles de rappeler l'histoire du massacre : « Le fait de masquer les images des morts aux caméras de télévision suffit pour effacer le crime, ou pour l'annuler virtuellement ". Il vise, d'autre part, en cachant les morts, à les dépouiller de leurs noms : « Or, quand le nom n'est plus, la personne elle-même disparaît aussi. " Ainsi réduit à l'anonymat, le Palestinien est dépouillé du sens de sa résistance.

La honte liée à leur défaite historique a empêché les Palestiniens d'écrire leur propre histoire. Sur le massacre de Șabrā et de Shātīlā, par exemple, "il n'existe que deux documents, israéliens. Le premier a été écrit par le journaliste Ammon Kapeliouk, et l'autre est le rapport de la commission israélienne Kahana » (Bāb, p. 349).

33. Ilyās Khūrī, «Qatl al-asmā'», Al-quds al-'arabī, 16 avril 2002. Et dans la Revue d'études palestiniennes, $n^{\circ}$ 84, été 2002, "L'Assassinat des noms », trad. en français par Mohammed El-Yamani. www.positions.fr 
Le traumatisme et l'humiliation ressentis suite à la nakba expliquent, selon Khūrī, la réticence des intellectuels et historiens palestiniens à écrire leur propre histoire : "Ils réalisent que l'écriture confirme et consacre ce qui est arrivé, un fait qu'ils n'admettent pas $^{34}$.»

Yūnus et Khalīl illustrent justement cette dialectique de l'oubli et de la mémoire. À l'opposé du coma de Yūnus, Khalīl tente de ressusciter l'histoire :

Ces événements mériteraient d'être gravés par la plus fine aiguille sur le coin même de la prunelle des hommes et seraient de la sorte un avertissement salutaire à tous ceux qui veulent faire leur fruit des événements du passée ${ }^{35}$.

Khūrī, faisant sienne cette phrase des Mille et Une Nuits, s'attelle à écrire une contre-narration qui, pour reprendre les mots d'Edward Saïd, «prend en compte l'expérience de subordination des faibles et des perdants ainsi que le souvenir des voix et des personnes oubliées ${ }^{36}$."

La littérature n'a pas pour rôle de produire des chroniques historiques, mais de comprendre ce qui est fondamental dans toute expérience humaine. Elle doit faire face à la cécité de l'histoire, mais se donne aussi pour objectif de libérer l’homme.

34. Ilyās Khūrī, Al-jadīd, n’ 18-19, 1998.

35. Les Milles et Une Nuits, "Le portefaix et les dames », traduction par René Khawwām, Paris, Phébus, 1986.

36. Edward Saïd, Des Intellectuels et du pouvoir, Paris, Seuil, 1996, p. 61. 


\section{5}

\section{Un roman arabe postmoderne? Elias Khoury en exemple}

Force est de constater que le postmoderne ne parle pas tellement aux intellectuels arabes, voire même aux " arabisants " qui dédient leurs recherches au monde arabe. Et il n'est pas rare de se voir interdire de recourir à ce concept sous prétexte que ni sa genèse ni les débats qu'il sollicite ne concernent la littérature ou l'histoire du monde arabe. Nous y reviendrons. Une excursion dans l'histoire de ce concept montre en tout cas les difficultés qu'il y a à en faire un outil d'analyse critique en littérature arabe.

\section{Genèse du terme " postmoderne "}

Le terme a commencé à s'imposer à partir des années 1960 . Sa genèse est toutefois antérieure. Dans Postmodern theory ${ }^{1}$, Steven Best et Douglas Kellner attribuent sa première apparition au peintre anglais John Watkins Chapman, qui l'emploie dans des années 1870 pour rompre avec le courant impressionniste français. En 1917, le terme est repris par Pannwitz dans son ouvrage Die Krisis der europaischen Kultur pour désigner, à la suite de Nietzsche, le nihilisme et la permutation des valeurs à l'œuvre dans la culture occidentale. Après la Seconde Guerre

1. Steven Best and Douglas Kellner, Postmodern theory, New York, The Guilford Press, 1991. 
Elias Khoury - De l'engagement au postmodernisme

mondiale, l'historien anglais Arnold Toynbee évoque un "âge postmoderne " succédant et rompant tout à la fois avec la modernité et avec la pensée issue des Lumières. Ces premières utilisations ne donnèrent lieu à aucun débat théorique autour de la notion.

Dans la postface de son ouvrage, The Dismemberment of Orpheus $^{2}$, Ihab Hassan recense d'autres références concernant les débuts de l'utilisation du terme: Federico de Onis l'emploie en 1930 dans son Antologia de la poesia hispanoamericana (18821932), publiée à Madrid en 1934. Dudley Fitts, en 1942, en fait usage dans son Anthology of contemporary Latin-American Poetry. Perry Anderson confirme la provenance hispanique du terme: dans Les Origines de la postmodernité, il réfute les présupposés courants selon lesquels le terme serait initialement apparu en Occident. Les deux termes « modernisme « et " postmodernisme ", dit-il, "sont nés dans la périphérie éloignée, et non au cœur du système culturel de l'époque : ils ne viennent ni d'Europe, ni des États-Unis, mais de l'Amérique hispanique ${ }^{3}$. » Le terme, resté confiné au cercle de la critique hispanique, avait une connotation négative et décrivait un reflux conservateur au sein du modernisme dont les traits principaux étaient l'abandon du souci du détail et l'ironie. Ce n'est qu'une génération plus tard que le terme fait son apparition dans le monde anglophone. Arnold Toynbee, cité par Anderson, l'emploie en 1954 dans le huitième volume de son œuvre majeure A Study of History. Plusieurs éléments alimentent la réflexion de Toynbee sur l'époque postmoderne: l'industrialisation masssive qui avait

2. Cf. Ihab Hassan, "Postface 1982 : Toward Postmodernism”, in The Dismemberment of Orpheus: Toward a Postmodern Literature, Wisconsin, University of Wisconsin Press, $2^{\text {nd }}$ revised edition, 1987, p. 259.

3. Perry Anderson, Les Origines de la postmodernité, Paris, Les Prairies ordinaires, 2010, p. 9. 
marqué l'histoire récente de l'Occident, commence, après la Seconde Guerre mondiale, à décliner. En même temps que se défont les frontières nationales, le nationalisme se renforce au sein des communautés ethniques et marginales. La suspicion envers l'impérialisme occidental est à son apogée pendant l'ère des décolonisations.

À partir des années 1970, la notion de postmodernisme se propage et donne lieu à des développements théoriques, alors que dans les années 1960, son acception n'était que négative et renvoyait à un relâchement des mœurs, au déclin des élites et à un goût accentué pour le burlesque. La prolifération des théories postmodernes est considérée par Steven Best et Douglas Kellner comme une réponse à une situation de crise :

La transition, qui a permis le passage de la société traditionnelle à la société moderne était vécue comme une crise requérant de nouvelles perspectives et solutions aux problèmes politiques et sociétaux perçus. De ce point de vue, les discours théoriques peuvent être lus comme des réponses à des crises historiques, à des développements économiques et technologiques n'ayant pas trouvé de solution, et à des turbulences sociales et intellectuelles produites par la désintégration du précédent mode de vie et de pensée stable et familier ${ }^{4}$.

Cependant, parler du postmodernisme comme d'une critique à l'encontre du modernisme ne révèle pas ce que le concept a de spécifique, le malaise et la suspicion ayant toujours accompagné

4. Cf. Steven Best et Douglas Kellner, Préface, op.cit., VIII-IX, « [...] the transition from traditional to modern society was experienced as a crisis which required new perspectives and solutions to the perceived social and political problems. From this vantage point, theoretical discourses can be read as responses to historical crises, to unsettling economic and technological developments, and to social and intellectual turbulence produced by the disintegration of previously stable and familiar modes of thinking and living. New theories and ideas articulate novel social experiences and a proliferation of emergent discourses therefore suggests that important transformation are taking place in society and culture $»$. 
le discours de la modernité. Frédéric Nietzsche est l'un des critiques les plus virulents de cette dernière. La problématique de la mort de Dieu, en même temps qu'elle rompt avec la conception platonicienne d'un monde vrai et immuable, débouche sur le perspectivisme selon lequel il n’y a pas de faits, mais seulement des interprétations; le monde devient ainsi un texte se prêtant à des lectures infinies. Marx et Freud sont tenus pour les maîtres du soupçon. Pour le premier, l'homme est le nœud des rapports sociaux. Pour le second, il est mû par des pulsions inconscientes sur lesquelles il a peu de prise. Toutefois, dans Les Idées politiques contemporaines ${ }^{5}$, Jean Baudouin souligne que ces entreprises de démantèlement du projet de la modernité sont encore modernes: Heidegger reproche à Nietzsche d'ériger une métaphysique de la volonté de puissance et de placer l'homme au centre de la subjectivité. Loin de remettre en question la primauté du sujet, Nietzsche la porte contraire à son degré extrême. Ainsi, selon Heidegger, le perspectivisme n'est, en fin de compte, qu'un subjectivisme, car l'hégémonie de la volonté de puissance sur le monde demeure la seule et véritable constante. Marx annonce l'émancipation de l'homme du capital et l'avènement d'une société sans classe. Le projet psychanalytique a pour but, quoique fragile et même parfois impossible, l'instauration d'un équilibre psychique. Ces pensées restent donc, par le projet utopiste d'émancipation qui les sous-tend, fondamentalement modernes.

C'est en architecture que l'élaboration théorique du postmodernisme s'est le plus particulièrement développée. Dans leurs démarches, les architectes ont cherché à s'opposer aux valeurs canoniques des Lumières. Ils ont souligné la disparition de l'idée

5. Jean Baudouin, Les Idées politiques contemporaines, Rennes, Presses universitaires de Rennes, 2002. 
de progrès et d'originalité en art par divers procédés tels que la juxtaposition de styles disparates, l'adoption de matériaux populaires, le choix d'un art de la surface, de l'imitation et du collage. La production architecturale et artistique de ces quarante et quelques dernières années n'est pas chaotique; elle correspond à une sensibilité contemporaine et est symptomatique des bouleversements qui affectent le monde d'aujourd'hui. Dans un livre consacré à l'architecture moderne et postmoderne, Joseph Belmont fait remarquer que les mouvements architecturaux ne sont pas l'œuvre de quelques esthètes isolés, mais la création collective de toute une société ; ils s'inscrivent dans un processus historique, politique, économique et social : «Toute société s'est représentée à travers son architecture : elle a traduit dans la pierre ses aspirations, ses enthousiasmes, ses doutes, ses renoncements ${ }^{6}$."

L'histoire de l'architecture épouse ainsi celle des civilisations. Dans les périodes de crise et d'incertitude, la création, au lieu d'aller " vers " quelque chose, réagit " contre " quelque chose, comme l'explique Belmont. Le mouvement postmoderne se situe dans la position de rejet des aspirations qui ont régi le mouvement moderne, issu de la pensée rationaliste du XVIII ${ }^{\mathrm{e}}$ siècle dont il a mené jusqu'au bout les idées utopistes.

Les travaux de Robert Venturi et de Charles Jencks, théoriciens et architectes, marquent la fin d'une époque. Ils inaugurent ce qui, depuis les années 1960-70, s’appelle le postmodernisme. Charles Jencks ${ }^{7}$, critique d'art britannique, emploie le terme en 1975 pour décrire les positions esthétiques de l'architecture contemporaine en rupture avec un courant hégémonique, le

6. Joseph Belmont, Modernes et Postmodernes, Paris, éditions du Moniteur, 1987, p. 89.

7. Cf. Charles Jencks, What is Postmodernism?, Manchester, Academy Edition, St. Martin Press, 1986. 
modernisme. Ce dernier était caractérisé par la standardisation et l'harmonisation de la construction et par le projet social et individuel auquel il est lié, celui d'une émancipation progressive de l'humanité. Ce nouveau mouvement se distingue "par sa recherche de la variété et de la contradiction, par son ironie et son ludisme, par son approche sans complexes de l'histoire et de la culture quotidienne ${ }^{8}$ ".

Le Langage de l'architecture postmoderne de Jencks marque une rupture radicale avec le moderne, la première partie du livre s'intitulant justement " La mort de l'architecture moderne ». "L'architecture moderne est morte à Saint Louis, Missouri, le 15 juillet 1972, à quinze heure trente deux (ou à peu près) quand l'ensemble tant décrié de Pruit Lodge, ou plus exactement certains de ses blocs reçurent le coup de grâce final à la dynamite $^{9}$." La destruction du complexe de Pruit Lodge ${ }^{10}$ est provoquée, selon Jencks, par des raisons sociales, l'architecture du bâtiment étant en contradiction avec les aspirations des couches sociales défavorisées.

Jencks critique le " réductionnisme élitiste » de l'architecture du mouvement moderne. Comme Venturi, il étend le langage architectural au vernaculaire, à la tradition et au jargon populaire. Il prône l'éclectisme et la cohabitation de plusieurs formes de langage accessibles à l'élite comme à l'homme de la rue. Avant de faire des études d'architecture, il avait étudié la littérature anglaise à Harvard. Il n'est donc pas étonnant qu'il voie dans l'architecture une sémantique et dans la forme architectonique

8. Bernd Evers, Théorie de l'architecture, de la Renaissance à nos jours, Cologne, Taschen, 2006, p. 538.

9. Charles Jencks, Le Langage de l'architecture postmoderne, Paris, Denoël, 1975, p. 9.

10. Le complexe de Pruit Lodge avait été construit par Minoru Yanasaki, le futur architecte du World Trade Center. 
une métaphore: « Il existe de nombreuses analogies entre l'architecture et le langage, et en donnant aux termes un sens large, on peut parler de "mots", de "phrases", de "syntaxe" et de "sémantique" architecturaux ${ }^{11}$."

Complexity and contradiction in Architecture ${ }^{12}$, de Robert Venturi, publié en 1966 par le Museum of Modern Art de New York, apporte une nouvelle approche architecturale. Son art se place sur le terrain de la contradiction et de la multiplicité des significations. Ce n'est plus l'objectivité qui légitime le travail mais la liberté artistique. Venturi reproche à l'architecture moderne son souci de pureté, son hermétisme et sa négligence des besoins sociétaux. Les principes architecturaux de Venturi prennent position contre «l'évidence de l'unité » et « la clarté des moyens ", pour le "désordre de la vie " et " la richesse des moyens ». L'assimilation des contraires se traduit par un éclectisme radical. Sa maison de retraite Guild House à Philadelphie ainsi que Vanna Venturi, maison de Chestnut Hill, construite pour sa mère, sont devenues emblématiques de l'architecture postmoderne. L'emploi de la couleur et le jeu des matériaux contrastent avec la froideur du modernisme. Les architectes postmodernes reprochent aux modernes leur souci exclusif de fonctionnalité qui les détourne de la sociabilité humaine. Ils optent pour l'hétérogénéité, la variété dans l'urbanisme et pour l'animation de la rue contre la régularité et l'uniformité des constructions modernes. Le retour aux traditions historiques et urbaines intégrant les images et les formes de l'imaginaire populaire traditionnel permet d'ancrer l'œuvre dans le temps, d'étudier son évolution et de créer un style architectural non abstrait ayant ses référents dans l'histoire. Le droit de renouer avec le passé prend

11. Charles Jencks, Le Langage de l'architecture postmoderne, op. cit., p. 39.

12. Robert Venturi, Complexity and contradiction in Architecture, New York, Museum of Modern Art, 1966; De l'ambiguité en architecture, Paris, Dunod, 1995. 
Elias Khoury - De l'engagement au postmodernisme

le contre-pied de la perpétuelle recherche moderne de la nouveauté.

L'école tessinoise, La Tendenza ${ }^{13}$, formée autour des thèses de Venturi, repose sur deux principes antimodernes : le rejet de la tendance universalisante du rationalisme, d'une part, et la valorisation des sources historiques accueillant les traditions locales, d'autre part.

Les architectes postmodernes se rapprochent des théories linguistiques contemporaines. Les philosophies de Jacques Derrida, de Jean Baudrillard, de Gilles Deleuze et de Jean-François Lyotard deviennent pour les architectes une lecture nécessaire. Les notions de déconstruction, de fragmentation, de discontinuité servent dès lors à appréhender aussi bien la réalité architecturale que la pensée philosophique. Ces notions finissent par caractériser le postmodernisme.

La littérature en hérite à son tour. L'œuvre littéraire devient éclectique, ouverte à des sens et à des interprétations infinis, rejette l'élitisme, intègre le populaire et le vernaculaire, renoue avec le passé et les traditions, et accorde une place croissante à l'autobiographie et à l'expérimentation où toutes les techniques d'expression pourront cohabiter.

Celui qui a marqué le plus durablement la pensée postmoderne est probablement Jean-François Lyotard. Il emploie le terme pour désigner l'état de la culture dans les sociétés les plus développées depuis la fin des années 1950, et qualifie la période historique lui correspondant de " postindustrielle ». Le passage à la société informationnelle affecte le savoir en le rendant plus complexe et plus mobile, et délégitime les métarécits fondateurs de la modernité :

13. Exposition « La Tendenza: architectures italiennes 1965-1985 », centre Pompidou, juin-septembre 2012. 
Quand ce métadiscours a recours explicitement à tel ou tel grand récit, comme la dialectique de l'Esprit, l’herméneutique du sens, l'émancipation du sujet raisonnable ou travailleur, le développement de la richesse, on décide d'appeler « moderne » la science qui s’y réfère pour se légitimer ${ }^{14}$.

Le postmoderne serait alors « l'incrédulité à l'égard des métarécits ${ }^{15}$ ". Les métarécits ou grands récits sont des narrations universalistes à fonction " légitimante " et " mythologisante "; ils donnent sens à la réalité humaine en propulsant l'action vers une réconciliation qui adviendra à la fin de l'histoire. La philosophie hégélienne de l'histoire en est le prototype :

La pensée et l'action des $\mathrm{XIX}^{\mathrm{e}}$ et $\mathrm{Xx}^{\mathrm{e}}$ siècles sont régies par une Idée (j'entends Idée au sens kantien). Cette idée est celle de l'émancipation. Elle s'argumente certes tout différemment selon ce qu'on appelle les philosophies de l'histoire, les grands récits sous lesquels on tente d'ordonner la foule des événements: récit chrétien de la rédemption de la faute adamique par l'amour, récit aufklärer de l'émancipation de l'ignorance et de la servitude par la connaissance et l'égalitarisme, récit spéculatif de la réalisation de l’Idée universelle par la dialectique du concret, récit marxiste de l'émancipation de l'exploitation et de l'aliénation par la socialisation du travail, récit capitaliste de l'émancipation de la pauvreté par le développement techno-industriel. Il y a entre ces récits matière à litige et même à différend. Mais tous situent les données qu'apportent les événements dans le cours d'une histoire dont le terme, même s'il reste hors d'atteinte, se nomme liberté universelle, acquittement de l'humanité tout entière ${ }^{16}$.

Un autre grand théoricien du postmoderne est Fredric Jameson. Contrairement à Lyotard qui ne fait pas de distinction

\footnotetext{
14. Jean-François Lyotard, La Condition postmoderne, op. cit.,p. 7.

15. Ibid.

16. Jean-François Lyotard, Le Postmoderne expliqué aux enfants, op. cit., p. 45.
} 
entre postmodernité et postmodernisme, il considère qu'il est impossible d'élaborer une théorie du postmoderne sans poser au préalable l'hypothèse d'une périodisation historique, quand bien même cette hypothèse serait problématique. La périodisation éviterait, d'une part, de faire du postmodernisme une simple question de style ou une composante culturelle parmi d'autres et, d'autre part, de confondre ses différentes caractéristiques avec celles développées dans tel ou tel modernisme antérieur, certaines caractéristiques du modernisme se révélant dès lors comme un postmodernisme avant la lettre. Jean-François Lyotard par exemple, englobe des auteurs modernes comme Kafka ou Montaigne dans le mouvement postmoderne.

Le postmodernisme serait dès lors « la dominante culturelle du capitalisme tardif ». Ce phénomène n'est pas entièrement nouveau, il traduit « une modification systémique de plus du capitalisme lui-même ${ }^{17}$. Le postmodernisme produit des personnes postmodernes capables de fonctionner au sein du nouveau système socio-économique émergent. Ce nouveau système a émergé, toujours d'après Jameson, depuis la Seconde Guerre mondiale qui a entraîné des transformations sociales et économiques profondes, et s'est consolidé lors des échecs politiques des utopies des années 1960 et durant les crises des années 1970. Les progrès vertigineux des médias et l'informatisation à grande échelle des sociétés ont contribué fortement à modifier irrémédiablement les mentalités et à façonner la culture et la sensibilité du nouveau monde.

S'il faut s'en tenir à une définition du postmodernisme, celle de Terry Eagelton a l'avantage de distinguer la postmodernité comme étape historique qui suit la modernité et le post-

17. Fredric Jameson, Le Postmodernisme ou la logique culturelle du capitalisme tardif, Paris, éditions Beaux-Arts-de Paris, 2007. p. 19. Titre original: Postmodernism, or the cultural logic of late capitalism, Duke University Press, 1991. 
modernisme comme étant ce qui, dans la culture, reflète cette nouvelle Weltanschauung. Cette distinction permet de saisir l'époque et les mutations culturelles qu'elle entraîne dans un même processus de détermination réciproque :

The Word "postmodernism" generally refers to a form of contemporary culture, whereas the term "postmodernity" alludes to a specific historical period. Postmodernity is a style of thought, which is suspicious of classical notions of truth, reason, identity and objectivity, of the ideas of universal progress or emancipation, of single frameworks, grand narratives or ultimate grounds of explanation. Against the Enlightenment norms, it sees the world as contingent, ungrounded, diverse, unstable, indeterminate [...]. This way of seeing, so some would claim, has real material conditions: It springs from an historic shift in the west to a new form of capitalism- to the ephemeral, decentralised world of technology, consumerism and the culture industry, in which the service, finance and information industries triumph over traditional manufacture, and classical class politics yield ground to a diffuse range of "identity politics". Postmodernism is a style of culture which reflects something of this epochal change, in a depthless, decentred, ungrounded, self-reflexive, playful, derivative, eclectic, pluralistic art which blurs the boundaries between "high" and "popular" culture, as well as between art and everyday experience. How dominant or pervasive this culture is, is a matter of argument ${ }^{18}$.

Cette approche ne fait pas l'unanimité. Le concept de postmoderne est sujet à des appréhensions diverses. Il est au centre d'une nébuleuse de théories ayant souvent peu de choses en commun. En outre, les romanciers libellés " postmodernes " ne forment pas un courant et ne revendiquent pas eux-mêmes cette appellation.

18. Terry Eagleton, The Illusions of Postmodernism, Blackwell, Oxford, 1997, préface p. VII-VIII. 
Certains récusent l'emploi du " post ", considérant qu'il introduit l'idée d'une rupture radicale avec le modernisme, alors qu'il n'en est rien. La recherche du nouveau est une caractéristique du modernisme et il n'est nul besoin d'un autre vocable pour évoquer les changements de tendances dans la culture. Lazare Bitoun et Claude Grimal se réfèrent à la romancière américaine Annie Dillard, pour substituer à l'expression « écrivains postmodernes " celle de "modernistes contemporains " ${ }^{19}$. Leur réticence est due à la diversité et l’hétérogénéité des tentatives de fixation théorique du postmodernisme:

Ces étiquettes de " métafiction » et de " postmodernisme », que les écrivains eux-mêmes refusent le plus souvent, ont un sens assez vague. Ces termes, apparus dans les années soixante-dix, désignent une tendance du roman et de la nouvelle à mettre au premier plan l'expérimentation formelle et la critique des moyens esthétiques. Bien évidemment, le degré d'innovation et d'autoréflexivité (commentaire sur les stratégies littéraires) varie suivant les auteurs. En raison de la diversité de leur engagement, il semble préférable de substituer ici à l'expression d'«auteurs postmodernes " ou "métafictionnels", celle - vague mais pratique - inventée par l'écrivain Annie Dillard, de "modernistes contemporains" (contemporary modernists) ${ }^{20}$.

La dénomination qu'elles récusent n’a pas empêché qu'elles parviennent au terme de leur analyse de nombre de romans américains d'" après 1945 ", aux mêmes caractéristiques du postmodernisme relevées plus haut. Les deux auteurs évoquent la démultiplication de l'histoire, la perte de linéarité et d'organisation logique du récit, le collage, l'incohérence voire même

19. Cf. Lazare Bitoun et Claude Grimal, Le Roman américain après 1945, Paris, Armand Colin, 2000, p. 100.

20. Ibid., p. 100. 
l'inexistence du héros traditionnel, la disparition de l'autorité de la perspective narrative, la métafiction :

Finie donc l'histoire univoque, le personnage et ses motivations, l'autorité narrative assurant des sources énonciatives claires, des causalités et des conclusions nettes. Cette destruction joyeuse donne aux modernistes contemporains une position esthétique enivrante et les mène souvent à faire de la fiction et du langage leur sujet de prédilection ${ }^{21}$.

Sur un autre plan, Michael Hardt et Antonio $\mathrm{Negri}^{22}$ se méfient des théories postmodernistes et les accusent de mauvaise foi. En voulant combattre le principe de domination issu des Lumières au nom des hiérarchies hybrides et fragmentaires, elles ne font que renforcer les nouvelles stratégies de pouvoir et même coïncider avec elles. Ces dernières, voulant asseoir leur domination, font précisément usage des mêmes stratégies fragmentaires que les postmodernistes et postcolonialistes croient combattre. Ce qui remet sérieusement en cause leur politique libératoire. L'économie postindustrielle se traduit par un nouveau type de domination dont la manipulation de l'affect - sentiments de plaisir, de bien-être, de satisfaction, d'excitation ou de passion - est l'une des manifestations.

Malgré les controverses et l'absence d'une définition faisant l'unanimité, nous pensons à la suite de Roland Barthes, qu'« il est toujours un peu dangereux et un peu vain de faire machine arrière dans l'emploi des mots quand ils sont passés dans l'usage ${ }^{23}$ ». D'ailleurs, Ihab Hassan se demande s'il serait possible de trouver un meilleur terme pour décrire cet âge curieux : " But

\footnotetext{
21. Ibid., p. 101.

22. Cf. Michael Hardt et Antonio Negri, Empire, Paris, Exils, 2000.

23. Roland Barthes, L'Aventure sémiologique, Paris, Seuil, 1985, p. 273.
} 
what better name have we to give this curious age ${ }^{24}$ ? ». Et d'ajouter : " Novelties are first repudiated as nonsense, then declared obvious, then appropriated by former adversaries as their own discoveries ${ }^{25}$ ». Fredric Jameson considère que des formulations telles que "poststructuralisme ", ou " sociétés postindustrielles " se sont avérées insatisfaisantes parce que trop marquées par leur domaine de provenance et, ainsi, incapables de cristalliser tout un faisceau de tendances provenues de domaines différents. Peu de gens réussissent encore à éviter ce terme, c'est pourquoi il serait plus judicieux d'essayer de comprendre les raisons derrière son émergence :

Il faut écrire l'histoire du succès du mot " postmodernisme ", en format de best-seller indéniablement; [...] Pourquoi avonsnous eu si longtemps besoin du mot postmodernisme sans le connaître, pourquoi une bande franchement hétéroclite de tous nouveaux compères se précipita-t-elle pour embrasser ce mot lors de son apparition, sont des mystères qui vont rester obscurs tant que nous ne serons pas capables de comprendre la fonction philosophique et sociale de ce concept, ce qui est à son tour impossible tant que nous ne serons pas capable de comprendre l'identité plus profonde qui existe entre les deux ${ }^{26}$.

Il ne s'agit pas pour nous de défendre cette terminologie mais de discerner dans quelle mesure une théorie du postmodernisme constitue un paramètre de lecture de l'œuvre de Khūrī. Cette démarche permet de saisir ensemble des caractéristiques telles que l'œuvre inachevée, la fragmentation de la narration, le

24. Ihab Hassan, POSTmodernISM: a Paracritical Bibliography, New Literary History, 1971; réédité in. Ihab Hassan, The Postmodern turn, Columbus, Ohio State University Press, 1987, p. 263.

25. Ibid., p. 262.

26. Fredric Jameson, Le Postmodernisme ou la logique culturelle du capitalisme tardif, op. cit., p. 20-21. 
perspectivisme, la déconstruction des grands récits et des grandes idéologies, l'impasse de la recherche du temps perdu, en les incluant dans une tendance plus globale qui éclaire leur genèse. Elle révèle, en outre, comment, loin d'être un jeu d'expérimentation, la technique narrative de Khūrī porte l'empreinte de l'époque. En plus, nous souscrivons à une théorie du postmodernisme qui établit une périodisation. La postmodernité serait la période qui commence dès la fin des années 1960. Le postmodernisme serait la culture contemporaine qui correspond à cette période. Cette périodisation s'appuie sur un axe politico-économique ponctué par la fin des Trente Glorieuses, l'échec de mai 1968 et par le début d'une récession mondiale, en 1973-1974. En même temps, la fin des années 1960 et le début des années 1970 voient l'essor de théories postmodernes et de leurs critiques. Jameson en fait le constat:

La fin de la Seconde Guerre mondiale a eu pour effet de réorganiser les relations internationales, décoloniser les colonies, et préparer le terrain à l'émergence d'un nouveau système économique mondial. Culturellement, cependant, cette condition préalable va se trouver dans les prodigieuses transformations des années soixante qui balayèrent une si grande part de la tradition en matière de "mentalités ". La préparation économique du postmodernisme ou capitalisme tardif commença donc dans les années cinquante, lorsqu'on se releva des pénuries de la guerre en biens de consommation et en pièces détachées et qu'on put lancer de nouveaux produits et de nouvelles technologies. D'un autre côté, «l'habitus " psychique de ce nouvel âge exigeait la coupure absolue, renforcée par une rupture générationnelle, qui ne se réalisa vraiment que dans les années soixante.[...] Cependant, j'ai le sentiment que les deux plans en question, infrastructure et superstructures - le système économique et « la structure du sentiment » culturelle - se sont en quelque sorte cristallisés dans le grand choc des crises de 1973 (la crise du pétrole, la 
fin de l'étalon or, la fin, censément, de la grande vague de " guerres de libération nationales ", le début de la fin du communisme traditionnel), qui révèle, maintenant que les nuages de poussières se sont dissipés, l'existence, déjà en place, d'un étrange et nouveau paysage ${ }^{27}$.

Cette délimitation temporelle n'est pas un cadre rigide. Les produits de la culture, notamment le roman, ont leur sensibilité propre et créatrice et ne se laissent pas enfermer dans des temporalités étroites. La périodisation ne peut pas, non plus, être extensible à l'infini, sinon elle perd sa pertinence et donne lieu à des amalgames et à des incohérences. Que les grands tournants des années 1960-1970 correspondent aux productions théoriques majeures sur le postmoderne n'est pas anodin et confirme l'imbrication étroite, sans être limitative ni exhaustive, entre le texte et son contexte.

\section{Un postmodernisme arabe: le débat a-t-il lieu?}

La difficulté surgit dès que l'on évoque le postmodernisme dans la littérature arabe. À l'heure où l'on aurait tendance à diagnostiquer une régression dans les pays arabes, évoquer une quelconque postmodernité pourrait constituer une aberration. En effet, le postmodernisme est perçu comme une notion importée de l'Occident, impropre à appréhender une littérature née dans des conditions différentes. En plus, les théories du postmodernisme, à ne prendre que le cas de la littérature libanaise, ne semblent pas interpeller directement les romanciers. Dans une interview accordée à L'Orient littéraire ${ }^{28}$, supplément culturel du quotidien libanais L'Orient-Le-Jour, Hasan Dāwūd avoue ignorer

27. Ibid., p. 29-30.

28. Cf. L'Orient Littéraire, "Hassan Daoud, du singulier à l'universel », par Katia Ghosn, numéro 21, 3 mars 2008. 
ce que le terme postmoderne peut signifier; il n'en a jamais tenu compte dans ses écrits. Si son œuvre était lue comme postmoderne, ce serait " complètement à son insu ", dit-il. De même pour Khūrī. Lors d'un colloque tenu en 2011 à l'EHESS autour de son œuvre et auquel il était convié, il dit n'en avoir jamais entendu parler avant la lecture d'al-Jabal al-șaghīr (La Petite Montagne, 1977) par Edward Saïd ${ }^{29}$.

Parler d'un postmodernisme arabe est quelque peu aventureux, comme le souligne Andreas Pflitsch dans son introduction à un livre collectif au sujet de romanciers arabes dont l'œuvre pourrait être envisagée selon des " perspectives postmodernes". Intitulé Arabic Literature: Postmodern perspectives, ce livre fut initialement publié en 2004, en allemand, sous le titre : Arabische Literatur, postmodern. Sa réédition, enrichie et récemment traduite en anglais, prouve l'intérêt croissant porté à la littérature arabe contemporaine et souligne la place qu'elle occupe au sein de la littérature mondiale. Il s'agit, surtout, aux yeux de ceux et celles qui ont mené les études, de montrer que la littérature arabe contemporaine hérite de la condition postmoderne, née en Occident, sans perdre ses spécificités pour autant. Bien au contraire, elle affirme comme jamais auparavant ses orientations propres. Pflitsch est conscient du caractère périlleux de l'entreprise et ne manque pas de le souligner: "While "postmodernism" provokes nothing more than a weary yawn in the West, the debate about "modernity" is raging in the Arab world. It seems that there can be no question of postmodernism there ${ }^{30}$."

29. Khūrī et Saïd se connaissaient avant de s'être croisés à l'université de Columbia. 30. Andreas Pflitsch, «The End of Illusions. On Arab Postmodernism », in Arabic Literature: Postmodern Perspectives, Neuwirth, Angelika, Pflitsch, Andreas, et Winckler, Barbara (eds.), Londres et Beyrouth, Saqi, 2010. p. 25. 
La question de la modernité, il est vrai, fait couler encore beaucoup d'encre dans le monde arabe. Dans Al-kitāb, al-khitāa b, al-hijāa («Le livre, le discours, le voile»), Adonis fustige la culture arabo-musulmane, réfractaire à la liberté de pensée et à l'autocritique, conditions sans lesquelles il serait impossible d'accéder à la modernité. Ce jugement, il l'avait déjà formulé dans Șadmat al-hadātha ("Le choc de la modernité »), une trentaine d'années auparavant, dans ce qui fut sa thèse de doctorat à l'époque:

Ceci est, fondamentalement, l'attitude que nous avons adoptée dans notre relation renouvelée avec l'Occident européen, en commençant par la confrontation à la modernité européenne, à travers l'entrée de Napoléon en Égypte, en 1798. Les penseurs de la nahḍa, al-Ṭahțāwī, al-Afghānī et Muḥammad 'Abdū, ont repris cette même attitude qui domine notre vie aujourd'hui, au niveau du gouvernement et des institutions. Nous avons repris l'esprit consensuel, fabriqué de toutes pièces, issu d'al-Ghazālī: "sur le plan matériel », nous prenons la culture occidentale et ses techniques, tandis que « sur le plan spirituel » nous restons dans la culture de la révélation $^{31}$.

Adonis déplore l'état de la culture arabo-musulmane, malheureusement fort éloignée des idéaux des Lumières. La modernité prône l'exercice de la raison, la tolérance, la séparation des pouvoirs religieux et politique, la liberté de penser, bref, une culture aux antipodes de la pensée religieuse dominante dans la culture arabe et musulmane aujourd'hui :

Il est impossible de concilier le progrès et l'islam dans sa façon d'interpréter qui prévaut maintenant, surtout dans tout ce qui concerne la pensée, l'art, la littérature, la femme,

31. Adonis, Al-thābit wa-l-mutahawwil (« Le stable et le mouvant »), troisième volume: Șadmat al-ḥadātha ("Le choc de la modernité »), Beyrouth, Dār al-'awda, 1979, p. 258. Traduit par nous. 
la sexualité, l'économie et la sociologie. Le progrès et «cet islam-là " sont deux pôles antinomiques. Cet islam "emprisonne » non seulement le corps mais l'esprit aussi. Bref, il est le contraire de tout ce qui fait l'homme: la liberté de pensée et la liberté du désir ${ }^{32}$.

On le voit bien, le sujet de la modernité est encore loin d'être dépassé dans le monde arabe. Ce qui explique pourquoi la question d'une postmodernité et d'un postmodernisme arabes suscite des sourires amusés, voire de l'incompréhension.

Cette résistance n'a pas empêché que des ouvrages sur le sujet du postmodernisme voient le jour, certes rares. Nous en citerons quelques uns à titre d'exemple, sans prétendre à l'exhaustivité. Sont parus en arabe The Illusions of postmodernism ${ }^{33}$ de Terry Eagleton comme l'ouvrage du critique d'art contemporain Edward Lucie-Smith: Les mouvements artistiques depuis $1945^{34}$, revu et traduit par Fakhrī Khalīl et Jabrā Ibrahīm Jabrā. Et récemment (2017), une traduction d'Ihab Hassan ${ }^{35}$. La revue alKarmil avait auparavant (1997) publié une traduction de « Toward a concept of postmodernism ${ }^{36}$ » de Hassan.

32. Adonis, Al-kitāb, al-khițāb, al-hijāo ("Le livre, le discours, le voile »), Beyrouth, Dār al-ādāb, 2009, p. 71.

33. Terry Eagleton, The Illusions of postmodernism, Oxford, Blakcwell, 1996. Tîri İgltun, Awhām mā ba'da al-ḥadātha, Beyrouth, Silsilat Abū 'Alī Yāsīn, 2000.

34. Edward Smith-Lucie, Movements in Arts since 1945, London, Thames and Hudson, 1999. İdward Smith, Mā ba'da al-ḥadātha: al-ḥarakāt al-fanniya mundhu 'ām 1945, Beyrouth, Al- mu'assasa al-'arabiyya li l-dirāsāt wa l-nashr, 1995.

35. Īhāb Ḥasan, Taḥawwulāt al-khițāb al-naqdī li-mā ba'da al-ḥadātha. Traduit par Al-sayyid Imām. Bassorah, Dār shahrayār, 2017.

36. Ihab Hassan, "Toward a concept of postmodernism », in The postmodern turn, Columbus, Ohio state University press. "Īhāb Ḥasan: Naḥwa mafhūm li-mā ba‘da al-ḥadātha", trad. par Șubḥi Ḥadīdī, Majallat al-Karmil, nº 51, printemps 1997, p. 84-96. 
Elias Khoury - De l'engagement au postmodernisme

May Ghușūb écrit Mā ba'd al-hadātha: Al-'arab fi laqțat video ("Le postmodernisme: les Arabes dans une séquence vidéo ${ }^{37}$ ", 1992). Et Muḥammad Sa'dallāḥ rédige Al-usus al-falsafiyya li naqd mā-ba'd al-bunyawiyya ${ }^{38}$ ("Les fondements philosophiques pour une critique du poststructuralisme »,2007). Un ouvrage collectif d'essais critiques: Tradition, Modernity, and Postmodernity in Arabic Literature: essays in honor of professor Issa J. Boullata ${ }^{39}$ témoigne également de cet intérêt, sans oublier les multiples travaux de Kamāl Abū Dīb. Quant aux revues électroniques, elles publient des dizaines de traductions et débats sur le thème du postmodernisme. Notons que beaucoup d'intellectuels dans le monde arabe connaissent au moins une langue étrangère et ont accès aux ouvrages récents dans leur langue d'origine. Mais c'est surtout à partir des réflexions d'Edward Saïd que le débat concernant une éventuelle spécificité postmoderne de la littérature arabe fut lancé, débat auquel Kamāl Abū Dīb consacrera par la suite nombre de recherches.

Cette palette d'ouvrages et d'articles ne constitue aucunement un quelconque courant de pensée arabe postmoderne, elle témoigne cependant d'un intérêt manifeste pour le sujet. Mais, faut-il s'étonner de la rareté des ouvrages dans le monde arabe sur ce sujet, lorsque dans un pays comme la France par exemple, le livre incontournable de Fredric Jameson Postmodernism, or the cultural logic of late capitalism (Le postmodernisme ou la logique culturelle du capitalisme tardif), n'est traduit qu'en 2007,

37. May Ghușūb, Mā ba'd al-ḥadātha: Al-'arab fi laqțat video, Beyrouth, Dar al- Sāqī, 1992.

38. Muhammad Sa'dallah, Al-usus al-falsafiyya li- naqd mā-ba'd al-bunyawiyya, Damas, Dār al-ḥiwār, 2007. Le livre est en ligne sur www.nizwa.com

39. Tradition, Modernity, and Postmodernity in Arabic Literature: essays in honor of professor Issa J. Boullata, edited by Kamal Abdel-Malek et Wael, Hallaq, Leyde, Brill, 2000. 
quinze ans après sa parution aux États-Unis. Et Gender trouble (Trouble dans le genre ${ }^{40}$ ), de Judith Butler, paraît en France également quinze ans après sa première édition aux États-Unis en 2005. Quant à Linda Hutcheon, la totalité de son œuvre est inexistante en français, pour ne citer qu'elle. « Un tel débat n’a jamais eu lieu en France ", souligne Isabelle Garo ${ }^{41}$; il s'est développé aux États-Unis et en Angleterre parce qu'il se nourrit d'enjeux globaux auxquels les théoriciens français sont restés insensibles. François Cusset ne manque pas non plus de le relever. Les penseurs français - Michel Foucault, Gilles Deleuze, Jacques Derrida, Jacques Lacan, Jean Baudrillard, Jean-François Lyotard... - considérés comme les inspirateurs du postmodernisme sont plus célèbres et célébrés de l'autre côté de l'Atlantique : "Ces auteurs français ont atteint aux États-Unis, vers le tournant des années 1980, un seuil de notoriété officielle et d'influence souterraine auquel ils n’avaient jamais accédé chez $\operatorname{eux}^{42}$."

Une théorie du postmodernisme serait ainsi inséparable de la question de sa réception. Réception qui suppose une reconfiguration de notre appréhension aussi bien du réel que de la connaissance. Pour Isabelle Garo, " ces théorisations antidialectiques impliquent donc une profonde transformation de la définition même de la pensée et de sa place dans le réel, conduisant à une redéfinition du réel lui-même ${ }^{43}$ ".

La pénurie d'études qui recourent expressément au postmodernisme comme angle de lecture de romans arabes contempo-

40. Judith Butler, Gender Trouble: Feminism and the Subversion of identity, New York, Routledge, 1990. Et Trouble dans le genre, Paris, La Découverte, 2005.

41. Isabelle Garo, Foucault, Deleuze, Althusser et Marx, Paris, Demopolis, 2011, p. 374.

42. François Cusset, French Theory, Paris, La Découverte, 2003, p. 12.

43. Isabelle Garo, op. cit., p. 373. 
Elias Khoury - De l'engagement au postmodernisme

rains est, comme nous l'avons évoqué, la résultante de résistances diverses.

Il faudrait, de surcroît, éviter que l'argument orientaliste ne devienne un prétexte au manichéisme et un alibi du rejet en bloc de ce qui vient de l'Occident, jugé a priori incompatible avec toute étude sérieuse sur l'Orient. L'argument selon lequel l'analogie entre l'Orient et l'Occident n'est pas pertinente relève, d'après le penseur syrien Ṣādiq Jalāl al-‘aẓm, d’un « orientalisme à rebours $^{44}$ " (Orientalism in Reverse). Dans une étude intitulée "L'Orientalisme à rebours : sur certaines tendances de l'orientalisme français après 1979 ", Gilbert Achkar synthétise les traits distinctifs de ce syndrome, dont un des arguments est que "l'Orient musulman ne peut pas être appréhendé avec les instruments épistémologiques des sciences sociales occidentales ${ }^{45} "$. Selon Achkar, cet " orientalisme à rebours " se retrouve aussi bien chez des auteurs arabes, que chez divers intellectuels français ou occidentaux.

De plus, le monde arabe, qui a connu une évolution historique bien particulière, est aujourd'hui pris dans le système capitaliste global né en Occident. Certains changements sociétaux et comportementaux dus à la mondialisation affectent ce monde, qui continue toutefois à suivre sa trajectoire propre. Ces transformations imprègnent l'écriture romanesque, sommée de trouver réponse aux changements et aux défis de ce nouveau siècle afin de se retrouver elle-même.

Michael Hardt et Antonio Negri affirment d'ailleurs que, quand bien même les pays et régions subordonnés ne seraient pas capables de suivre le processus d'informatisation au même

44. Cf. Sadik Jalal al-Azm, Ces interdits qui nous hantent. Islam, censure, orientalisme, Marseille, Parenthèses-MMSH-IFPO, 2008.

45. Gilbert Achkar, Marxisme, orientalisme, cosmopolitisme, Arles, Actes Sud, 2015, p. 57 
degré et par le même chemin que les pays capitalistes dominants, ce changement est irréversible et leur sera imposé de toute manière.

\section{Lectures postmodernes des romans de Khūrī}

Nous mentionnerons trois études ayant abordé l'œuvre de Khūrī selon des perspectives postmodernes.

Edward Saïd. Saïd est le premier à avoir parlé de l'existence d'un romanesque postmoderne chez Khūrī, qui serait caractérisé par des vérités instables, des valeurs en déclin et, au niveau de la forme, par un récit rebelle à tout modèle préétabli.

Sur la quatrième de couverture d'al-Jabal al-ṣaghīr - le premier roman de Khūrī - figure un commentaire de Saïd ; ce dernier lie la fragmentation de l'écriture au contexte éclaté :

C'est l'histoire d'une société en décomposition où le narrateur est forcé de quitter sa maison. Il combat dans les rues de la ville et dans les montagnes, vit l'expérience de la mort de ses compagnons et celle de l'amour et finit son récit en s'adressant à un ancien combattant perdu dans les passages et sur le quai du métro à Paris. La singularité inouïe d'al-Jabal al-ṣaghīr tient à ce qu'elle évite le mélodrame et le commun. Khūrī tisse les chapitres sans recourir à une trame ou à un modèle qu'on pourrait deviner à l'avance. Il ressemble fort en ceci à un prisonnier libéré subitement, qui commence à errer d'un endroit à un autre, de l'arrière vers l'avant. Il exprime ce qui lui arrive dans une langue réaliste, bien articulée, tout en étant toujours dans l'approximation qui, dans une certaine mesure, rend le narrateur confus. En cela, l'œuvre de Khūrī incarne réellement l'impasse du Liban. Ilyās Khūrī est un artiste qui donne une voix aux exils enracinés, au malheur des réfugiés pris au piège, aux frontières évanescentes, aux identités changeantes, aux exigences radicales et aux langues nouvelles. 
Cette analyse, Saïd la réitère dans Reflections on Exile and other Essays ${ }^{46}$, un ouvrage rassemblant plusieurs études écrites entre 1967 et 1998. Dans un chapitre consacré à l'impact des bouleversements politiques sur la littérature arabe, intitulé « Après Maḥūz ", il soutient que, contrairement à l'Égypte dont les soubresauts de l'histoire n'ont ébranlé ni la cohésion de la société civile ni l'enracinement identitaire du peuple, le Liban, comme d'ailleurs la Palestine, est soumis à une désintégration permanente. Le Caire affiche une puissance et une pérennité qui contrastent avec la ville fragile, en mal d'être qu'est Beyrouth.

L'écriture se construit à l'image du monde qu'elle déconstruit. La narration est fragmentée en une multitude de récits tout comme l'identité libanaise, confrontée à de nombreux conflits, est éclatée, voire perdue. Le texte s'éparpille, s'ouvre aux possibles et demeure inachevé, de même que l'idée du pays que pourrait être le Liban reste à construire. Les personnages, en quête d'un sens introuvable, sont dépressifs, et leur identité est incertaine. Le réel ressemble à un miroir brisé :

Khūrī est, avec Maḥmūd Darwīsh, cet artiste qui parle des exilés n'ayant pas perdu leurs racines, de la situation difficile des réfugiés qui voient les portes se refermer devant eux, de la disparition du territoire, de la transformation des identités, des revendications radicales et des nouvelles langues. De ce point de vue, les œuvres de Khūrī font inévitablement leur adieu à Mahfūz tout en lui témoignant une profonde reconnaissance ${ }^{47}$.

46. Edward Saïd, Reflections on Exile and other Essays, Harvard, Harvard University Press, 2002, London, Granta books, 2001.

47. Nous nous sommes référée à la traduction arabe de Reflections on Exile and Other Essays: Ta 'ammulāt hạla-l-manfā, Beyrouth, Dār al-ādāb, 2004, traduit par Thā 'ir Dīb, p. 187. 
Le récit informe serait, ajoute Saïd, l'une des caractéristiques fondamentales du postmodernisme dans l'œuvre de Khūrī :

Le trait le plus représentatif et le plus beau dans la littérature arabe moderne serait, selon Ilyās Khūrī, celui qui est emprunté, non aux formes stables et répétées, qu'elles soient locales et liées à la tradition arabe (la poésie) ou importées de l'Occident (le roman), mais à ces œuvres qu'il qualifie d'informes: Yawmiyyāt nā îb fi-l-aryā $f$ de Tawfīq al-Hakīm, al-Ayyām de Ṭāha Husayn et les écrits de Jibrān et Nu'ayma.[...] Ce que Khūrī trouve dans ces œuvres informes correspond précisément à ce que les théoriciens occidentaux ont appelé "postmoderne » : ce mélange structurel entre autobiographie, nouvelle, légende et introspection ironique, éclairant fortement ces œuvres d'une nostalgie pressante, étrange et effrayante ${ }^{48}$.

Saïd étend, d'une part, la caractéristique "postmoderne " d'absence de forme à des auteurs comme Ṭāha Ḥusayn (18891973), Tawfīq al-Ḥakīm (1898-1987) Jibrān (1883-1931) et Nu'ayma (1889-1989), fondateurs de la modernité arabe et antérieurs à Maḥfūz, et, d'autre part, il fait débuter la guerre civile libanaise dans les années 1970, ignorant les guerres antérieures à Khūrī, mais auxquelles l'œuvre de ce dernier fait constamment allusion. Plus encore, il reprend le terme " moderne " pour évoquer ces œuvres, mais qualifie la forme romanesque de ces mêmes œuvres de "postmoderne ". Il entoure ainsi de flou la délimitation précise de ce qui est moderne et de ce qui relève du postmodernisme.

Mettre ensemble Khūrī, Ṭāha Ḥusayn, Tawfīq al-Ḥakīm, Jibrān Khalīl Jibrān et Mikhāîl Nu'ayma comme autant d'auteurs du récit sans forme semble quelque peu hâtif. Khūrī n’a eu de cesse d'instaurer une rupture avec la génération précédente.

48. Ta 'ammulāt hawla-l-manfā, p. 184-185. 
Elias Khoury - De l'engagement au postmodernisme

Nous l'avons relevé dans Mamlakat al-ghurabä'. Sobhi Boustani le soulève dans son étude sur Yalū :

Par sa volonté de se démarquer du projet poétique de la génération précédente qui avait pour ambition de changer le monde, il renonce tout simplement au rôle du " prédicateur ". La vision d'Elias Khoury est ici similaire à celle de Darwish. Il crée un personnage qui est à l'opposé du héros sauveur, du héros idéalisé. Le statut même de la littérature moderne est reconsidéré par l'auteur ${ }^{49}$.

Kamāl Abū Dīb, évitant les confusions de Saïd, s'efforce lui de mettre en évidence, à travers l'œuvre de Khūrī, d'une évolution de la position de ce dernier en matière de valeurs. La foi en un monde meilleur reste, selon Abū Dīb, présente dans al-Jabal al-șaghīr ; c'est dans ses romans ultérieurs que Khūrī donnerait plus sûrement des gages de postmodernisme.

Kamāl $A \boldsymbol{b} \bar{u} \mathbf{D} \boldsymbol{D} \boldsymbol{b}$. Occupant la chaire d'études arabes de l'université de Londres, il est connu pour avoir traduit en arabe les deux ouvrages fondamentaux d'Edward Saïd: Orientalism ${ }^{50}$ et Culture and Imperialism ${ }^{51}$. Dans une étude intitulée "Views and Study of Elias Khouri's Bāb al-shams as a nascent postmodernist text ${ }^{52}$ ", il commence par souscrire à la définition donnée par Terry Eagelton de la postmodernité et du postmodernisme : la postmodernité est la condition historique correspondant, en Occident, à un tournant vers une autre forme de capitalisme, et

49. Sobhi Boustani, "violence et marginalité: essai sur le roman Yâlû d'Elias Khoury », op.cit.

50. Edward Saïd, Orientalism, New York, Vintage Books, 1978.

51. Id., Culture and Imperialism, London, Vintage, 1978.

52. Kamāl Abū Dīb, «Views and Study of Elias Khouri's Bāb al-shams as a nascent postmodernist text ». Ce texte a fait l'objet d'une conférence à la Georgetown University à Washington, 2007; il reste non publié à ce jour; une copie nous a été remise par Ilyās Khūrī avec l'accord de Kamāl Abū Dīb. 
le postmodernisme est la manifestation culturelle de l'époque concernée.

Pour Abū Dīb, il ne fait aucun doute que le monde dans lequel nous vivons aujourd'hui a subi des changements profonds et obéit désormais aux règles de la discontinuité, de la multiplicité et de la fragmentation, faisant vaciller la domination culturelle de l'Occident telle qu'elle s'exerçait auparavant :

An immense amount of richness can be encountered everywhere we look, and a great degree of diversity, contradiction, tension, absence of singularity, multiplicity and fragmentation distinguishes cultural output in today's world. What is undoubtedly true is that there have been acts and processes of discontinuity, change, transformation, explosions of bubbling energies all over the place. The old rules of organic growth, determinism and evolutionary change no longer appear to govern the world in which we live. And the centrality of Western cultural production has been shattered -I should say "fragmented", in order to be faithful to the spirit of much of my work ${ }^{53}$.

D’après Abū Dīb, l'œuvre de Khūrī, notamment Bāb al-shams, installe cette fragmentation autant qu'elle en est le produit. Emboîtant en cela le pas de Saïd, Abū Dīb considère que le contexte historique marque le texte d'empreintes spécifiques et, par conséquent, que l'œuvre de Khūrī a évolué au gré des transformations politiques enregistrées au Liban et dans la région. Il souligne la façon dont l'auteur a vécu la situation, ce qui l'amène à lire son œuvre en la classant selon trois périodes : chacune marque un stade dans l'évolution de la question des valeurs et de la foi qui peut leur être encore accordée dans un monde en proie à la violence et à la décomposition.

53. Kamāl Abū Dīb, op. cit., p. 17. 
La première période est celle du début de la guerre civile, à laquelle correspond le premier roman de Khūrī, al-Jabal al-ṣaghīr (1977). Ce roman, écrit au tout début de la guerre, promeut, malgré l'explosion des violences, une grande narration, la dévotion à une cause juste. Nous citerons, malgré sa longueur, tout le développement d'Abū Dīb, pour montrer comment, tout en partant des mêmes prémisses que Saïd, son raisonnement fait pourtant d'al-Jabal al-șaghīr un roman qu'on ne pourrait pas encore qualifier véritablement de postmoderne, en raison justement de la foi portée via la narration en un monde meilleur. Il ajoute que le style de ce roman est pur et entièrement en arabe littéraire, ce qui ne sera plus le cas ultérieurement:

Behind the whole project there lies a grand narrative, to use Lyotard's term. Everything is deeply rooted in place and time, a specific place and specific time and is imbued with a powerful devotion to a cause, a dream and a project, by a totalizing vision and a quest for collective redemption. The place is Beirut and the "little mountain" (the hill of Ashrafiyya in East Beirut) is both the point of departure for the journey to change the world and the site for emotional attachment and social categorization. The narrative is powerful, diachronic, coherent, evolving in time and place; the characters are well shaped, meaningful, exploding with life, ideas and dreams; the language is pure Fusha, artistically conceived and elegantly, sometimes even poetically, crafted. The orbit of action and development is partly tragic, as any truthful depiction of a civil war situation anywhere is bound to be. But the certainties, the faith, the devotion to a cause, the sense of a future in the making and the necessity, indeed, inevitability of struggle and conflict and war are unshakeable. The social cohesion that is dreamt of is a part of the grand project, although social conflict and struggle are taking place; the conflict is inevitable but purposeful, it is between evil and good, deprived classes and exploitative classes. There is a nobility of purpose 
that justifies violent actions and bestows an aura of majesty to human tragedies ${ }^{54}$.

S’ensuit une période médiane où l'enlisement de la situation entraîne le scepticisme quant à la possibilité de construire un nouveau monde. Abwāb al-madīna (1981), où le narrateur semble vivre un cauchemar dont il n'arrive pas à se réveiller, correspond à cette période : "It is the point at which the revolutionary impulse begins to become hazy, scepticism creeps, the old certainties begin to crumble. At this point, Khouri writes Abwab al-Madina ${ }^{55}$. "

La dernière période est celle de la perte totale de foi dans l'histoire et dans l'individu, provoquant l'émergence d'une narration fragmentée qui se remet en question à travers un discours métafictionnel devenu central. Bāb al-shams est l'illustration la plus accomplie de cette période :

Then came the fragmentation and multiplicity at a point where the old certainties appeared completely crushed. At this stage, Khouri's work takes a different shape: the vision is clear now that the past was a failed, tragic project, that the grand narrative was hollow; language becomes totally mixed, indeed hybrid; the moral purity of narrative is replaced by the vulgar morality of the language of the street (for the first time in serious fiction we encounter words like tuzz, khara and the explicit vocabulary of sexuality); the characters are no longer the intellectuals and revolutionaries but ordinary, often morally suspect people, the narrative loses its cohesion and a multiplicity of voices, narratives, events, tales and a huge number of sceptical questions dominate the narratives. The grand questions which are now being asked do not concern the revolution and social and political issues, but the medium itself, the nature of narrating, the truth-value of narra-

54. Kamāl Abū Dīb, op. cit., p. 10-11.

55. Ibid., p. 11. 
tive, the role and authority of the narrator and the author, the illusive, indeed, deceptive nature of fiction, the impossibility of knowing what we want to narrate and the constant lying in every narrative one is told ${ }^{56}$.

Selon Abū Dīb, la fragmentation, la vanité de chercher refuge dans un passé lacunaire, la vérité introuvable, sont autant de caractéristiques narratives qui permettent de lire Bāb al-shams ainsi que les derniers romans de Khūrī à partir d'al-Wujūh al-bayḍa $\bar{a}^{\prime}$ (1981) dans une perspective postmoderne.

La périodisation d'Abū Dīb lie indéniablement le texte à son contexte historique. Cependant, s'agissant de son analyse d'alJabal al-șaghïr, nous ne partageons pas l'affirmation selon laquelle la narration serait diachronique et cohérente et le caractère des personnages bien dessiné. Le roman est, certes, porté par une cause qui en fait un grand récit, mais la narration est discontinue et les personnages apparaissent vacillants.

Par ailleurs, nous avons montré que, contrairement à l'affirmation d'Abū Dīb, les derniers romans de Khūrī, en particulier Bāb al-shams, Yālū et Ka'annahā nā'ima révèlent, malgré leur noirceur, la persistance d'une quête d'idéal et la recherche d'une nouvelle voie, manifestes à travers l'image omniprésente du Christ et la valeur de vie accordée à l'acte narratif.

Sonja Mejcher-Atassi. Dans un ouvrage consacré à l'œuvre romanesque de Khūrī ${ }^{57}$, Sonja Mejcher-Atassi, professeure à l'université américaine de Beyrouth, analyse l'urgence d'écrire le présent durant la guerre civile libanaise. Elle considère, à la suite d’Edward Saïd, que cette œuvre rompt avec l'écriture de Maḥfūz.

56. Ibid.

57. Sonja Mejcher-Atassi, Geschichten über Geschichten. Erinnerung im Romanwerk von Elias Khoury («Histoires sur histoires. Mémoires à propos de l'œuvre romanesque d'Elias Khoury »), Reichert Verlag, Wiesbaden, 2001. 
Les romans de Khūrī, caractérisés par la rupture avec les modèles préétablis et par un mélange des genres, fraieraient le chemin à une écriture nouvelle, que nombre de critiques considèrent comme postmoderne :

His novels are characterized by a high degree of experimentation and innovativeness that many critics have labeled postmodern. Transgressing literary genres, they reflect the conditions and possibilities of narrative fiction beyond preset models. Their reference points are manifold, ranging from contemporary European and American literature via contemporary literature from Latin America, Africa and India through to classical Arabic literature ${ }^{58}$.

La recherche de nouvelles voies narratives marque un tournant dans la littérature libanaise contemporaine. L'écriture expérimentale de Khūrī correspondrait bien, selon Mejcher, à ce que les critiques qualifient de postmoderne.

\section{Le roman de Khūrī est-il postmoderne?}

Certaines caractéristiques narratives du roman de Khūrī le situent donc dans la mouvance postmoderne. Ouverture de l'œuvre, liberté de l'interprétation, effondrement de l'énonciation, affirmation d'une identité plurielle, perte du sens et des valeurs, absence de vérité, cohabitation des contraires, dialectique amputée de sa synthèse, écriture métafictionnelle et expérimentale, histoire métafictionnelle, popularisation de la langue et légitimation du dialectal - autant d'éléments qui rejoignent les propriétés du postmodernisme.

D'autres caractéristiques de son œuvre peuvent, toutefois, être jugées contraires à l'esprit du postmodernisme.

58. Id., "On the Necessity of Writing the present: Elias Khoury and the Birth of the Novel in Lebanon", in Arabic literature: Postmodern Perspectives, op.cit., p. 87. 
L'engagement, la lutte pour les valeurs, la mainmise du narrateur sur son récit, le rôle rédempteur attribué à la parole, vont à l'encontre de la fragmentation et du scepticisme qui caractérisent l'époque contemporaine et le roman qui lui correspond.

Pouvons-nous parler, dès lors, sans nous contredire, de postmodernisme chez Khūrī ?

Oui. Si l'on considère que le postmodernisme se refuse à l'idée de l'absorption ou de l'élimination des éléments « inintégrables ", et laisse cohabiter les contraires. Ainsi, certaines tensions narratives ne sont plus destinées à être résorbées. Nous avons vu que la déconstruction de l'héroïsme dans $B \bar{a} b$ al-shams ne mène pas forcément à l'abandon de cette notion mais à sa redéfinition en fonction d'autres valeurs. C'est l'humain dans ce qu'il a de plus tragique, de plus fragile, et de plus fuyant qui est considéré comme le nouveau visage de l’héroïsme. De même pour Yālū ; tout en étant un marginal et un violeur, il est transfiguré par la souffrance et par l'injustice subie. Dans Ka'annahā nā'ima se côtoient également deux discours divergents; le délire pathologique de l'héroïne, tout en relevant de la pathologie, contient une part rédemptrice.

Nous nous sommes également attachée à le montrer, cette divergence se redéploie au niveau de l'autorité narrative: la volonté de puissance du narrateur se juxtapose à l'aveu d'impuissance de ce même narrateur. L'oscillation non résolue entre des mouvements contraires est caractéristique d'ailleurs de toute grande œuvre qui se cherche et se construit dans le doute et la douleur. Robbe-Grillet a évoqué cette tension dans les termes d'un dosage entre deux forces antagonistes, le besoin idéologique d'ordre et de classement, d'un côté, et l'aspiration à la liberté, de l'autre :

L'expérimentation problématique de la matière romanesque s'imposait à moi [...] comme le champ le plus propice pour 
mettre en scène dans son déséquilibre permanent cette lutte à mort de l'ordre et de la liberté, ce conflit insoluble du classement rationnel et de la subversion, autrement nommée désordre ${ }^{59}$.

Cette juxtaposition inattendue de positions contradictoires est considérée comme un procédé auquel recourt le postmodernisme. Jameson parle de " décentrement " ou encore de " schizofragmentation ". La disjonction ou l'écriture schizophrène définit, selon lui, le « style culturel ${ }^{60}$ » du postmodernisme, caractérisé par la désintégration du tissu narratif. L'existence d'éléments contradictoires, libérée de la recherche de l'union des contraires, est ainsi conçue comme la manifestation de la richesse, des différences et du pluralisme de la réalité.

Les éléments qui semblaient ainsi, à première vue, rebelles à une lecture postmoderne des romans de Khūrī, ne le sont plus lorsqu'on intègre cette dimension de «l'indétermanence ", pour reprendre le terme forgé par Ihab Hassan. L'indétermanence (indeterminacy) est formée à partir de deux termes, "indétermination " et "immanence " qui constituent, selon Hassan, les deux tendances constituantes du postmodernisme: là où le modernisme privilégiait des notions telles que la forme close, la hiérarchie, l'œuvre magistrale et centrée, la totalisation, la synthèse, les genres, les limites, l'interprétation magistrale, la profondeur, la présence, l'hégémonie, la grande narration et la transcendance, le postmodernisme, par contre, se définit par des notions comme l'antiforme ou la forme disjointe et ouverte, l'anarchie, la déconstruction, l'absence, la dispersion, les petites narrations, la schizophrénie, l'ironie, l'immanence.

59. Alain Robbe-Grillet, Le Miroir qui revient, Paris, Seuil, 1984, p. 26.

60. Fredric Jameson, Le Postmodernisme ou la logique culturelle du capitalisme tardif, op. cit., p. 73. 
L'expérimentation formelle n'est pas un laboratoire qui fonctionne en cercle clos; elle répond aux impératifs de l'histoire et se trouve être, par conséquent, une réaction politique. C'est pourquoi, quand bien même le postmodernisme évacue l'idée de progrès et de grands récits, il est, à tort, interprété comme « perte d'historicité » ou " surdité à l'histoire ", dixit Jameson ${ }^{61}$. L'absence d'historicité est impropre à penser le postmodernisme et mène à considérer que « tout se vaut ». En effet, Michael Archer explique dans son ouvrage sur l'art contemporain depuis 1960, que la destruction des modèles originaux à partir desquels une pluralité de styles et d'images pourraient se juxtaposer de façon cohérente n’implique pas un déni d'historicité :

Il y avait aussi dans le postmodernisme un goût pour l'incongruité d'un art fait d'emprunts. Juxtaposer des styles et des images disparates faisait violence à l'intégrité historique et aux intentions de l'original. [...] Ceux que cette attitude dérangeait conclurent que le postmodernisme n'avait, tout simplement, aucun sens de l'histoire, que ses produits n'étaient qu'un amalgame cynique d'éléments choisis uniquement pour leur séduction visuelle superficielle et qu'il ne s'agissait donc que d'un art de la surface, sans substance ${ }^{62}$.

Cela dit, la méfiance à l'égard du postmoderne ne décroît pas. Bien au contraire, elle est ravivée par des polémiques diverses: la crise du capitalisme mondialisé annonce-t-elle la fin d'une époque ou sommes-nous, plus que jamais, coincés au sein d'un même système ? Comment affirmer qu'il y a fin d'une période quand nous constatons une expansion mondiale du marché, un accroissement de la productivité, un regain des luttes sociales et des revendications ouvrières ? Quand on assiste, non pas à une disparition des modes anciens de domination, mais à leur

61. Ibid., p. 17.

62. Michael Archer, L'Art depuis 1960, Paris, Thames et Hudson, 1998, p. 144-145. 
délocalisation massive, et non pas au déclin de l'engagement, mais à sa redéfinition?

On ne saurait prétendre apporter des réponses à ces questions, mais les soulever est déjà important, dans la mesure où elles témoignent de la complexité de la problématique postmoderne. La diversité des théories postmodernes n'est pas forcément une cacophonie, car, comme le souligne Isabelle Garo, ces théories relèvent d'une interrogation générale qui reste commune :

Pourtant, la théorisation du postmodernisme va systématiser, schématiser et populariser un certain nombre de traits ou de tendances que l'on rencontre chez tous les auteurs de cette génération. Le mérite de la notion est de permettre la distinction de voies critiques générales et d'en proposer une épure, même si elle tend de ce fait à simplifier des thèses philosophiques plus subtiles, dont les élaborations singulières rendent difficiles leur affiliation à une mouvance néanmoins commune ${ }^{63}$.

Les thèses du postmodernisme rendent compte des transformations politiques sociales et culturelles de l'époque. Elles permettent, en outre, de rompre avec une approche purement interne et formaliste de l'œuvre littéraire et de penser la jonction de la conscience créatrice avec l'environnement historique. Car l'externe et l'interne, la forme et le fond sont dans un rapport de " détermination réciproque " (Wechselwirkung), pour reprendre l'expression d'Arnold Hauser. En introduisant une périodisation, le postmodernisme ne s'érige pas en modèle global mais inclut en lui-même son propre dépassement. Il se présente, non comme une représentation du monde, mais comme la manifestation et la redéfinition du réel dont il proclame épouser les contours complexes.

63. Isabelle Garo, Foucault, Deleuze, Althusser et Marx, op. cit., p. 371. 
Une approche de l'œuvre de Khūrī sous l'angle du postmodernisme permet de prendre la mesure des mutations aussi bien du monde d'aujourd'hui que de la littérature contemporaine. Restant à l'écoute des spécificités relatives à chaque région et à chaque auteur, elle limite les égarements conceptuels et la dictature de schémas universels. Quoi qu'il en soit, cette œuvre interagit avec les questions qui se posent à son époque, qu'on veuille ou non appeler cette ère postmodernité et que l'on considère ou non que ses manifestations dans la culture relèvent d'une théorie du postmodernisme. 


\section{Conclusion}

Les oscillations internes à l'œuvre de Khūrī, mises en évidence au fil de notre travail, pourraient expliquer les lectures divergentes auxquelles celle-ci a donné lieu : certains l'abordent comme narration ouverte ; d'autres mettent en avant l'omniprésence d'un narrateur qui n'hésite pas à intervenir dans son récit pour commenter les événements et amener le lecteur à épouser ses points de vue. Cette œuvre porte l'empreinte aussi bien d'une pensée tragique de l'absurde que d'une exaltation de la vie. La notion d'héroïsme, malgré sa déconstruction, garde sa place : les victimes sont en quelque sorte sanctifiées. Quant aux narrateurs des différents romans, ils ont en commun l'intelligence et la force de la parole. La critique de l'histoire ne se conclut pas par un rejet du roman historique, bien au contraire. D'ailleurs, jamais les écritures fictionnelles de l'histoire n’ont été aussi présentes dans la littérature arabe contemporaine.

Dire, comme Robbe-Grillet, que les tensions romanesques sont le signe de toute écriture qui se cherche, ou y voir comme Jameson une caractéristique de l'écriture schizophrène, emblématique de la culture contemporaine qui perd la boussole, ne dispense pas d'interroger de plus près l'instance narrative, cette instance étant le lieu où se manifestent ces tiraillements. L'action du narrateur chez Khūrī se lit principalement en fonction de trois quêtes, littéraire, politique et christique qui sont à la fois distinctes et imbriquées. Toutefois, son positionnement 
particulier au sein de chacune ne laisse pas d'engendrer des ambiguïtés. Passons-les en revue.

\section{La voix narrative: entre confusion et profusion de vie}

La parole est un acte; le narrateur le sait mieux que quiconque: "J'ai rassemblé moi-même l'histoire; j'ai arrangé tes phrases éparpillées pour qu'elles deviennent une histoire ", dit Khalìl à Yūnus (Bāb, p. 34). Cette affirmation pourrait être reprise à leur compte par tous les narrateurs des romans de Khūrī. Plus que tout autre personnage, le narrateur détient les compétences susceptibles de lui permettre d'ordonnancer le chaos des histoires. Il est soit le personnage principal (Yālū et Bāb al-shams), soit celui qui raconte une histoire sans vis-à-vis, étant donné que les protagonistes sont ou bien morts au combat ou bien de simples rapporteurs d'histoires dont on ne sait quasiment rien. Ce faisant, il se positionne de facto comme le seul détenteur d'une parole fondatrice. Dans Mamlakat al-ghurabä', il est à la fois un écrivain et un militant. C'est un Libanais de gauche, enrôlé dans le Fatah, qui part en Jordanie soutenir la lutte des Palestiniens. En tant qu'auteur, il témoigne de son vécu de la guerre et de la lutte de ses compagnons morts au combat. Ce double engagement, militant et littéraire, n'est pas sans rappeler la trajectoire personnelle de l'auteur Ilyās Khūrī. Confronté à la mort, il s'interroge sur la valeur de l'écriture dans un monde où tout vacille. Cependant, ses hésitations ne l'amènent pas à renoncer à agir. Bien au contraire, il ressent le devoir de lutte et de résistance. Le récit est indéniablement, sur ce plan, un allié. Le narrateur doit triompher des discours faux et dominants en instaurant à la place un discours critique, plus à même de remporter l'adhésion de son lecteur. 
Un autre roman, Majma al-asrār, révèle également un narrateur lucide et fort d'une réflexion profonde. Il cherche à comprendre pourquoi l'Arabe est irrémédiablement un étranger. Sa capacité d'analyse lui assure une position de surplomb, lui permettant, d'une part, de produire l'intelligibilité de l'histoire et, d'autre part, de résister à la mélancolie qui s'empare des personnages.

Dans Yālū, c'est Yālū qui raconte. En prison, en plus des tortures physiques atroces qu'il endure, on lui inflige comme autre châtiment celui de mettre par écrit le récit de sa vie. Instrument de torture au début, car Yālū est sommé de réécrire son histoire sitôt rendue chaque version, le récit se transforme en un moyen de salut. Bāb al-shams accorde à la parole un pouvoir salvateur. En racontant, Khalīl se métamorphose et se libère. Dans $\mathrm{Ka}^{\prime}$ annahā nā'ima, le narrateur endosse la voix et les valeurs de Mīlyā. N'ayant pas poursuivi des études poussées et étant proie au délire, la parole de cette dernière perd de son autorité. Le narrateur qui la supplée se présente, là aussi, en véritable détenteur du récit.

On comprend dès lors la proximité du narrateur avec deux grandes figures qui impactent profondément son écriture : Schéhérazade et le Messie. L'une et l'autre ont en commun d'avoir affronté les ténèbres et vaincu la mort. La première par le récit, le second en incarnant le verbe de Dieu.

Comme c'est le cas pour la tisserande des nuits, le récit chez Khūrī est l'antidote de la mort. Il est un adjuvant et un synonyme de vie. C'est pourquoi, par exemple, Dunyā, une rescapée du massacre de Shātīlā, est morte de n'avoir pu continuer à raconter son histoire : "Dunyā s'est effondrée parce qu'elle s'est tue après le congrès du Carlton " ( $B \bar{a} b, \mathrm{p}$. 257). L'être humain est un " homme-récit ${ }^{1}$ "; cette formule de Todorov a son équivalent

1. Cf. Tzvetan Todorov, Poétique de la prose, op. cit., 1971. 
Elias Khoury - De l'engagement au postmodernisme

chez Khūrī pour lequel " lorsque les paroles finissent, tout finit » (Bāb, p. 457) :

J'ai appris du docteur Munā que Dunyā ne faisait rien d'autre que raconter ce qui lui était arrivé. Elle surprenait ses auditeurs à chaque fois en relatant des événements nouveaux qu'elle n'avait pas dits les fois précédentes. Les journalistes ou les responsables d'organisations humanitaires internationales arrivaient, Dunyā s'asseyait dans le bureau de la fondation des handicapés au camp des réfugiés et parlait. Docteur Munā traduisait ce qu'elle ne parvenait pas à dire en anglais. Dunyā était devenue une histoire qui racontait son histoire. (Bāb, p. 257-256)

Et de commenter :

Tu te souviens de Dunyā, elle est morte maintenant. Ce n'est pas grave, diras-tu. Ce n'est pas grave, dirai-je. Nous allons tous mourir. Mais Dunyā est morte parce qu'elle n'arrivait plus à jouer le rôle de la victime. Cette période est révolue. Les organisations humanitaires internationales ne s'intéressent plus à nous. L'intérêt est passé à la Cisjordanie et à Gaza. Il n’y avait plus d'oreilles pour écouter Dunyā, c'est pourquoi elle est morte. (Bāb, p. 441)

L'histoire est l'équivalent de la vie. Les gens disparaissent lorsqu'ils n'ont plus d'histoires à raconter. La parole a une valeur thérapeutique. En racontant, Khalīl échappe à la folie :

Ta mort est arrivée à point pour me sauver. Grâce à toi je suis redevenu médecin. Tu m'as fait habiter avec toi à l'hôpital et tu m'as permis de reprendre goût à la vie. Oui, j'étais incapable de vivre. Je sentais l'air pénétrant mes poumons comme autant de couteaux qui me blessaient. Je sentais les fourmis s'incruster dans mon visage et j'avais le vertige. En jargon médical, cela s'appelle un début de dépression nerveuse. (Bāb, p. 498) 
Quand bien même " ce qui importe c'est la vie, non l'histoire " ( $B \bar{a} b$, p. 43 ), il n'en reste pas moins que le récit est la médiation par laquelle la vie accède à la conscience d'elle-même.

Il faudrait toutefois distinguer une parole, authentique, d'une autre, inauthentique: «Est-ce que tu crois que la parole est un traitement ? Si c'était le cas, nous aurions libéré la Palestine depuis longtemps » (Bāb, p. 223). Bāb al-shams critique durement l'intellectuel embourgeoisé, de connivence avec le pouvoir établi : «Tu sais comment réfléchissent ces intellectuels : ils croient résoudre leur problème de conscience avec des statues, des poèmes ou des romans " (Bāb, p. 348). Ou encore: « Tu n’as pas connu Sāmiḥ Baraka, tu détestes les intellectuels, surtout ceux qui viennent voir les combattants, ils théorisent et font de la philosophie puis ils tournent le dos et repartent vers le confort de leurs maisons". (Bāb, p. 482). Pour Khūrī, l'intellectuel, s’il joue son rôle, produit un contre-discours dont la fonction est d'empêcher la conscience de s'endormir. D'ailleurs le couple Yūnus-Khalīl représente cette double orientation de la parole. Celle de Yūnus, endormie et tournée vers le passé et celle de Khalīl, critique et libératrice.

La parole est ainsi une arme à double tranchant. Elle n'est pas uniquement au service de la vie, elle peut également donner la mort. Khalīl avoue achever Yūnus, Shams et tous les autres personnages à coups de récits: " Je sais qu'en racontant son histoire je la tuerai. Shams va mourir maintenant assassinée par les mots " (Bāb, p. 472). Nous avions relevé par ailleurs la caractéristique anthropophagique qui nourrit la relation du narrateur à ses personnages. Il donne la mort, trahit et avale ses personnages pour les ressusciter par la suite à sa guise, affirmant par là sa liberté — qui ne manque pas de lui prodiguer une jouissance littéraire infinie.

Cependant, nous l'avons souligné (voir chapitre 1), la phrase qui revient le plus souvent dans la bouche du narrateur est « je 
ne sais pas ". Le roman est ainsi travaillé par deux dynamiques contraires : l'une admet les limites du narrateur et l'autre montre le triomphe des vertus vivifiantes et libératrices du récit. Le narrateur est affaibli et perdu, mais fort au milieu de la tempête. Passer d'une position à l'autre se répercute sur la forme narrative, laquelle oscille, de la même manière, entre les doutes digressifs et la force du verbe.

\section{Engagement politique et littérarité: la tentation de l'autofiction}

Le narrateur est le discriminateur idéologique de l'œuvre; il est celui qui porte les valeurs. Or, il n'est pas, chez Khūrī, un acteur objectif et neutre. Son engagement politique, à l'instar de celui de l'auteur, n'a jamais failli. L'œuvre de Khūrī est un exemple d'écriture de résistance. Comme lieu de la mémoire, où s'affrontent passé et présent, son roman ne peut être serein. De plus, le choix d'une écriture engagée, à une époque qui assiste au reflux de l'engagement, se répercute sur la position inconfortable du narrateur tiraillé entre raison d'agir et déraison de l'histoire. Ce tiraillement détermine aussi bien la vision du réel qui se dégage des romans que les choix des techniques narratives employées. Forte de ses positions engagées, l'œuvre de Khūrī évite l'écueil du roman à thèse, qui vise à présenter un modèle, ou un contre-modèle fictionnel dont sont exclues les contradictions et les ambiguïtés.

On le voit bien, la question qui est au cœur de l'engagement n'est pas seulement politique, elle est surtout littéraire, puisqu'il s'agit de déterminer dans quelle mesure la littérature parvient à s'engager politiquement sans que sa singularité ne soit subordonnée à des considérations entièrement politiques. Khūrī tente de satisfaire l'une et l'autre exigence: celle que dictent ses choix 
politiques et celle qu'impose la littérarité. Cette double contrainte ne serait toutefois pas propre à l'auteur libanais; elle est, d'après Benoît Denis, celle du "roman simultanéiste ", et fut assumée par Sartre et Camus. Elle consiste, pour la voix narrative, à garantir la production du sens tout en évitant de se compromettre. Le narrateur se retrouve ainsi dans une place inconfortable, se faisant constamment violence à lui-même. Cette technique, décrite par Benoît Denis, éclaire bien les rapports compliqués entre politique et littérature et permet, en outre, de comprendre les contradictions du narrateur, sa position ambiguë étant la conséquence de son engagement à la fois maintenu et impossible :

Schématiquement résumée, cette technique consiste à refuser l'omniscience du narrateur et à lui substituer une polyphonie de voix narratives: le récit se focalise successivement sur une série de personnages dont il épouse le point de vue situé et limité. La linéarité du récit se trouve ainsi brisée en une série de fragments juxtaposés qu'aucune voix ne relie ou n'articule explicitement entre eux: loin de présenter la parfaite intelligibilité du roman traditionnel, l'histoire apparaît ici comme obscure, pleine de vides et d'incertitudes, sujette à interprétations divergentes. Ce que le roman perd en lisibilité, il le gagne cependant en réalisme et en efficacité: la multiplication et la dispersion des points de vue produit l'impression d'une Histoire en train de se faire et sur laquelle le lecteur a prise. Car cette technique narrative, loin de proposer les réponses univoques et contraignantes du roman à thèse, produit un récit ouvertement problématique qui invite le lecteur au questionnement et au travail critique, étape préliminaire à tout engagement. [...] Le roman simultanéiste, s'il constitue une forme ouverte de littérature engagée, pose néanmoins un problème quant à la place de l'auteur. Celui-ci, en effet, s'efface au profit d'une série de points de vue entre lesquels il ne choisit pas. Il en résulte que sa position est nécessairement incertaine et ambiguë: il est à la fois absent, hors du coup, et, en même temps, on peut constamment le soupçonner d'orchestrer très consciemment 
la polyphonie narrative derrière laquelle il se cache. Dès lors, le roman engagé atteint une impasse qu'on aurait tort de négliger: l'auteur, insituable, se trouve dans une position duplice qui contrevient à l'une des exigences majeures de l'engagement (assumer et objectiver sa position) ${ }^{2}$.

L'œuvre littéraire de Khūrī témoigne de cette nécessité impossible de l'engagement. Oscillant entre les incertitudes liées à son action politique et le devoir de rester fidèle aux engagements pris, l'auteur ménage un entre-deux où s'inscrit sa présence problématique. La perte de sa foi dans l'histoire ne l'empêche pas de continuer à agir. Dans une interview donnée à l'Orient littéraire ${ }^{3}$, Khūrī explique cette contradiction en se référant à la célèbre formule de Gramsci, qui écrivait dans ses cahiers de prison qu'«il faut allier le pessimisme de la raison à l'optimisme de la volonté ». La morale de l'action l'emporte. Khūrī ajoute :

L'action a un sens dans la mesure où elle est une manifestation de la vie. L'optimisme de la volonté prend le dessus sur mon pessimisme et me pousse à m'engager. Malgré une situation peu rassurante, je continue à soutenir les revendications qui me paraissent justes. Je n'y vois pas de contradiction. Nous savons que l'amour finit, nous continuons à aimer pour autant. L'homme n'obéit pas à sa seule raison, heureusement d'ailleurs, sinon il n’y aurait ni vie ni littérature.

Pour Khūrī, la littérature a pour fonction, entre autres, de déconstruire les systèmes de domination. Sa position se rapproche de la thèse de Linda Hutcheon selon laquelle « l'expérimentation esthétique postmoderne possède une dimension politique irréductible et est intrinsèquement liée à une critique

2. Benoît Denis, Littérature et engagement, de Pascal à Sartre, Paris, Seuil, 2000, p. 87-88.

3. L'Orient littéraire, "Élias Khoury, l'optimisme de la volonté », par Katia Ghosn, $1^{\text {er }}$ janvier 2012. 
de la domination ${ }^{4}$ ». Linda Hutcheon est influencée par la pensée de Michel Foucault. Selon ce dernier, «l'action de l'intellectuel opère un véritable changement dans la société en détruisant le régime politique, économique, institutionnel de production de la vérité et en détachant le pouvoir de la vérité des formes d’hégémonies (sociales, économiques, culturelles) à l'intérieur desquelles pour l'instant elle fonctionne ${ }^{5}$ ".

La littérature est invitée à rendre la parole aux dominés. Ce faisant, elle rompt avec le Nouveau Roman et renoue avec l'engagement. Le désengagement des "nouveaux romanciers ", en opposition à l'engagement sartrien est souligné par Roger-Michel Allemand ${ }^{6}$. La littérature arabe ne peut se permettre le luxe de

4. Linda Hutcheon, The Politics of postmodernism, op. cit., p. 2. " Postmodern aesthetic experimentation should be viewed as having as irreductible political dimension. It is inextricably bound up with a critic of domination. »

5. Citation de Michel Foucault, in Jean-François Bert, Introduction à Michel Foucault, Paris, La Découverte, 2011, p. 24.

6. Cf. Roger-Michel Allemand, Le Nouveau Roman, Paris, Ellipses, 1996: "Ils considèrent que l'art est personnel et ne doit en aucun cas se soumettre à des événements ou des considérations qui lui sont étrangers par nature, puisque politiques et non pas esthétiques. C'est notamment ce que Robbe-Grillet s'efforce de démontrer dans un article qu'il publie dans L'Express en 1957 (plus tard repris dans "Pour un Nouveau Roman"), dont le titre provocateur, "Sur quelques notions périmées", annonce l'évacuation de toute idée d'engagement de l'écrivain autrement que dans le processus même de la création, parce que révolution sociale et révolution des formes artistiques sont précisément d'ordre différents et incompatibles. Même s'il peut s'engager à titre individuel, en tant que citoyen, dans la société (ce que plusieurs « nouveaux romanciers » feront par la signature du Manifeste des 121, lors de la guerre d'Algérie), son art ne peut être subordonné à un quelconque objectif en dehors de lui-même, libération du prolétariat ou autre, pour la seule raison que l'art n'est pas un moyen mais un but en lui-même, ainsi que Claude Simon le signalera également en stigmatisant l'utilitarisme de principe des écrivains engagés, tandis que Sarraute se montrera plus nuancée ( « Il y a eu et il y aura des œuvres dites engagées qui sont des œuvres d'art authentiques ». Esprit, juillet 1964). Pour le Nouveau Roman comme pour le Gautier parnassien, il " n'y a vraiment de beau que ce qui ne peut servir à rien » (préface à Mademoiselle de Maupin, 1835), parce que l'« art est une fin sans finalité » (Kant) ». p. 23-24. 
Elias Khoury - De l'engagement au postmodernisme

l'art pour l'art. Andreas Pflitsch rapporte à ce sujet la controverse qui a opposé Robbe-Grillet et l'auteur palestinien Jabrā Ibrāhīm Jabrā, lors d'un festival de littérature à Bagdad, en 1988 :

Robbe-Grillet could not conceal his amusement about an Iraqi literature professor who demanded a commitment to social issues from literature. "We've moved on from this", he remarked, "we've finally overcome this foolish delusion". Jabra defended the professor, making it abundantly clear that in illiberal societies such as those that exist in Arab countries one simply could not indulge in the luxury afforded to writers in the West; that is to achieve such a degree of distance in art and literature that they are decoupled entirely from society and social conditions ${ }^{7}$

L'impossibilité de ne pas s'engager, position tenue par Jabrā ou Șun'allāh Ibrāhīm, est identique, selon Pflitsch, à la posture d'Ilyās Khūrī. La question n'est pas de savoir si la littérature arabe devrait être engagée ou pas, mais de savoir comment elle pourrait l'être. Il va sans dire que la notion d'engagement ne se manifeste plus dans la littérature arabe de la même façon que celle qui était en vogue dans les années 1950, et qu'on peut retrouver dans al-Hayy al-lātīnī (Le Quartier Latin, 1954) de Suhayl Idrīs, par exemple. L’idée d'engagement dans l'œuvre de Khūrī a changé d'expression. Pflitsch considère que ce tournant est lié à deux événements marquants de l'histoire de cette région, la fin du nassérisme en 1967 et la guerre libanaise de 1975 :

With the ideological edifice of Nasserism collapsing like a house of cards and the era of a new dawn and belief in progress and developement coming to an abrupt end, it was not only Egyptian society that was propelled into a state of shocked rigidity. There was hardly a single Arab author

7. Andreas Pflitsch, «The End of Illusions. On Arab Postmodernism », in Arabic Literature, Postmodern Perspectives, op.cit.,p. 28-29. 
whose belief in progress was not profondly shaken and who was not suddenly deprived of any ideological orientation: in short, who had not begun to doubt the tenets of modernity ${ }^{8}$.

Malgré le défaitisme entretenu par une succession de guerres perdues, l'engagement demeure un facteur déterminant de la littérature arabe. Il s'est, toutefois, libéré de la dépendance vis-àvis de l'idéologie dominante du nassérisme et il est devenu sceptique à l'encontre des lectures totalisantes de l'histoire : "The postmodernist skepticism voiced in these works against any claims of absoluteness and one-dimensional explanations, amidst the clamor of Middle East political ideologies on the one hand and religious self-assurance on the other, is highly political $^{9}$.»

La question de l'engagement à l'époque contemporaine doit donc être repensée. S'il ne s'inscrit plus dans une idéologie totalisante, l'engagement trouve toujours sa source dans la réaction face à des réalités ou des événements jugés inacceptables. Khūrī se situe dans cette mouvance : "Il est vrai que les mouvements de gauche peinent actuellement à trouver un ancrage et se trouvent affaiblis à cause de l'expérience stalinienne et de la politique menée par la Chine et la Corée, cependant il est de notre devoir de revaloriser l'idée de justice sociale dans le monde " (L'Orient littéraire, janvier 2012). Roger-Michel Allemand, citant Sartre, le dit bien: "En face d'un enfant qui meurt, la Nausée ne fait pas le poids ${ }^{10}$ » car, poursuit-il, « la seule chose à faire pour un écrivain est de parler pour les opprimés ${ }^{11}$ ».

\footnotetext{
8. Ibid., p. 29-30.

9. Ibid., p. 29.

10. Roger-Michel Allemand, Le Nouveau Roman, p. 25.

11. Ibid.
} 
Le roman, chez Khūrī, prend le parti des marginaux et des opprimés, dénonce l'injustice et est mû par un mouvement de libération : libération du poids des idéologies passéistes et des grands récits de domination. L'engagement ne devrait jamais perdre de vue l'exigence inconditionnelle de liberté. C'est ce qu'exprime l'aveu de Khalīl à Yūnus dans Bāb al-shams :

Je t'avoue que j'ai peur.

J'ai peur de l'Histoire lorsqu'elle est un récit unique. L'Histoire a des dizaines de récits différents, mais lorsqu'elle se fige en un seul, cela ne conduirait qu'à la mort.

Je t'en supplie, mon père, il ne faut pas que nous devenions une histoire unique. Même toi, même Nahīlā. Je t'en supplie, permets moi de te libérer de l'histoire d'amour, de voir en toi un être qui trahit, regrette, aime, qui a peur et qui meurt. Crois-moi, c'est le seul moyen pour ne pas se figer et mourir. $\mathrm{Tu}$ n'es pas figé dans une seule histoire. Tu meurs mais tu es libre. Libre de tout, y compris de ta propre histoire. (Bāb, p. 292)

La juxtaposition des points de vue différents des protagonistes crée une polyphonie qui interdit une lecture univoque du texte, sans toutefois que l'on puisse s'émanciper de l'engagement personnel du narrateur, ou de l'auteur. Cette position permetelle de considérer le roman de Khūrī comme une autofiction? Benoît Denis avance que la meilleure solution pour un écrivain engagé de préserver la dimension littéraire de son intervention est de recourir aux pouvoirs, eux-mêmes ambigus, de l'autofiction :

Quoique cette catégorie dépasse de loin les limites de la littérature engagée, elle permet de rendre compte des enjeux littéraires et existentiels qui l'animent; par l'autofiction, le matériau biographique, emprunté au vécu et à la réalité contemporaine, et qui atteste l'engagement de l'auteur, se trouve revisité et réorganisé par l'écriture, produisant une 
manière de "mentir-vrai ", qui est comme la condition de possibilité d'une littérature engagée authentiquement littérature et pleinement engagée ${ }^{12}$.

D'ailleurs, les frontières entre mémoire et histoire ne sont pas nettes. Le désir de faire état des mémoires particulières qui gouverne la littérature contemporaine serait en passe de mener à une histoire à la première personne. Car comment écrire sur le présent, que l'on connaît directement, sans que le récit s'apparente à une écriture de soi ?

\section{Dimension christique}

Venons-en maintenant à la figure du Christ. Dans la christologie biblique, le Crucifié est le Messie : il est celui qui vainc la mort et retourne auprès de Dieu. Chez Khūrī, il est abandonné par le Père, résolument absent. Dès lors, les deux natures du Christ, l'humaine et la divine, se trouvent scindées, la seconde abandonnée au profit de la première.

La figure du Christ apparaît fondamentalement humaine et tragique. Majma' al-asrār présente le Christ comme l'Étranger par excellence. Dans Mamlakat al-ghurabä', les récits de guerre dans les camps palestiniens, au Liban et en Jordanie, sont constamment entrecoupés par des apparitions soudaines, que rien ne semble anticiper, de l'image du Christ. De plus, le narrateur, en racontant comment il tenait Maryam par la main devant le cimetière où a été enterré son ami 'Alī, dans le camp de Shātīlā, introduit, au beau milieu de son récit, les paroles par lesquels Joseph d'Arimathée supplie Ponce Pilate de lui donner le corps de Jésus, afin de lui rendre les derniers honneurs (Mathieu 27, Marc 15, Luc 23). Son ami, mort comme un étranger, est identifié

12. Benoît Denis, Littérature et engagement, op. cit., p. 49. 
au Christ. Or 'Alī, comme son nom l'indique, est de rite chiite. La crucifixion devient le symbole de l'humanité en souffrance. La vie est une croix sous laquelle ploie l'individu. C'est ce que Yūnus explique à son épouse, tous les deux, d'ailleurs, de religion musulmane :

Ce jour-là, je lui ai dit que la vie est la croix de l'homme et tu lui as parlé du Christ. Elle t’a écouté et a apprécié tes paroles. Elle a dit que tu parles comme ta mère qui cachait l'icône de la Vierge Marie sous son oreiller. Tu as raconté à Nahīla que Jésus à été crucifié sur la croix de sa vie qu'il n'avait pas vécue. La vie est comme la croix; à la fin, nous nous retrouverons cloués dessus. (Bāb, p. 472)

L'humain contient en lui-même une dimension christique, révélée au moment des grandes tragédies. Yālū, comme Khalīl, relèvent du Christ, mais en relève également le peuple palestinien, ou encore tout être innocent accablé d'une grande injustice.

Le Christ est la victime par excellence. Toutefois, dans les Écritures, sa vie obéit au schéma narratif en forme de U décrit par Frye. Ce schéma se décline en deux mouvements, un long et un court:

La vie du Christ a une version longue [...] dans laquelle il " descend » des cieux [...] comme le dit le Credo, pour naître sur la terre, exerce son ministère sur la terre, puis remonte dans le ciel avec l'Ascension. Ce mouvement est répété à un niveau inférieur lors de la Passion; Jésus meurt sur la croix le vendredi saint, est enterré, descend dans le monde inférieur durant ce qui est, du point de vue des chrétiens, le dernier sabbat, et revient à la surface de la terre lors de la Résurrection le matin du dimanche de Pâques ${ }^{13}$. 
"La Bible chrétienne, quand on la considère comme un récit, a comme héros le Messie » (Bāb, p. 242). De la même manière voir notre chapitre sur la trilogie de la Sainte Famille (supra p. 50) - il est permis de penser que le véritable héros de $B \bar{a} b$ alshams, de Yālū et de Ka'annahā nā'ima est le Christ ou Messie. Cette figure est indéniablement la clé de lisibilité de ces œuvres. C'est encore plus évident dans le cas de Bāb al-shams. L'injonction que Khalìl fait à Yūnus d'être le Fils est l'horizon vers lequel tend la narration :

Je ne peux imaginer le monde qui t'attend. Crée-le toi-même. Crée-le comme tu veux, neuf et beau. Dis à la montagne de se déplacer et elle se déplacera. 'T̄sā, que la paix soit avec lui, ne disait-il pas aux montagnes de se déplacer, n'était-il pas le Fils qui avait tracé l'image de son père lorsqu'il est mort sur la croix?

Sois le Fils. Que ton lit soit ta croix.

Qu'en dis-tu?

Tu n'aimes pas l'image du Fils? N'est-elle pas plus belle que toutes les autres images qui nous avons dessinées jusqu'à présent, pendant ces six longs mois passés ensemble, ici? Recommençons dès le début. ( $B \bar{a} b, \mathrm{p} .445)$

Que le héros de Bāb al-shams soit le Christ est annoncé par le titre même du roman. Dans les Écritures, Jésus est considéré comme la Lumière ou le Soleil de justice. Une comparaison relevée d'ailleurs par Yālū (p. 153). De plus, nous ne pouvons pas ne pas penser à l'affirmation de Jésus dans saint Jean : " Je suis la porte " (Jean 10,9). Le titre du roman « Bāb al-shams " s'offre, par ses deux composantes, «bāb » la porte et «shams » le soleil, comme une allusion au Christ.

Toutefois, de transcendante, l'image du Christ devient, chez Khūrī, immanente. Le combat pour le salut est mené tous les jours, sans certitude. Et c'est ici-bas qu'il advient, non dans une 
vie future, post mortem. La caverne de Bāb al-shams (« la porte du soleil ") se trouve en Palestine, et c'est la Palestine retrouvée : elle n'est pas dans le Ciel comme la cité céleste chère aux Pères de l'Église. Comme pour donner crédit à cette approche adoptée dans le roman, un article paru dans le quotidien en ligne Arab48 (11/01/2013) rapporte la construction par des militants de la résistance populaire palestinienne d'un village sur un fragment de terre situé à l'est de Jérusalem, désigné par E1, auquel ils ont donné le nom de « Bāb al-shams ", dans un acte d'opposition à la politique de colonisation israélienne. La déclaration d'intention indique que le nom du village est emprunté au roman de l'écrivain libanais Ilyās Khūrī. On lit encore : " La porte du soleil est notre porte pour la liberté et pour la résistance. C'est notre porte pour Jérusalem. La porte du soleil est la porte du retour "...

Pour en revenir au narrateur, lui aussi s'identifie au Christ et se sent abandonné:

Je savais que je n'allais pas devenir un héros. J'avais tenté l'héroïsme une seule fois et j'avais échoué. J'avais quitté la barque de pêche, nous pêchions le poisson dans la mer de 'Ayn al-mraysī. J'étais sorti et j'avais marché sur la surface de l'eau. Je leur avais dit que j'allais marcher sur l'eau et j'avais marché. Ils m'avaient tous vu marcher. C'est ce qu'ils m’avaient dit, mais moi je m'étais noyé. Je m'étais retrouvé englouti; l'eau devenait comme une couverture au dessus de moi. L'apôtre Pierre avait eu peur pendant qu'il se noyait; il s'était noyé parce qu'il avait eu peur. Le Christ s'était réveillé et l'avait sauvé. Moi, personne n'était venu me sauver. Je ne voulais personne. Je voulais marcher et me noyer. Je m'étais noyé sans marcher. Ils avaient dit qu'ils m'avaient vu marcher, mais moi je m'étais noyé. Par la suite j'avais cru ce que les autres avaient dit. L'héroïsme, c'est cela, c'est croire ce que les autres vous disent. »(Mamlakat, p. 19) 
Cette identification n'est pas sans rappeler les vers de Maḥmūd Darwīsh dans al-jidāriyya ${ }^{14}$ (Murale), que Khūrī cite, d'ailleurs, dans l'épigraphe de son roman Yālü:

Comme le Christ marcha sur le lac

Je marchai dans mes visions

Mais je descendis de la croix

Car je crains l'altitude

Et n’annonce pas la résurrection. (Yālū, p. 7)

Or, quand bien même le narrateur sait qu'il est livré à luimême, il possède la puissance du Verbe. Bāb al-shams revient sans cesse sur l'idée de commencement, en référence à la phrase de Jean : "Au commencement était le Verbe [logos] " (Jean 1,1). Mais le Verbe est aussi la force créatrice de la parole ou du langage. C'est de là que le narrateur puise son autorité. S'arrogeant le pouvoir d'instaurer un ou des commencement(s) à son récit, le narrateur ne s'attribue-t-il pas, le même prestige que le Fils, celui d'être le Verbe ? Une telle identification n'est pas étrangère au narrateur de Mamlakat al-ghurabä', lui-même écrivain. Au bord du Jourdain, où Jésus fut baptisé, il voit Jésus et lui parle. Pendant cette brève apparition, il lui dit être en train d'écrire son histoire. L'histoire de Jésus est à la fois le sujet du livre et la parole elle-même :

Nous sommes allés de Amman au Jourdain où a commencé notre baptême d'eau, d'esprit et de sang. Je l'ai rencontré devant le fleuve. Jésus était partout. [...] Le Seigneur était seul, comme un étranger. Et moi j’étais devant lui. Ce jour-là, on lui a demandé, comme on lui demandera chaque jour « es-tu Élie? " Et il leur a répondu " non », comme il le fera toujours. Cette fois-ci, ils m'ont posé la question à moi. Je ne sais pas ni d'où ils sont venus, ni pourquoi. Je les ai vus subitement

14. Maḥmūd Darwīsh, Al-Jidāriyya, Beyrouth, Riyāḍ al-Rayyis, 2000. 
devant moi et ils m’ont demandé: « Es-tu Élie? ». J’ai répondu: non [...] ils ont dit: "Qui es-tu? ». J’ai dit: « Celui qui écrit l'histoire ». [...] Jésus s'est tourné vers moi et m’a demandé: "Quelle histoire "? " Ton histoire, Seigneur ». " Mais elle est écrite ", a-t-il dit. J'ai répondu: "Je l'écris parce qu'elle est écrite "; on écrit ce qui est écrit. Si ce n’était pas déjà écrit, nous n’aurions pu écrire. » (Mamlakat, p. 29-30)

"J'écris ce qui est déjà écrit " signifie, dès lors, reproduire l'acte primordial qu'est l'incarnation du Verbe de Dieu.

Le Christ est le lieu d'une tension ; il est le symbole de la souffrance humaine et l'incarnation du Verbe par lequel cette souffrance pourrait être transcendée. Celui qui détient le récit détient en même temps les clés de la porte du soleil. Cependant, le Christ incarne aussi le doute quant à cette même visée prophétique. Parce qu'il a été abandonné, le parcours mythologique de la Bible en forme de U, relevé par Frye, ne s'accomplit pas. Et la parole vivifiante du narrateur est, à son tour, marquée du sceau de l'incertitude.

Par cette démarche, l'œuvre de Khūrī se différencie de celle de Jibrān, un nahḍāwī chrétien, qui puise également dans la liturgie biblique pour bouleverser l'ordre social établi. Dans Khalīl al-Kāfir ( "Khalīl l'apostat », 1908), le personnage de Khalīl, qui évoque celui du Christ, s'insurge contre le pouvoir de l'argent et se révolte contre l'institution religieuse qui pérennise la tyrannie des traditions et des tabous sociaux. Toutefois, l'approche de Khalīl est utopiste : " Les loups peuvent dévorer la brebis sous le couvert de la nuit, mais les traces de son sang resteront sur les graviers du ruisseau jusqu'à ce que vienne l'aurore et se lève le soleil ». Khūrī rompt avec la vision de Jibrān en ce que la sienne est incertaine de l'accomplissement de l'ordre qu'elle voudrait instaurer. 
Acculée au scepticisme engendré par les leçons tragiques de l'histoire tout en restant sous-tendue par la foi dans la puissance du récit comme acte de vie, l'écriture se trouve prise dans des dynamiques génératrices de tension. Ces dynamiques font de l'œuvre littéraire de Khūrī tout aussi bien une expérience profondément humaine qu'une expérimentation narrative singulière.

La nouveauté que l'œuvre de Khūrī présente ne se réduit pas à une catégorie esthétique mesurée par des facteurs formels. Elle est aussi une catégorie historique qui assimile un moment de l'histoire pour provoquer l'effondrement des schémas révolus et des conventions sclérosées, poser des questions nouvelles et ouvrir l'activité de l'auteur et du lecteur sur une production créative. Cela sans oublier l'aveu de Khalīl dans Bāb al-shams (p. 288) : «L'écriture mon ami, c'est l'ambiguïté. Qui est capable d'écrire les ambiguïtés de la vie, dis-moi ?» 



\section{Ilyās Khūrī en quelques dates}

- 1948 : naissance à Beyrouth.

— 1969 : rencontre avec Ghassān Kanafānī à Beyrouth.

— 1971 : mariage avec Najla Jraysātī. Enfants: 'Ablā (1972) et Ṭalāl (1976).

- 1971 : rencontre avec Maḥmūd Darwīsh.

— 1971 : diplôme d'histoire et de sociologie à l'Université libanaise.

- 1968-1994: membre du Fatah. Combats en Jordanie et au Liban.

- 1971-1973: diplôme d'études approfondies (DEA) à l'École des hautes études en sciences sociales (EHESS); travail de recherche sur la guerre civile libanaise de 1840-1860, sous la direction d'Alain Touraine.

- 1973-1979: chercheur, à Beyrouth, au centre de recherche de l'OLP (Organisation pour la libération de la Palestine). Éditeur avec Maḥmūd Darwīsh de la revue mensuelle Shu'ūn Filasținiyya ("Revue des affaires palestiniennes ").

- 1975-1979: secrétaire de rédaction de la revue mensuelle Shu’ūn Filasțīniyya.

- 1979-1981. Et 1983-1990: directeur de rédaction de la page culturelle du quotidien libanais al-Safir.

- 1980-1981: directeur de rédaction avec Maḥmūd Darwīsh d'alKarmil, revue trimestrielle.

— 1981-1982: professeur invité à l'université de Columbia à New York.

- 1983-1986: directeur de la collection "Dhākirat al-shu'ūb" ("Mémoire des peuples »), sur la littérature du tiers-monde, éditée par Markaz al-abhāth al-arabiyya (Institut de recherches arabes), 
Elias Khoury - De l'engagement au postmodernisme

Beyrouth; cette collection a traduit plusieurs grands classiques comme C. Fuentes et G. G. Marquez.

— 1991 : rédaction avec Marūn Baghdādī et Didier Decoin du scénario du film Hors la vie, réalisé par Baghdādī; le film est récompensé du prix du jury au festival de Cannes.

- 1992-2008: rédacteur en chef du supplément culturel du quotidien libanais al-Nahār.

- 1993: Mudhakkarāt Ayyūb ("Les Mémoires de Job »), pièce de théâtre, réalisée par Roger 'Assāf et présentée au théâtre de Beyrouth (1993) et au théâtre du Rond-Point à Paris (1994).

- 1992-1998: directeur artistique du théâtre de Beyrouth.

- 1998 : prix Palestine pour son roman Bāb al-shams.

- 2000 : réalisation avec Rabī` Mruwwa de Three posters, à partir de l'enregistrement vidéo de Jamīl al-Sātī, qui a réalisé une opération suicide, en 1985, contre l'armée israélienne au Liban-Sud. Présenté au festival Aylūl.

- 1996-2001: codirecteur, à Beyrouth, du festival Aylūl pour les arts contemporains.

- 2001-2015: Global distinguished professor à l'université de New York.

- 2004 : adaptation au cinéma du roman Bāb al-shams par le réalisateur égyptien Yusrī Nașrallāh.

-2004-2006: fondation du Mouvement de la gauche démocratique; il est membre du comité exécutif du mouvement.

- 2007 : lauréat du prix littéraire arabe du festival Metropolis bleu, Montréal, pour l'ensemble de son œuvre.

- 2008: prix du roman arabe (prix délivré par le Conseil des ambassadeurs arabes en partenariat avec l'Institut du Monde arabe) pour $K a$ ' annahā nā 'ima.

- 2010-...: rédacteur en chef de la Revue d'études palestiniennes.

- 2012 : prix Sharjah de l’Unesco. 


\section{Ouvrages d'Ilyās Khūrī dans l'ordre de parution}

\section{Romans}

'An 'alāqāt al-dā'ira (" Les liens du cercle »), Beyrouth, Mu'assasat al-’ādāb al-'arabiyya, 1975.

Al-Jabal al-ṣaghīr, Beyrouth, Dār al-ādāb, 1977. Trad. par Saadia Zaim, La Petite Montagne, Paris, Arléa, 1987.

Abwāb al-madīna ("Les portes de la ville »), Beyrouth, Dār Ibn Rushd, 1981.

Al-Wujūh al-bayḍā', Beyrouth, Dār Ibn Rushd, 1981. Réédition Dār al-ādāb, 2003. Trad. par Luc Barbulesco, Un Parfum de paradis, Paris, Arléa, 2007.

Riḥlat Ghandī al-ṣaghīr, Beyrouth, Dār al-ādāb, 1989. Trad. par Luc Barbulesco, Le Petit Homme et la guerre: Le voyage du petit Ghandi, Paris, Arléa, 1994. Actes Sud, 2004.

Mamlakat al-ghurabä' ("Le royaume des étrangers"), Beyrouth, Dār al-ādāb, 1993.

Majma' al-asrār, Beyrouth, Dār al-ādāb, 1994. Trad. par Rania Samara, Le Coffre des secrets, Arles, Actes Sud, 2009.

Bāb al-shams, Beyrouth, Dār al-ādāb, 1998. Trad. par Rania Samara, La Porte du soleil, Arles, Actes Sud, 2003.

Yālū, Beyrouth, Dār al-ādāb, 2002. Trad. par Rania Samara, Yalo, Arles, Actes Sud, 2004.

Ka'annahā nā'ima, Beyrouth, Dār al-ādāb, 2007. Trad. par Rania Samara, Comme si elle dormait, Arles, Actes Sud, 2007. 
Elias Khoury - De l'engagement au postmodernisme

Sinalkūl, Beyrouth, Dār al-ādāb, 2012. Trad. par Rania Samara, Sinalcol: Le miroir brisé, Arles, Actes Sud, 2013.

Awlād al-ghetto: Ismī Ādam, Beyrouth, Dār al-ādāb, 2017. Trad. par Rania Samara, Les Enfants du ghetto: Je m'appelle Adam, Arles, Actes Sud, 2018.

\section{Nouvelles}

Al-Mubtada wa l-Khabar ( La phrase nominale »), Beyrouth, Mu'assasat al-abḥāth al-‘arabiyya, 1984.

Ră’ihat al-ṣābūn (" L’odeur du savon »), Beyrouth, Dār al-ādāb, 2002.

\section{Essais}

Tajribat al-bahth 'an ufuq: muqaddima li-dirāsat al-riwāyā al-'arabiyya ba'da al-hazīma ("Tentative de recherche d'un horizon: introduction à l'étude du roman arabe après la défaite "), Beyrouth, Markaz al-abḥāth al-filasținiyya, 1974.

Dirāsāt fi naqd al-shi'r ("De la critique poétique »), Beyrouth, Dār ibn Rushd, 1979.

Al-Dhākira al-mafqūda ("La mémoire perdue »), Beyrouth, Dār al-ādāb, 1982.

Zaman al-ihtilāl ("Le temps de l'occupation »), Beyrouth, Mu'assasat al-ādāb al-'arabiyya, 1985.

La Méditerranée libanaise, Elias Khoury et Ahmad Beydoun, (Les Représentations de la Méditerranée. Fabre Thierry et Ilbert Robert éds.), tome 4, Paris, Maisonneuve et Larose, 2000.

\section{Théâtre}

Mudhakkarāt Ayyūb ("Les mémoires de Job »), mise en scène par Rabī’ Mruwwa, Masraḥ al-madīna (Théâtre de la Ville), 1993. 


\section{Ouvrages cités}

Abū Dīb, Kamāl, « Views and Study of Elias Khouri's Bāb al-shams as a nascent postmodernist text ». Ce texte, qui a fait l'objet d'une conférence à la Georgetown University de Washington, en 2007, reste non publié à ce jour.

Achkar, Gilbert, Marxisme, orientalisme, cosmopolitisme, Arles, Actes Sud, 2015.

Adonis, Al-thābit wa-l-mutahawwil, troisième volume: Șadmat al-ḥadātha, Beyrouth, Dār al-awda, 1979.

Adonis, Al-kitāb, al-khițāb, al-hijāb, Beyrouth, Dār al-ādāb, 2009.

Allemand, Roger-Michel, Le Nouveau Roman, Paris, Ellipses, 1996.

Anderson, Perry, Les Origines de la postmodernité, Paris, Les Prairies ordinaires, 2010.

Archer, Michael, L'Art depuis 1960, Paris, Thames et Hudson, 1998.

Barthes, Roland, L'Aventure sémiologique, Paris, Seuil, 1985.

Baudouin, Jean, Les Idées politiques contemporaines, Rennes, Presses universitaires de Rennes, 2002.

Bayard, Pierre, Qui a tué Roger Ackroyd? Paris, Minuit, 1998.

Belmont, Joseph, Modernes et Postmodernes, Paris, éditions du Moniteur, 1987.

Bert, Jean-François, Introduction à Michel Foucault, Paris, La Découverte, 2011.

Best, Steven, and Kellner, Douglas, Postmodern theory, New York, The Guilford Press, 1991.

Bitoun, Lazare et Grimal, Claude, Le Roman américain après 1945, Paris, Armand Colin, 2000. 
Elias Khoury - De l'engagement au postmodernisme

Boustani, Sobhi, «Violence et marginalité: essai sur le roman Yâlû d'Elias Khoury ", in Aux marges de la littérature arabe contemporaine, Denooz, Laurence et Luffin, Xavier (éds.), Helsinki, Academia scientiarum fennica, 2013.

Brunel, Pierre, Mythocritique, Paris, Puf, 1992.

Butler, Judith, Gender Trouble: Feminism and the Subversion of identity, New York, Routledge, 1990, et Trouble dans le genre, Paris, La Découverte, 2005.

Caiani, Fabio, Contemporary Arab Fiction: Innovation from Rama to Yalo, London and New York, Routledge, 2007.

Camus, Albert, L'Étranger, Paris, Gallimard, 1971.

Cheniki, Ahmed, "Les Mille et Une Nuits, la culture populaire et le théâtre arabe ", in Les Mille et Une Nuits et l'imaginaire du Xx ${ }^{e}$ siècle, Chaulet-Achour, Christiane (éd.), Paris, L'Harmattan, 2005.

Coleridge, Taylor, Biographia Literaria, volume II, 1983.

Cusset, François, French Theory, Paris, La Découverte, 2003.

Darwīsh, Maḥmūd, Al-jidāriyya, Beyrouth, Riyāḍ al-Rayyis, 2000.

Denis, Benoît, Littérature et engagement, de Pascal à Sartre, Paris, Seuil, 2000.

Devictor, Agnès, "La notion de martyr en sciences politiques: des croyances aux mobilisations ", congrès AFSP, Strasbourg, 2011. www.congres-afsp.fr.

Eagleton, Terry, The Illusions of postmodernism, Oxford, Blackwell, 1996.

Eco, Umberto, Interprétation et surinterprétation, Paris, Puf, 1996.

Eco, Umberto, L'CEuvre ouverte, Paris, Seuil, p. 25.

Evers, Bernd, Théorie de l'architecture, de la Renaissance à nos jours, Cologne, Taschen, 2006.

Foucault, Michel, L'Ordre du discours, Paris, Gallimard, 1971.

Frye, Northrop, Le Grand Code, Paris, Seuil, 1984.

Garo, Isabelle, Foucault, Deleuze, Althusser et Marx, Paris, Demopolis, 2011.

Ghazoul, Ferial, "Shahrazad postmoderne ", in Les Mille et Une Nuits en partage (actes du colloque, 25 au 29 mai 2004), Chraïbi, Aboubakr (éd.), Arles, Actes Sud, 2004. 
Ghosn, Katia, "Le roman de Rachid el-Daïf à l'ère de la globalisation ", Rachid el-Daï: Le roman arabe dans la tourmente de la modernisation, Ghosn, Katia (éd.), Paris, Demopolis, coll. "Quaero ", 2016.

Ghușūb, May, Mā ba'd al-hadātha: Al-arab fi laqțat video, Beyrouth, Dār al- Sāqī, 1992.

Greimas, Algirdas Julien, Essais de sémiotique poétique, Paris, Larousse, coll. L, Paris, 1972.

Ḥadīdī, Șubḥī, "Majma al-asrār: jadal al-ḥāja ila l-ḥikāyāt ", al-Ṭarīq, décembre-février 2001.

Hankins, Jérôme, "Les Palestiniens ", in Genet à Chatila (textes réunis par Jérôme Hankins), Paris, Solin, 1992.

Hardt, Michael, et Negri, Antonio, Empire, Paris, Exils, 2000.

Hassan, Ihab, The Dismemberment of Orpheus: Toward a Postmodern Literature, Wisconsin, University of Wisconsin Press, 2nd revised edition, 1987.

Hassan, Ihab, POSTmodernISM: a Paracritical Bibliography, New Literary History, 1971; réédité in. Ihab Hassan, The Postmodern turn, Columbus, Ohio State University Press, 1987.

Ḥasan, İhāb, Taḥawwulāt al-khițāb al-naqdī li-mā ba'da al-ḥadātha. Traduit par Al-sayyid Imām. Bassorah, Dār shahrayār, 2017.

Hassan, Ihab, " Toward a concept of postmodernism ", in The postmodern turn, Columbus, Ohio state University press. İhāb Ḥasan: Naḥwa mafhūm li-mā ba'da al-ḥadātha, trad. par Șubḥī Ḥadīdī, Majallat al-Karmil, n 51, printemps 1997.

Hutcheon, Linda, The Politics of postmodernism, London and New York, Routledge, 1989.

İd al-, Yumnā, al-Kitāba, taḥawwul fi al-taḥawwul, Beyrouth, Dār al-ādāb, 2003.

İgltun, Tīrī, Awhām mā ba'da al-ḥadātha, Beyrouth, Silsilat Abū 'Alī Yāsīn, 2000.

Imhoff, Aliocha et Quiros, Kantuta, Artpress, Cinémas contemporains, $\mathrm{n}^{\circ}$ 21, mai-juin-juillet 201. http:// wwwartpress:com.

Jablonka, Ivan, L'Histoire est une littérature contemporaine, Paris, Seuil, 2014. 
Elias Khoury - De l'engagement au postmodernisme

Jalal al-Azm, Sadik, Ces interdits qui nous hantent. Islam, censure, orientalisme, Marseille, Parenthèses-MMSH-IFPO, 2008.

Jameson, Fredric, Le Postmodernisme ou la logique culturelle du capitalisme tardif, Paris, éditions Beaux-Arts de Paris, 2007. Postmodernism, or the cultural logic of late capitalism, Duke University Press, 1991.

Jauss, Hans Robert, Pour une esthétique de la réception, Paris, Gallimard, 1978.

Jencks, Charles, What is Postmodernism, Manchester, Academy Edition, St. Martin Press, 1986.

Jencks, Charles, Le Langage de l'architecture postmoderne, Paris, Denoël, 1975.

Karoui-Elounelli, Salwa, "le récit de la quête dans le roman américain postmoderne: entre version parodique et stéréotype. L'exemple de John Barth ", Cahier de narratologie, 2011. http://naratologie.revues.org/1192.

Kassir, Samir, Histoire de Beyrouth, Paris, Perrin, 2012.

Khalīfa, Saḥar, Așl wa- fașl, Beyrouth, Dār al-ādāb, 2009.

Khūrī, Ilyās, « Filasțīn, Lubnān, al-riwāya wa kayfa tașīr al-ḥikāyāt riwāya ", al-Ṭarīq, nْ 1, janvier-février, 2001.

Khūrī, Ilyās, al-Ādāb, nº 7-8, juillet-août 1993.

Kodmani, Basma, "Une génération arabe traumatisée par la défaite ", Le Monde diplomatique, juin 2007.

Lyotard, Jean-François, La Condition postmoderne, Paris, Minuit, 1979.

Lyotard, Jean-François, Le Postmoderne expliqué aux enfants, Paris, Galilée, 2005.

Les Milles et Une Nuits, "Le portefaix et les dames ", traduction par René Khawwām, Paris, Phébus, 1986.

Lambin, Gérard, Genèse d'un genre littéraire en Grèce, Rennes, Presses universitaires de Rennes, 1991.

Landry, Pierre Luc, "Quand l'auteur joue avec la (méta)fiction », in Salon double, 2011. http://salondouble.contemporain.info.

Larzillère, Pénélope, " Le martyre des jeunes Palestiniens pendant l'intifada al-Aqsa: analyse et comparaison ", in Repères, 4-2001. www.ifri.org. 
Rorty, Richard, et Engel, Pascal, À quoi bon la vérité?, Paris, Grasset, 2005.

Lucie-Smith, Edward, Movements in Arts since 1945, London, Thames and Hudson, 1999. Lūsī-Smith, İdward, Mā ba'da al-ḥadātha: al-ḥarakāt al-fanniya mundhu 'ām 1945, Beyrouth, Al- mu'assasa al'arabiyya lil-dirāsāt wa-l nashr, 1995.

Marquez, Gabriel Garcia, Chronique d'une mort annoncée, Paris, Grasset, 1981.

Mansuy, Michel, Gaston Bachelard et les éléments, Paris, José Corti, 1967.

Mejcher-Atassi, Sonja, Geschichten über Geschichten. Erinnerung im Romanwerk von Elias Khoury, Reichert Verlag, Wiesbaden, 2001.

Pflitsch, Andreas, "The End of Illusions. On Arab Postmodernism ", in Arabic Literature: Postmodern Perspectives, Neuwirth, Angelika, Pflitsch, Andreas, et Winckler, Barbara (éds.), Londres et Beyrouth, Saqi, 2010.

Prochasson, Christophe, L'Empire des émotions: les historiens dans la mêlée, Demopolis, 2008.

Robbe-Grillet, Alain, Le Miroir qui revient, Paris, Seuil, 1984.

Rushdie, Salman, Les Enfants de Minuit, Paris, Plon, 1997.

Saïd, Edward, Orientalism, New York, Vintage Books, 1978.

Saïd, Edward, Culture and Imperialism, London, Vintage, 1978.

Saïd, Edward, Reflections on Exile and other Essays, Harvard, Harvard University Press, 2002, London, Granta books, 2001. Traduction en arabe par Thā ỉr Dīb, Ta ammulāt ḥawla-l-manfā, Beyrouth, Dār al-ādāb, 2004.

Saïd, Edward, Des Intellectuels et du pouvoir, Paris, Seuil, 1996.

Sa'dallah, Muhammad, Al- usus al-falsafiyya li- naqd mā-ba'd albunyawiyya, Damas, Dār al-ḥiwār, 2007. En ligne sur www.nizwa. com

Sartre, Jean-Paul, L'Être et le néant, Paris, Gallimard (1943), 1976.

Sermain, Jean-Paul, Métafictions, Paris, Honoré Champion, 2002.

Ṣīdāwī, Rafīf, al-Naẓra al-riwāìyya ilā-l-ḥarb al-lubnāniyya:19751995, Beyrouth, Dār al-Fārābī, 2003. 
Elias Khoury - De l'engagement au postmodernisme

Swaydān, Sāmī, Faḍā āt al-sard wa-madārāt al-takhayyul, Beyrouth, Dār al-ābāb, 2006.

Swaydān, Sāmī, Abḥāth fì al-nașș al-riwāè al-arabī, Beyrouth, Dār al-ādāb, 2000.

Tamer, Jana, Dictionnaire étymologique, Maisonneuve et Larose, Paris, 2005.

Todorov, Tzvetan, Poétique de la Prose, Paris, Seuil, 1971.

Venturi, Robert, Complexity and contradiction in Architecture, New York, Museum of Modern Art, 1966.

Wāzin, 'Abdū, Riwāyat al-ḥarb al-lubnāniyya, madkhal wa namādhij, Dubai, Dār al-Șadā, 2009.

Weber, Edgard, Le Secret des mille et une nuits: L'inter-dit de Shéhérazade, Toulouse, Eché, 1987.

Zarāqiț, 'Abdulmajīd, F̄̄ binā' al-riwāya al-lubnāniyya (1972-1992), tome 1, Beyrouth, éditions de l'Université libanaise, 1999.

Zertal, Idith, La Nation et la mort, Paris, La Découverte, 2004.

Zrayq, Qusțanțin, Ma'nā al-nakba, Beyrouth, Dār al-'ilm lil-malāyīn, 1948. 



\section{Table des matières}

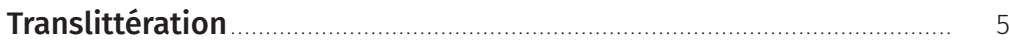

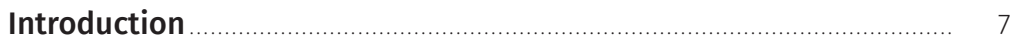

Ilyās Khūrī: une vie, une œuvre

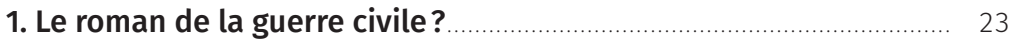

Littérature de guerre, mais de quelle guerre? ............................... 26

Une littérature d'« après 60 »....................................................... 33

Impact du contexte sociopolitique sur l'écriture et

émergence d'une interrogation métafictionnelle ............................ 35

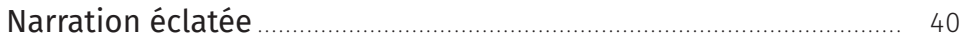

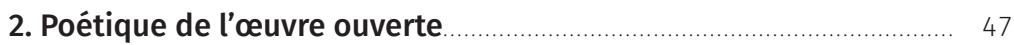

Modalités et perspectives

Les procédés de l'ouverture.................................................... 47

La mort du personnage, prélude à la libération du récit.............. 50

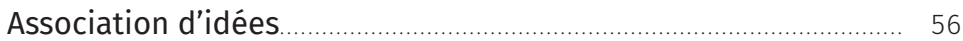

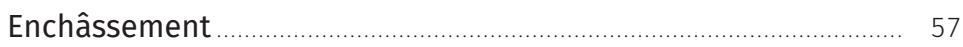

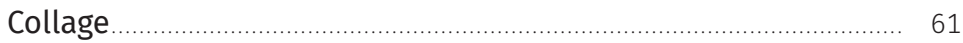

Problématisation de l'autorité fictive: entre déconstruction et instauration. L'exemple de Majma' al-asrär (Le Coffre des

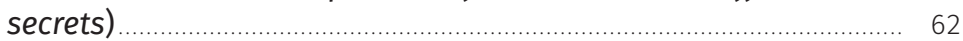

Relecture de Chronique d'une mort annoncée de Marquez ........... 63

Surinterprétation ou narration inventive? .................................. 69

3. Bāb al-shams, Yālū, Ka'annahā nā'ima

Trilogie de la Sainte Famille ....................................................... 77

Déconstruction de la Sainte Famille biblique ................................. 78

Autres convergences ............................................................... 94

Stratégies de rédemption .................................................... 96

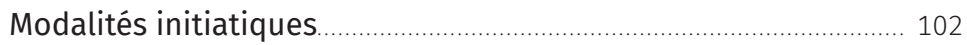


4. Histoire et littérature

Le roman comme contre-narration

Métafiction historiographique.

Une crise de confiance et un exemple: l'enquête sur la mort de Khalīl Jābir.

Déconstruction des figures de l'héroïsme: le fedayin, le martyr.. 121

Une contre-histoire: figure sacrale de la victime............................ 135

Réinventer le Palestinien ............................................................... 139

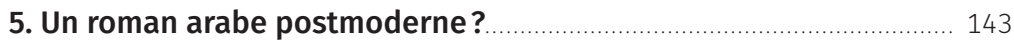

Elias Khoury en exemple

Genèse du terme « postmoderne »

Un postmodernisme arabe: le débat a-t-il lieu ?............................ 158

Lectures postmodernes des romans de Khūrī .................................. 165

Le roman de Khūrī est-il postmoderne? ...................................... 173

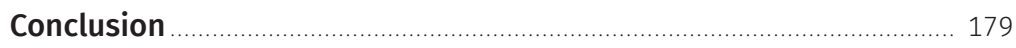

La voix narrative: entre confusion et profusion de vie .................. 180

Engagement politique et littérarité: la tentation de l'autofiction 184

Dimension christique ............................................................... 191

Ilyās Khūrī en quelques dates ........................................................... 199

Ouvrages d'Ilyās Khūrī dans l'ordre de parution ................................. 201

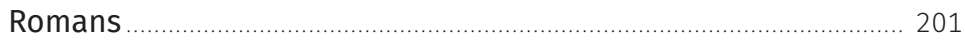

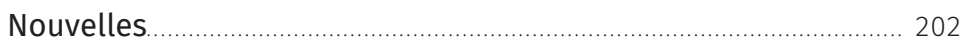

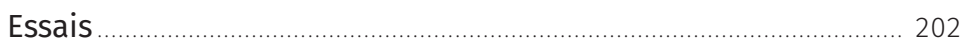

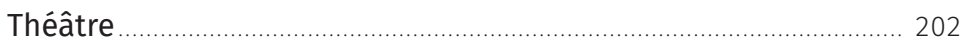

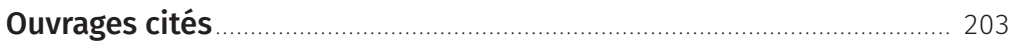





\section{Déjà parus aux éditions DEMOPOLIS}

$\begin{array}{ll}\text { Brossat, Alain } & \text { Durpaire, François - } \\ \text { Abécédaire Foucault } & \text { Richomme, Olivier } \\ \text { Boltanski, Luc } & \text { L'Amérique de Barack Obama } \\ \text { Rendre la réalité inacceptable } & \text { Obama face à la crise } \\ \text { Borvo Cohen-Seat, Nicole et Cohen- } & \text { Garo, Isabelle } \\ \text { Seat, Patrice } & \text { Foucault, Deleuze, Althusser et Marx } \\ \text { Réinventer la gauche } & \text { Gaulard, Mylène } \\ \text { Bourdieu, Pierre - Boltanski, Luc } & \text { Karl Max à Pékin - Les racines de la } \\ \text { La Production de l'idéologie } & \text { crise en Chine capitaliste } \\ \text { dominante } & \text { Guérin, Isabelle } \\ \text { Césaire, Aimé - Malcolm X } & \text { La microfinance et ses dérives } \\ \text { Black révolution } & \text { Hobsbawm, Éric } \\ \text { Clover, Charles } & \text { Marx et l'histoire } \\ \text { Surpêche } & \text { Hroub, Khaled } \\ \text { Cohen-Seat, Patrice } & \text { Le Hamas } \\ \text { Peuple! Les luttes de classes au } & \text { Jaurès, Jean } \\ \text { xxle siècle } & \text { Le socialisme et la Révolution } \\ \text { Chuzeville, Julien } & \text { française } \\ \text { Zimmerwald. L'internationalisme } & \text { Jennar, Raoul Marc } \\ \text { contre la première guerre mondiale } & \text { Khieu Samphan \& les Khmers } \\ \text { Da Lage, Olivier (sous la dir. de) } & \text { rouges } \\ \text { Qatar: les nouveaux maîtres du jeu } & \text { Kautsky, Karl } \\ \text { Denord, François } & \text { Les luttes de classe pendant la } \\ \text { Néo-libéralisme, version française } & \text { Révolution française } \\ \text { Dhume-Sonzogni, Fabrice } & \text { Khaldi, Eddy } \\ \text { Communautarisme. Enquête sur une } & \text { Abc de la laïcité } \\ \text { chimère du nationalisme français } & \text { Abc de la laïcité pour les jeunes } \\ \text { Duclert, Vincent } & \text { Khaldy, Eddy - Fitoussi, Muriel } \\ \text { Occupy Gezi } & \text { Main basse sur l'École publique } \\ & \text { La République contre son école } \\ & \text { Kalfon, Pierre } \\ & \text { Chroniques chiliennes } \\ & \\ & \end{array}$


Kamata, Satoshi,

Toyota: l'usine du désespoir

Labat, Séverine

Les islamistes tunisiens - entre

l'état et la mosquée

Landriève, Sylvie

L'immobilier. Une passion française

Latour, Bruno - Lippman, Walter

Le public fantôme

Lénine

Petit manuel pour rompre avec le capitalisme

1914, repenser le nationalisme et la guerre

Mamdani, Mahmood

La CIA et la fabrique du terrorisme islamique

Marx, Karl

Qu'est-ce que le capitalisme?

Les Crises du capitalisme

Le Capital financier

Mendès-France, Pierre

Liberté, liberté chérie

Mordillat, Gérard -

Prieur, Jérôme

De la crucifixion considérée

comme un accident du travail

Mussolini

Gérard Mordillat présente le

fascisme de Mussolini

Nsar, Vali

Le renouveau chiite
Pivert, Marceau

L'Église et l'École

Prochasson, Christophe

L'Empire des émotions:

les historiens dans la mêlée

Rebérioux, Madeleine

Vive la République

Rodinson, Maxime

Islam et capitalisme

Sassen, Saskia

Critique de l'État

Saurin, Patrick

Les prêts toxiques: une affaire d'État

Shah, Sonia

Cobayes humains: le grand secret

des essais pharmaceutiques

Tanuro, Daniel

Le moment Trump - Une nouvelle

phase du capitalisme mondial

Uchitelle, Louis

Le salarié jetable

Wallerstein, Immanuel

L'Universalisme européen:

de la colonisation au droit

d'ingérence

Wilkinson, Richard

L'égalité, c'est la santé 


\section{Collection « QUAERO »}

Cassin, Barbara et Wosny, Danièle (dir.)

Les intraduisibles du patrimoine en Afrique subsaharienne

Dawod, Hosham (dir.)

La constante "Tribu », variations

arabo-musulmanes

Ehrenfreund, Christian et Schreiber, Jean-Philippe (dir.)

Les marranismes. De la religiosité cachée à la société ouverte

Espagne, Michel et

Maufroy, Sandrine (dir.)

L'hellénisme de Wilhelm von

Humboldt et ses prolongements Européens

Espagne, Michel et Jin Guangyao (dir.) avec la collaboration de Julie Gary

Conférences chinoises de la rue d'Ulm

Ethis, Emmanuel

Le cinéma près de la vie

Fernandez Garcia, Alicia et

Petithomme, Mathieu (dir.)

Contester en Espagne

Fontaine, Alexandre

Aux heures suisses de l'école républicaine

Ghasarian, Christian

Rapa. île du bout du monde, île dans le monde

Ghosn, Katia (dir.)

Rachid El-Daïf. Le roman arabe dans la tourmente de la modernisation
Gorog, Françoise et Cassin, Barbara (dir.)

Psychanalyser en langues.

Intraduisibles et langue chinoise Lessing, Gotthold Ephraim Adam Neuser (1774) Mattina, Cesare, Monier, Frédéric, Dard, Olivier et Engels, Jens Ivo (dir.) Dénoncer la corruption

Marquis, Émeline et Billault, Alain (dir.)

Mixis. Le mélange des genres chez Lucien de Samosate

Mattina, Cesare; Monier, Frédéric, Dard, Olivier et Engels, Jens Ivo (dir.), Dénoncer la corruption. Chevaliers blancs, pamphlétaires et promoteurs de la transparence à l'époque contemporaine

Nguyen, Aubert, Hoai Hong et Espagne, Michel Le Vietnam, une histoire de transferts culturels

Nguyen, Thi Hanh, Les conflits frontaliers sinovietnamiens de 1885 à nos jours Niveleau, Charles-Édouard (dir.) Vers une philosophie scientifique. Le programme de Brentano Oléron Evans, Émilie Nikolaus Pevsner. Arpenteur des arts Olivier, Laurent (dir.) La Mémoire et le Temps. L'œuvre transdisciplinaire d'Henri Hubert 
Rabault-Feuerhahn,

Pascale (dir.)

Théories intercontinentales.

Voyages du comparatisme

postcolonial

Richter, Jean-Paul

Vie de Maria Wutz, le joyeux

petit maître d'école d'Auenthal.

Une manière d'idylle

\section{Collection Philosophie en cours}

Cavaillé, Christian

Les jeux de langage chez

Wittgenstein

Cavaillé, Christian

Montaigne et l'expérience

Chauve, Alain

Le Tractacus: logique et

métaphysique
Salamagne, Michèle- $\mathrm{H}$. et Thominet, Patrick (dir.), Accompagner. Trente ans de soins palliatifs en France

Xiao, Yingying Une subjectivité fluide. Modernité et perception esthétique à travers les ouvrages de Gao Xingjian
Kail, Michel

Jean-Paul Sartre. Conscience et subjectivité

Sfez, Gérald

Machiavel et la vérité politique

Tomès, Arnaud

Castoriadis. L'imaginaire, le rationnel et le réel

\section{Collection Bande Dessinée}

En coédition avec Les Arènes

Durpaire, François \& Boudjellal, Farid

La Présidente Tome 1

Totalitaire Tome 2

La Vague Tome 3 
Achevé d'imprimer en France en 2018 dans les ateliers de Dupli-print à Domont (95) $\mathrm{N}^{\circ}$ d'impression : Dépôt légal : juin 2018 